Dear Author,

Please, note that changes made to the HTML content will be added to the article before publication, but are not reflected in this PDF.

Note also that this file should not be used for submitting corrections. 


\title{
The DNA damage response and immune signaling alliance: Is it good or bad? Nature decides when and where
}

\author{
Q3 Ioannis S. Pateras ${ }^{\mathrm{a}, 1}$, Sophia Havaki ${ }^{\mathrm{a}, 1}$, Xenia Nikitopoulou ${ }^{\mathrm{a}, 1}$, Konstantinos Vougas ${ }^{\mathrm{b}}$, Paul Townsend ${ }^{\mathrm{c}, \mathrm{d}}$, \\ Michalis I. Panayiotidis ${ }^{\mathrm{e}}$, Alexandros G. Georgakilas ${ }^{\mathrm{f}}$, Vassilis G. Gorgoulis a,b,c,d,* \\ a Molecular Carcinogenesis Group, Department of Histology and Embryology, School of Medicine, University of Athens, Athens, Greece \\ b Biomedical Research Foundation, Academy of Athens, Athens, Greece \\ c Institute for Cancer Sciences, University of Manchester, Manchester Academic Health Science Centre, UK \\ d Manchester Centre for Cellular Metabolism, University of Manchester, Manchester Academic Health Science Centre, Manchester, UK \\ e School of Life Sciences, Heriot Watt University, Edinburgh, UK \\ ${ }^{f}$ School of Applied Mathematical E' Physical Sciences, National Technical University of Athens, Zografou 15780, Greece
}

\begin{abstract}
Abbreviations: 53BP1 (TP53BP1), P53-binding protein 1; 9-1-1, Rad9-Rad1-Hus1 complex; Ab(s), antibodie(s); AGS, Aicardi-Goutières syndrome; AJCC, American Joint Committee

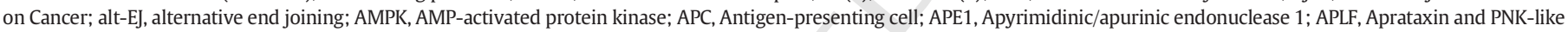

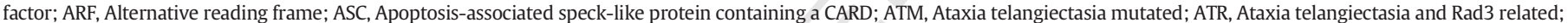

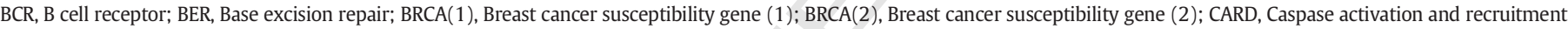

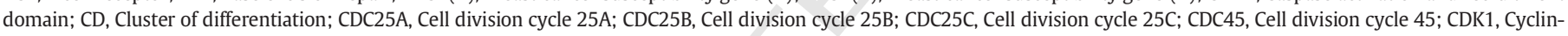

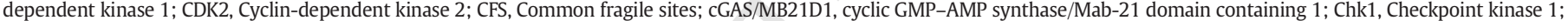

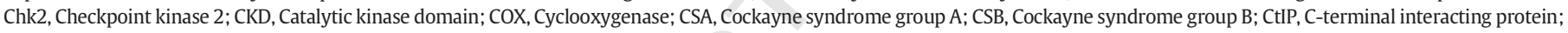

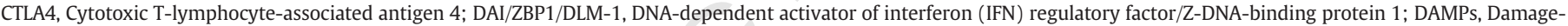

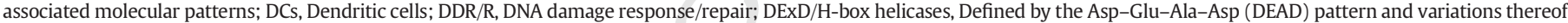

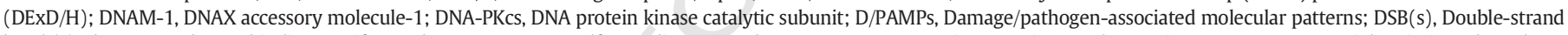

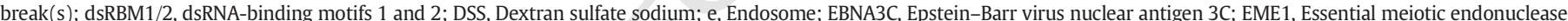

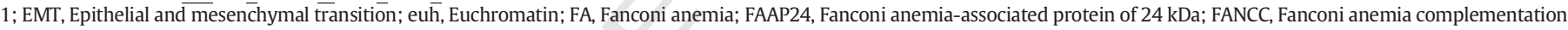

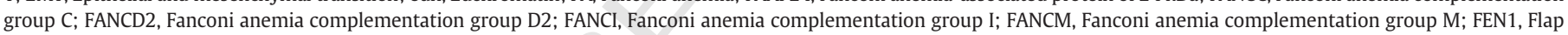

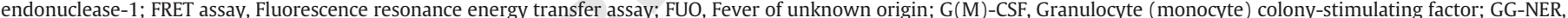

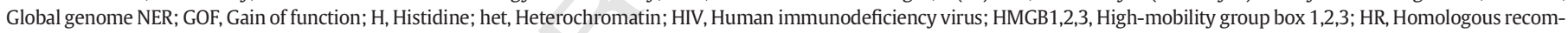

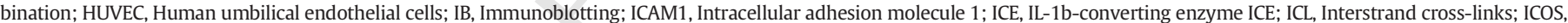

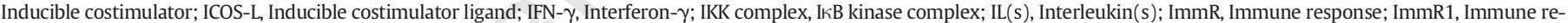

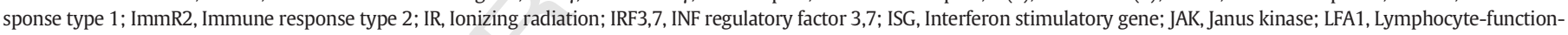

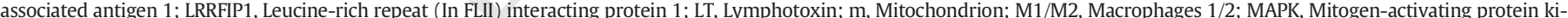

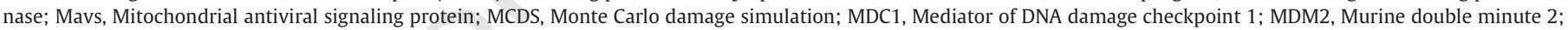

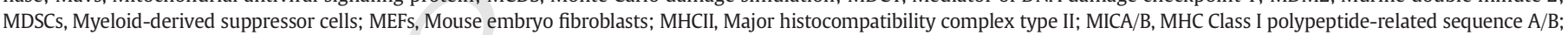

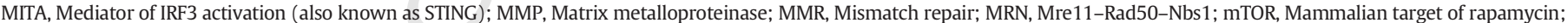

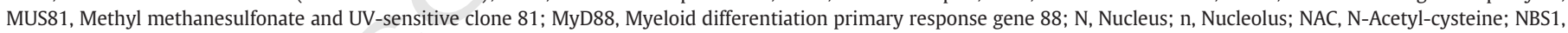

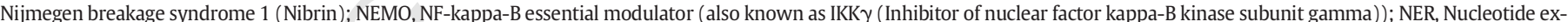

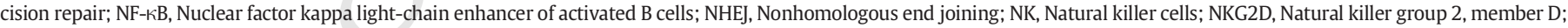

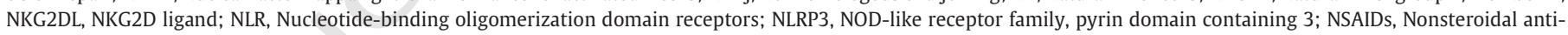

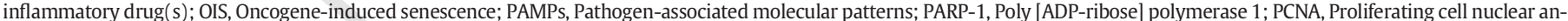

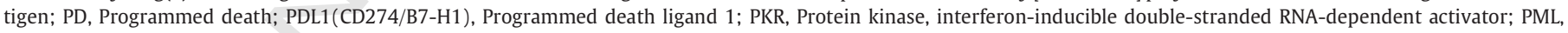

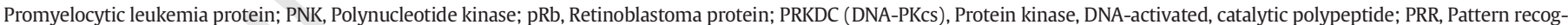

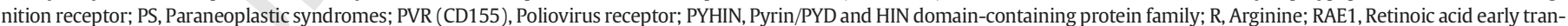

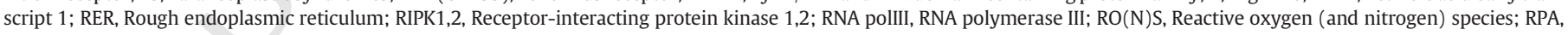

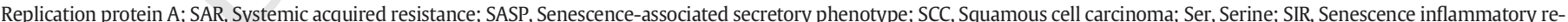

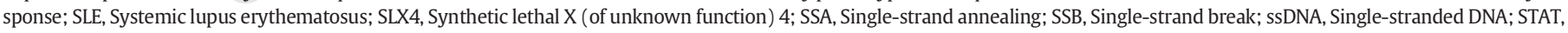

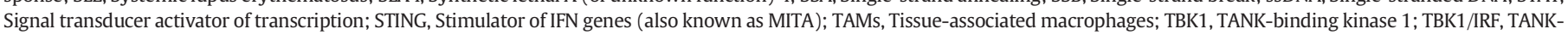

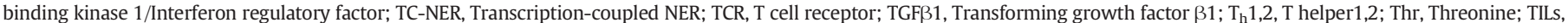

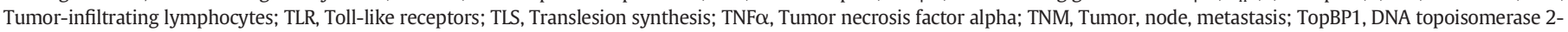

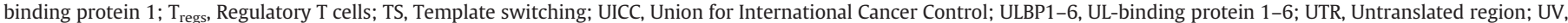

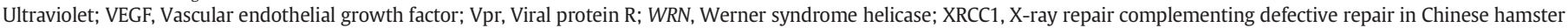
cells 1; XRCC5/Ku80, X-ray repair complementing defective repair in Chinese hamster cells 5; XRCC6/Ku70, X-ray repair complementing defective repair in Chinese hamster cells 6.

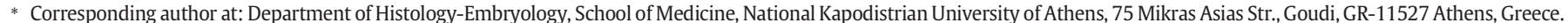
Tel.: +30210 7462352; fax: +30210 7462340.
\end{abstract}

E-mail addresses: vgorg@med.uoa.gr, vgorgoulis@gmail.com (V.G. Gorgoulis).

1 These authors contributed equally to this work. 


\section{A R T I C L E I N F O}

\section{Keywords:}

DNA damage response and repair machinery

Immune response

Pattern recognition receptors

Inflammation

Cancer

Autoimmunity

\begin{abstract}
A B S T R A C T
The characteristic feature of healthy living organisms is the preservation of homeostasis. Compelling evidence 20 highlight that the DNA damage response and repair (DDR/R) and immune response (ImmR) signaling networks 21 work together favoring the harmonized function of (multi)cellular organisms. DNA and RNA viruses activate the 22 $\mathrm{DDR} / \mathrm{R}$ machinery in the host cells both directly and indirectly. Activation of DDR/R in turn favors the immuno- 23 genicity of the incipient cell. Hence, stimulation of DDR/R by exogenous or endogenous insults triggers innate 24 and adaptive ImmR. The immunogenic properties of ionizing radiation, a prototypic DDR/R inducer, serve as suit- 25 able examples of how DDR/R stimulation alerts host immunity. Thus, critical cellular danger signals stimulate de- 26 fense at the systemic level and vice versa. Disruption of DDR/R-ImmR cross talk compromises (multi)cellular 27 integrity, leading to cell-cycle-related and immune defects. The emerging DDR/R-ImmR concept opens up a 28 new avenue of therapeutic options, recalling the Hippocrates quote "everything in excess is opposed by nature." 29
\end{abstract} (c) 2015 Published by Elsevier Inc.
Contents
1. The DNA damage response/repair and immune signaling networks: Is their intertwining a teleological demand? . . 0
2. Evidence supporting a bidirectional connection between DDR/R and ImmR . . . . . . . . . . . . . . . . 0
3. The ATM apical DDR/R kinase as a hub of the DDR/R-ImmR network . . . . . . . . . . . . . . . . . . . 0
4. Questions and perspectives from the DDR/R-ImmR link in human diseases . . . . . . . . . . . . . . . . . . 0

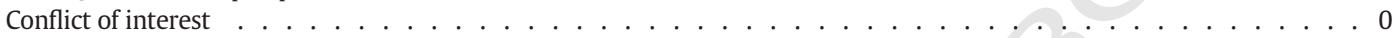

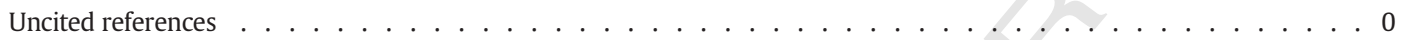
Acknowledgments . . . . . . . . . . . . . . . . . . . . . . . . . 0
References

\section{The DNA damage response/repair and immune signaling networks: Is their intertwining a teleological demand?}

To perform its physiological function, the cell requires, above all, the integrity of all of the encoded information it harbors. Experiencing numerous genotoxic insults on a daily basis, it has developed a highly conserved and sophisticated DNA damage recognition and repair network to cope with the variety of DNA lesions that occur. The DNA damage response (Jackson \& Bartek, 2009) is a hierarchically structured signaling pathway consisting of DNA damage sensors, mediators, transducers, and effectors (Fig. 1A). Depending on the specific types of alterations and the cell cycle phase they occur in, the DNA damage response/repair (DDR/R) signaling cascade demonstrates variations in order to coordinate effectively recognition of the defect and "assign" the proper repair process (Fig. 1A) (Thompson, 2012). In the event of unrepaired lesions and depending on the extent and type of damage, the cell either passes the mutated genome to its offspring or is neutralized by programmed cell death (apoptosis) or senescence (Ciccia \& Elledge, 2010).

When apoptosis ensues at the multicellular level (metazoa), a clearance process removes the apoptotic bodies, thus preserving tissue homeostasis. Senescent cells must be removed as well, because they can systemically affect neighboring cells by triggering various pathologies, including cancer, due to their so-called senescence-associated secretory phenotype (SASP), despite being a beneficial response, particularly in oncogenic events (Coppe et al., 2008). In both cases, the cells are cleared by the mononuclear phagocyte system, the main cellular compartment of the innate immune system that recognizes exposed ligands on apoptotic and senescent cells (Munoz-Espin \& Serrano, 2014). Within this system, p53, one of the main downstream effectors of the DDR/R pathway, has been shown to drive an inflammatory response contributing to tumor clearance by eliminating tumor cells undergoing senescence (Xue et al., 2007). Given that the triggering signal is extensive DNA damage in the majority of these cases, this type of cellular recognition is considered as a damage-associated molecular pattern (DAMP), thus represents a link between DDR/R and immune response (ImmR) (Chatzinikolaou et al., 2014; Ermolaeva \& Schumacher, 2014).

As with the DDR/R cascade, the ImmR system is also organized in a hierarchical manner. It relies on both innate and adaptive immune subsystems (Fig. 1Bi). The innate subsystem is considered a generic 83 first-line defense against pathogens, and it does not confer long- 84 lasting immunity to the host, unlike the adaptive immune subsystem. 85 Conversely, the adaptive immune subsystem is highly specialized, com- 86 posed of cells that are capable of discriminating "non-self" from "self," 87 through the process of antigen presentation. These cells develop 88 responses that are tailored to eliminate specific antigens effectively, 89 and most importantly they are capable of "remembering" (immunolog- 90 ical memory) the "pathogen" and thus being prepared if it reappears 91 (Fig. 1Bi).

The innate immune subsystem employs individual germ-line- 93 encoded pattern recognition receptors (PRRs), which recognize non- 94 self products from infectious agents, including foreign nucleic acids, 95 termed pathogen-associated molecular patterns (PAMPs), as well as 96 host molecules called DAMPs, as previously mentioned. Toll-like recep- 97 tors (TLRs) are among the best-characterized PRRs. In particular, the 98 TLR9 recognizes the highly immunogenic CpG motifs frequently found 99 in bacteria. As discussed later, this activates the transcription factors nu- 100 clear factor kappa B (NF-אB) and interferon-regulatory factor 7 (IRF7), 101 which in turn induce a number of pro-inflammatory cytokines promot- 102 ing an inflammatory response (Bauer et al., 2001). This is an example 103 demonstrating that immunosurveillance is capable of discriminating 104 foreign from host DNA in a sequence-independent manner, as 105 suggested, by recognizing physicochemical structural differences 106 (Kawasaki et al., 2011). However, DNA replication by-products that 107 are not rapidly turned over and released from the "immune-privileged" 108 nucleus into the cytoplasm can also act as potent immunostimulators 109 engaging DNA sensors, eventually setting the pathophysiological basis 110 for autoimmune reactions. At another level, innate immune system 111 adaptors have been shown to interact with DNA damage sensors in 112 the cytosol. A similar interaction is observed between caspase activation 113 and recruitment domain 9 (CARD9) and the DNA damage sensor Rad50, 114 a key component of the Mre11-Rad50-Nbs1 (MRN) DNA double-strand 115 break (DSB) recognition complex, thus forming a module required for 116 $\mathrm{NF}-\kappa \mathrm{B}$ activation and pro-interleukin (IL)-1 $\beta$ induction (Roth et al., 117 2014). One of the most characteristic links between innate immunity 118 and $\mathrm{DDR} / \mathrm{R}$ is the activation of natural killer group 2, member D 119 (NKG2D) ligands in DNA-damaged cells by ataxia telangiectasia 120 
mutated (ATM), which alerts and recruits mainly natural killer (NK) cells at the injured site (Gasser et al., 2005). The macrophage is common to both the innate and acquired immune subsystems: On the one hand, it is a key player in innate immunity and, on the other, it is capable of antigen presentation, placing it in the front line of the cells that initiate acquired immunity. A number of cell surface molecules involved in antigen presentation and expressed by macrophages, such as intercellular adhesion molecule 1 (ICAM-1), CD59, lymphocyte-function-associated antigen-3 (LFA-3), and CD58, are activated by p53 (Gazouli et al., 2002; Gorgoulis et al., 2003). Moreover, DDR/R activation can trigger antigen-presenting-like functions in fibroblasts and in turn activate naive cytotoxic T cells in a DNA-dependent manner, which demonstrates the ability of the DDR/R to modulate both the innate and adaptive ImmR (Tang et al., 2014).

From these introductory paradigms, an interplay between DDR/R and ImmR is evident, clearly emerging as a necessity in metazoans, during their long evolutionary transition from their unicellular ancestors, to supervise and intervene at both the systematic and cellular levels. As presented in the following sections, several bidirectional DDR/RImmR links are evident, which we believe will steadily increase in the future providing us with a novel insight into how these fundamental biochemical and cellular networks orchestrate their function during pathological conditions.

\section{Evidence supporting a bidirectional connection between DDR/R and ImmR}

Over the past years, our perception into the immunological pro- 146 perties of DNA and RNA has changed significantly, with studies demon- 147 strating that nucleic acids trigger a robust ImmR under certain 148 circumstances. The vigorous cellular reactions occurring after foreign 149 genetic material is detected within the cytoplasm or the nucleus of eu- 150 karyotic cells as well as the systemic immune reactions occurring after 151 DNA damage herald a new era in the conceptualization of the defense 152 mechanisms of (multi)cellular organisms. In the following section, we 153 provide strong evidence supporting the bidirectional relationship be- 154 tween DNA damage and ImmRs (Fig. 2). We begin our study of the 155 $\mathrm{DDR} / \mathrm{R}-\mathrm{ImmR}$ cross talk by first investigating the activation of the 156 DDR/R machinery via infection of eukaryotic cells by foreign genetic 157 material.

2.1. Lessons from viruses, part 1: the first evidence supporting the DDR/R-ImmR cross talk

In 1963, Isaacs et al. (1963) demonstrated that infection of mouse 161 cells with chick nucleic acid triggered the production of interferons 162 (IFNs), which supports the notion of IFN stimulation as a cell response 163

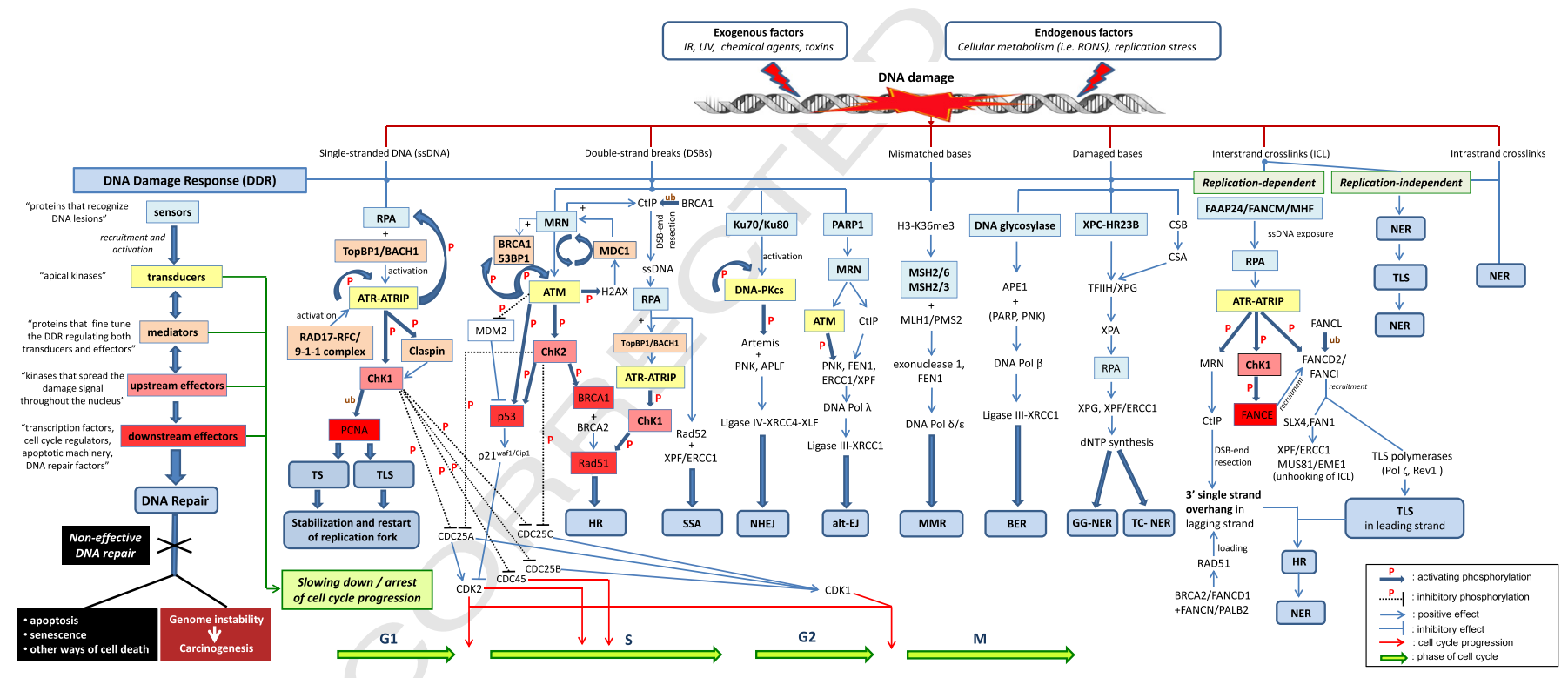

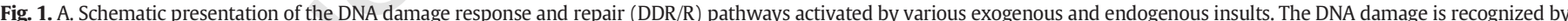

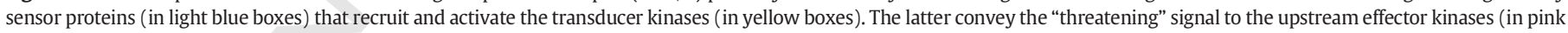

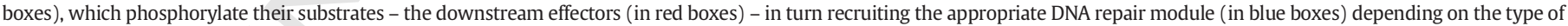

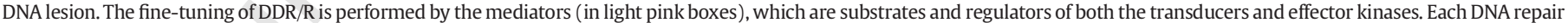

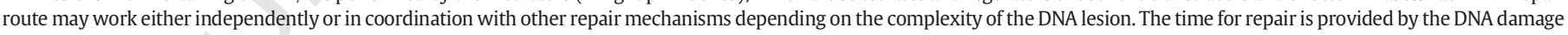

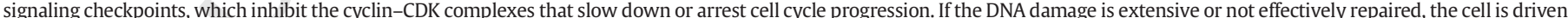

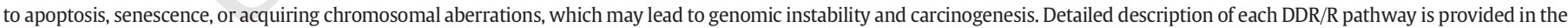

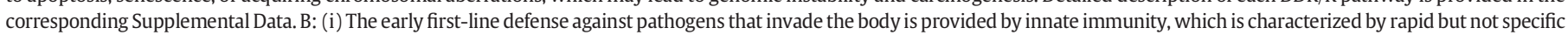

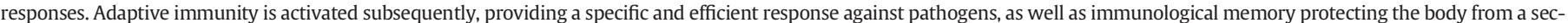

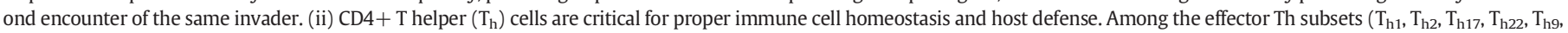

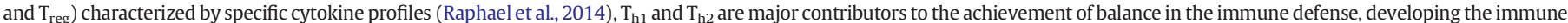

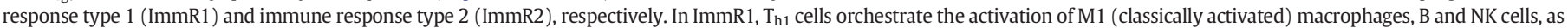

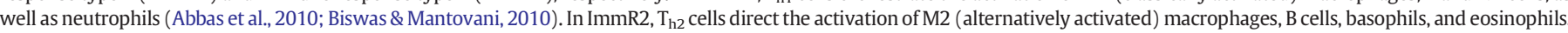

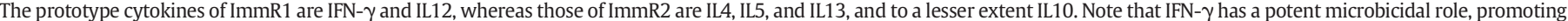

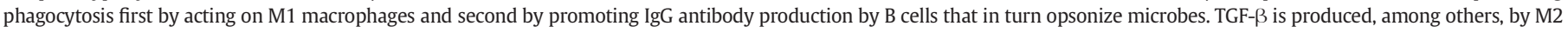

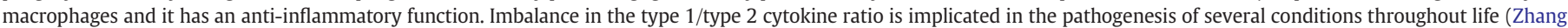

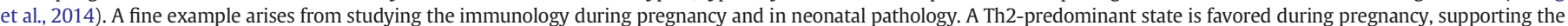

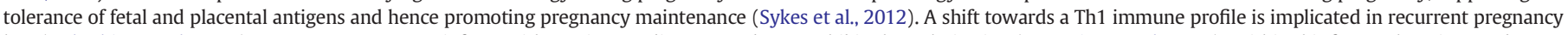

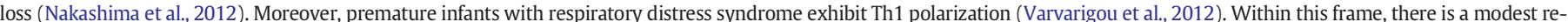

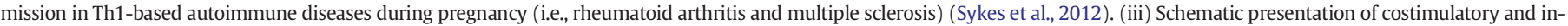

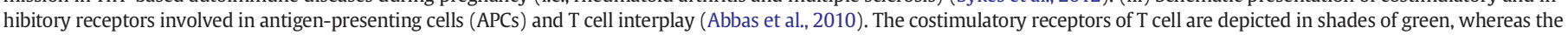
inhibitory receptors of $\mathrm{T}$ cell are depicted in shades of red. 
Bi.

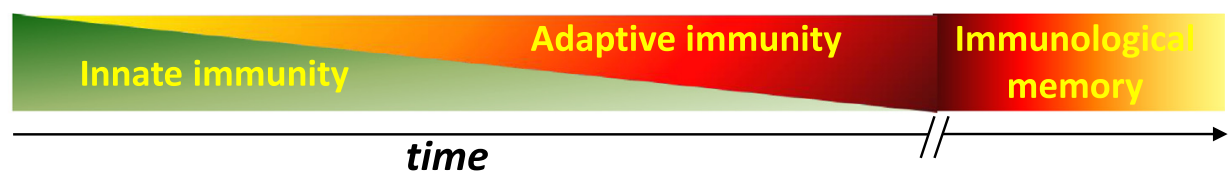

Bii.

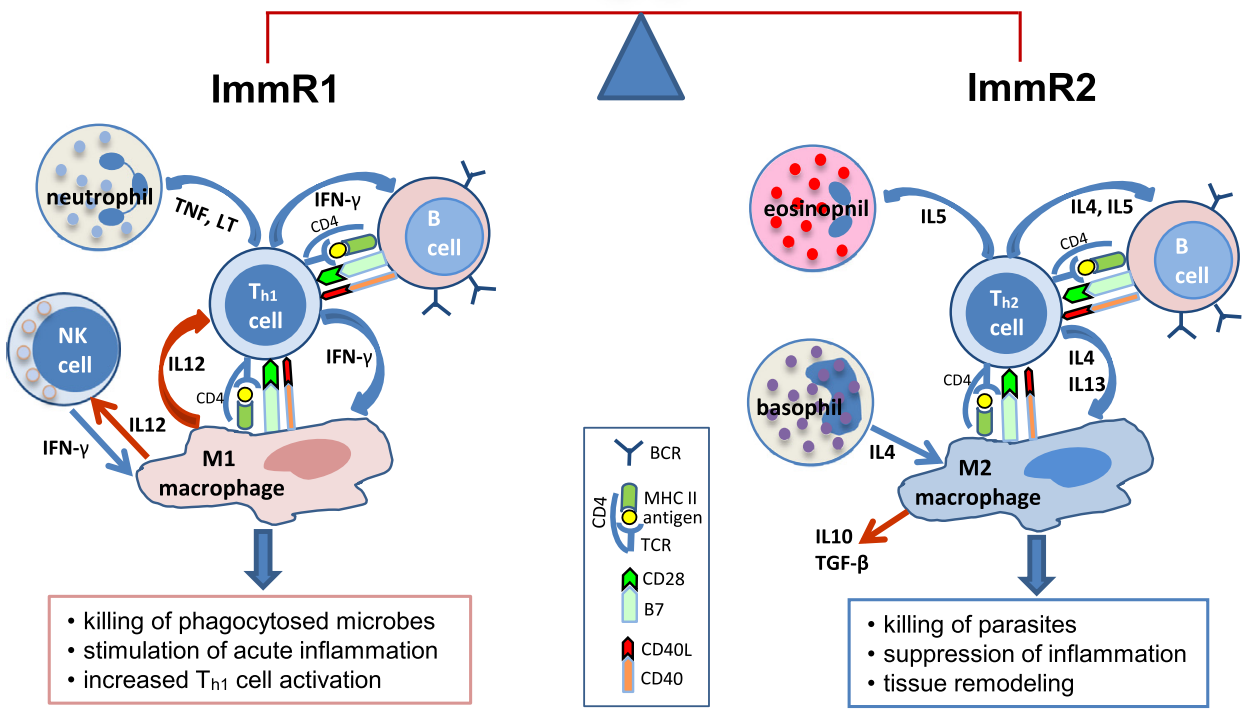

Biii.

Costimulatory and inhibitory receptors

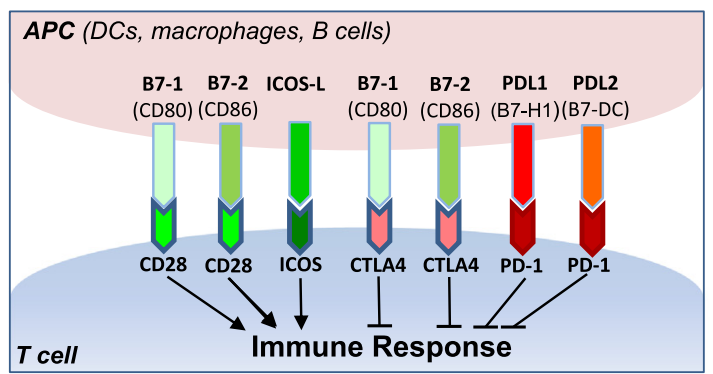

Fig. 1 (continued).

to the introduction of foreign nucleic acids. The term "interferon" was introduced because these cytokines were capable of interfering with viral replication (Isaacs \& Lindenmann, 1957). Currently, it is well established that viral genetic material triggers animal immunity by directly inducing Type I IFN in most cases, mainly IFN- $\alpha$ along with its numerous isoforms as well as IFN- $\beta$, and Type III IFN comprising IFN- $\lambda 1$, IFN- $\lambda 2$, and IFN- $\lambda 3$ to a lesser extent (McKenna et al., 2005; Fensterl $\&$ Sen, 2009). IFN- $\gamma$, also called Type II IFN, is produced as an indirect response to viral PAMPs, with a less potent antiviral effect than Type I and III IFNs. The action of IFNs action lies at the intersection of innate and adaptive immunity, promoting an "antiviral state" in an autocrine, paracrine, and systemic manner. Hence, it is not surprising that knockout mice lacking Type I IFN receptors are highly susceptible to viral infections. In a similar manner to animals, introduction of viral nucleic acids in plants elicits a systemic defense mechanism that travels ahead of the virus, named as systemic acquired resistance (SAR) (Kachroo \& 179 Robin, 2013). Interestingly, it has been demonstrated that viral infection 180 in plants leads to systemic DNA genetic and epigenetic changes includ- 181 ing an increased frequency of homologous recombination along with al- 182 tered methylation patterns. In turn, these alterations possibly favor the 183 creation of resistance $(R)$ genes with varying specificities, thus promot- 184 ing the antiviral defense of the host plant (Lucht et al., 2002; Kovalchuk 185 et al., 2003; Boyko \& Kovalchuk, 2011). Of note, induction of SAR not 186 only protects the individual plant but also passes on the immune mem- 187 ory to the next generations (Luna et al., 2012; Slaughter et al., 2012). 188

\subsection{PRRs: behind the curtains}

In both animals and plants, PRR-induced defense is the core of the 190 ImmR to infection by foreign genetic material. So far, six categories of 191 

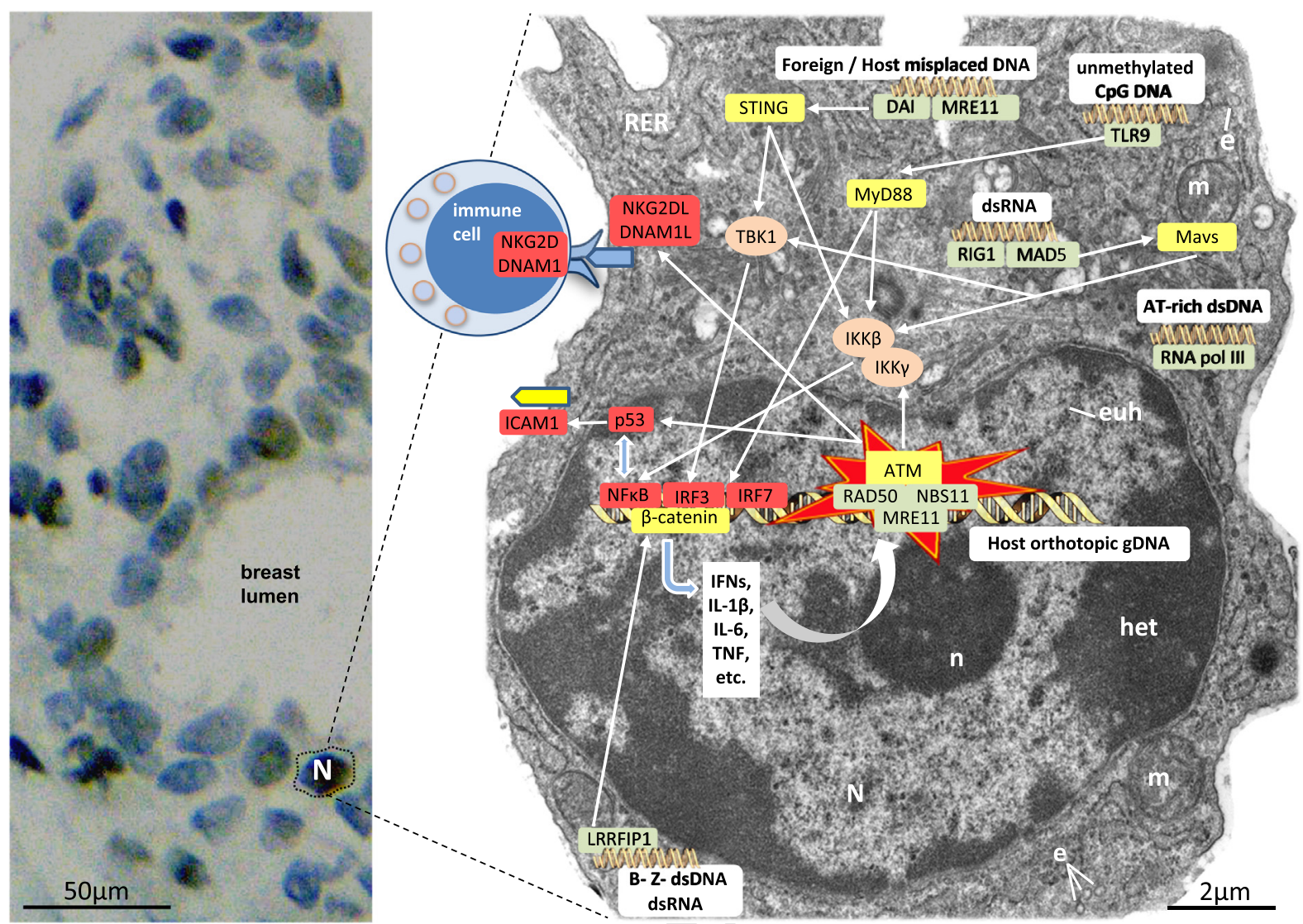

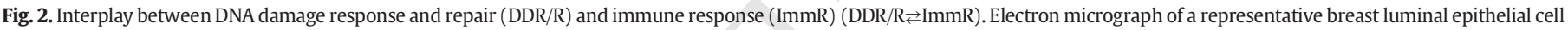

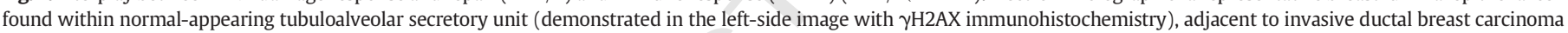

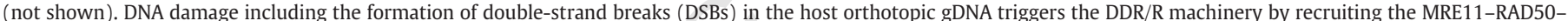

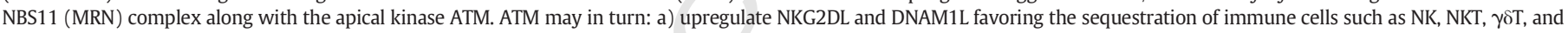

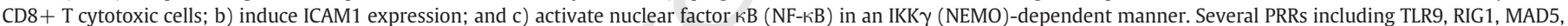

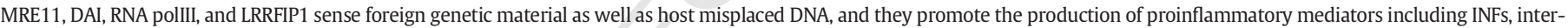

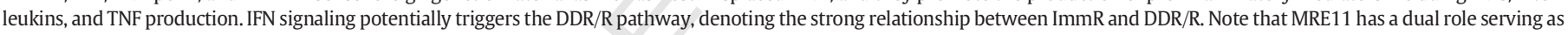

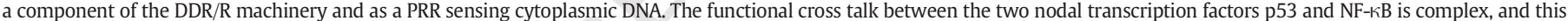

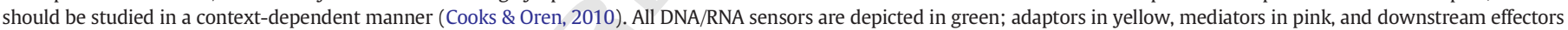

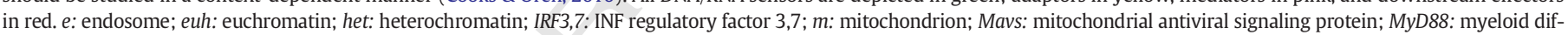

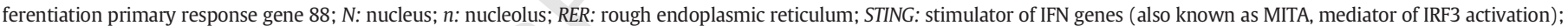
TBK1: TANK-binding kinase 1; arrow: positive effect; double ended arrow: bidirectional effect; curved arrow: potential activation of DDR/R pathways.

PRRs sensing nucleic acids have been recognized, including TLR, NODlike receptor (NLR), PYHIN, DExD/H-box helicases, DDR/R families, as well a few additional unclassified receptors presented as "other" in Table 1; this list will continue to grow. Because several of these PRRs were discovered only recently, at present, we cannot verify that all sensors included therein are indeed bona fide sensors (Unterholzner, 2013). Nevertheless, the multiplicity of DNA/RNA sensors underlines their significance in host immunity. This supports the original view of Charles A. Janeway, who introduced the term PRR in 1989 in the pioneering article titled "Approaching the asymptote? Evolution and Revolution in Immunology." He stated that PRRs are part of a primitive immune system before the onset of clonal selection (Janeway, 1989). Beyond their diversity, PRRs share a common structural pattern, evolutionarily conserved especially among vertebrates (Tam \& Jacques, 2014), consisting of a high-affinity domain for nucleic acids (Table 1, depicted in red) attached to a domain mediating protein-protein interaction (Table 1, colored in blue). The latter is involved in the recruitment of the appropriate adaptor protein for linking the specific PAMP-PRR pair with the stimulation of identical but shared signaling pathways (Fig. 2).

\subsubsection{Effects following PAMP-PRR axis activation}

So far, the most well described adaptors include STING, MyD88, Mavs, and $\beta$-catenin (interacting with leucine-rich repeat (in FLII) interacting protein 1 (LRRFIP1)) (Ishikawa \& Barber, 2011; Keating 214 et al., 2011; Cavlar et al., 2012; Paludan \& Bowie, 2013; Maringer \& 215 Fernandez-Sesma, 2014; Ran et al., 2014). Mostly IFN $\beta$ are directly pro- 216 duced by nonimmune cells including epithelial cells and fibroblasts, as 217 well as IFN $\alpha$ by plasmacytoid dendritic cells (DCs), when the STING- 218 TANK-binding kinase 1 (TBK1)-IRF3, MyD88-IRF7-NF-KB, Mavs- 219 TBK1-IRF3, and $\beta$-catenin-IRF3 signaling pathways are activated 220 (Fig. 2). Interaction between IFNs and the corresponding receptors 221 (with the generic term IFNR) in the target cells activates the Janus ki- 222 nase (JAK)-signal transducer activator of transcription (STAT) pathway 223 that a) leads to the transcription of interferon-stimulated genes (ISGs) 224 and b) favors adaptive immunity, altogether inducing cellular defense 225 (driving an antimicrobial and antitumoral state) (further discussed, 226 Schoggins et al., 2011). Of note, negative feedback mechanisms are acti- 227 vated in parallel in order to balance and inhibit the pro-inflammatory 228 signaling pathways (Ivashkiv \& Donlin, 2014). In addition, several Q6 other inflammatory mediators are released, including IL-6, IL-8, IL-12, 230 and tumor necrosis factor (TNF), in a NF- $\mathrm{KB}$ - or p38-dependent manner, 231 therefore enhancing host immunity (Langefeld et al., 2009). In immune 232 cells including macrophages and DCs as well as in epithelial cells, mem- 233 bers of the NLR family and the PYHIN protein AIM2 associate in a 234 stimulus-specific manner with apoptosis-associated speck-like protein 235 containing a CARD (ASC) by homotypic interactions via the CARD and 236 
t1.1 Table 1

t1.2 Well-characterized types of PRRs along with the corresponding members functioning as intracellular DNA/RNA sensors. A few still-unclassified PRRs are t1.3 presented as "other." The size of the protein domains is not depicted to scale; blue-colored domains are implicated in protein-protein interactions, t1.4 whereas red-colored domains interact with nucleic acids. Detailed description of each PRR member is provided in the corresponding Supplemental Data.

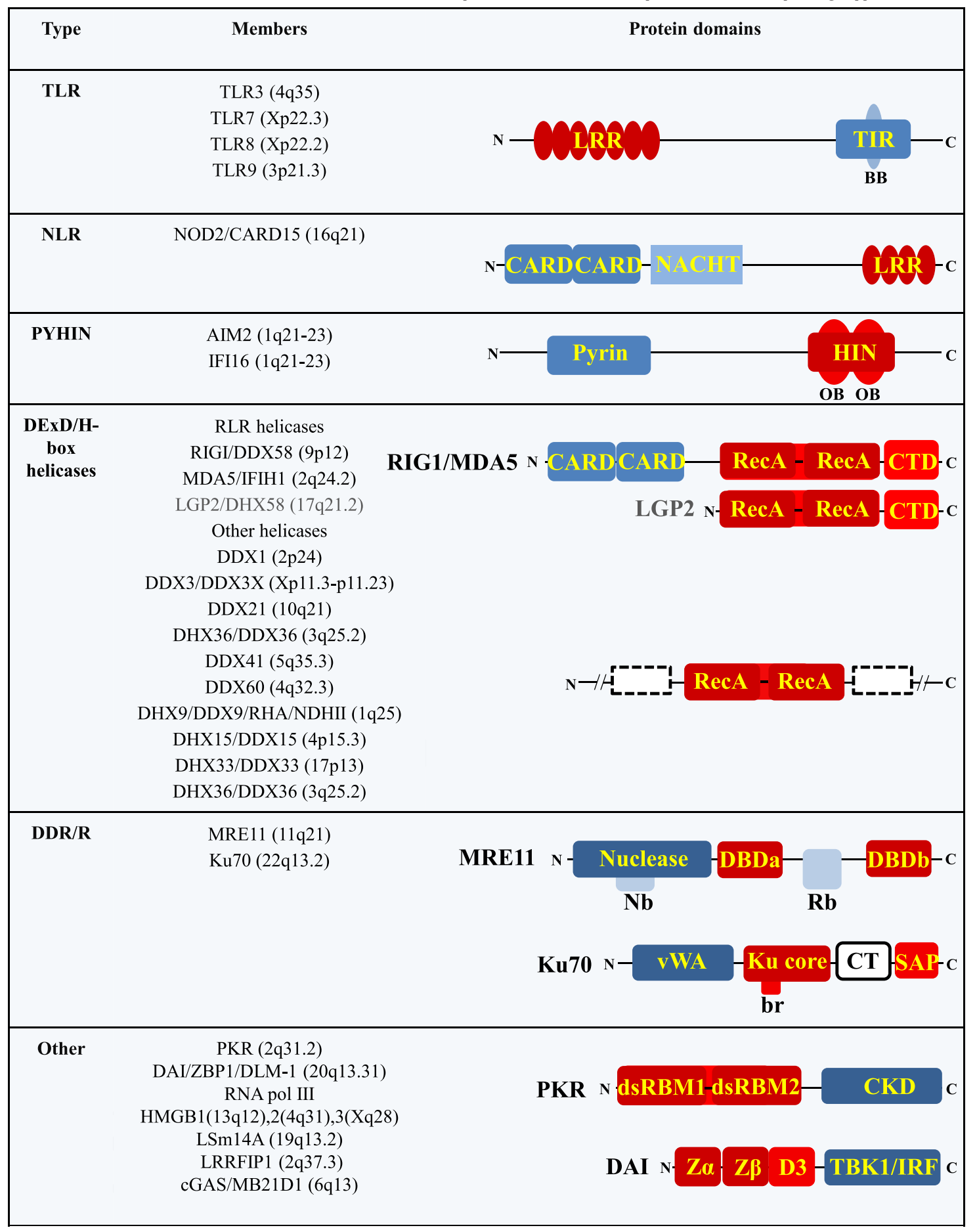

Pyrin/PYD domains. This in turn favors the recruitment of the 45-kDa procaspase-1 (also described as zymogen), forming a multimeric cytosolic complex termed as an inflammasome (Mariathasan \& Monack, 2007). Inflammasome assembly triggers the autoactivation of caspase1 (previously known as ICE), leading to the production of the potent pyrogen IL-1 $\beta$ responsible for fever reactions IL-18 coupling innate to adaptive immunity (Kim et al., 2010; Rathinam et al., 2010a, 2010b;
Kersse et al., 2011; Lamkanfi, 2011). Besides this, stimulation of the 244 caspase-1 inflammasome complex may also promote pyroptosis, a pro- 245 grammed form of cell death, wherein cells lose their membrane integri- 246 ty. Therefore, in contrast to apoptosis, it is a highly inflammatory type of 247 cell death (Aachoui et al., 2013). Interestingly, induction of AIM or 248 NLRP3 inflammasomes in macrophages can be accompanied by autoph- 249 agy in a p62-dependent manner, which limits inflammasome activity, 250 
suggesting a negative feedback loop by autophagy that restricts excessive inflammation (Shi et al., 2012). However, a large volume data also support the pro-inflammatory role of autophagy, including the induction of NF-KB activity and the stimulation of the Type I INF axis, suggesting that the interplay between autophagy and innate immunity remains a key challenge (Faure \& Lafont, 2013). In addition, activation of PRRs triggers immunological "silent" apoptosis as well as necrosis, including a form of necrotic cell death termed as necroptosis, which is dependent on TNF and mediated by RPK1 and RPK3 (Vanlangenakker et al., 2012; Aachoui et al., 2013).

The regulation of the cell's fate by PRR activity is followed by metabolic and cell cycle modulations. Stimulation of TLR signaling shifts the metabolism of immune cells towards aerobic glycolysis, a phenomenon originally described in cancer metabolism known as the "Warburg effect" (Cheng et al., 2014). Furthermore, there is strong evidence of PRRs interfering with critical modulators of the cell cycle (Ludlow et al., 2005). Overexpression of IFI16 and the murine p202 and p204 HIN-200/PYHIN proteins induces cell cycle arrest through their interaction with the pRb-E2F1 and p53-p21 molecules (Choubey et al., 1996; Sangfelt et al., 1999; Hertel et al., 2000; Johnstone et al., 2000). Noticeably, IFI16 and p53 form a positive feedback loop (H. Song et al., 2008; L.L. Song et al., 2008). On the one hand, IFI16 directly binds to the Cterminal region of p53 and promotes p53-mediated transcriptional activity, and on the other p53 directly upregulates IFI16, through a functional p53 DNA-binding site in the 5' regulatory region of IFI16. Hence, it is not surprising that IFI16 expression favors cellular senescence both in human normal and cancerous prostatic epithelial cells and in human fibroblasts (Xin et al., 2003; Xin et al., 2004; Song et al., 2010;
Duan et al., 2011). In addition, there is evidence supporting the cross 279 talk of the cytosolic and nucleic double-stranded DNA (dsDNA) sensors 280 of the PYHIN/HIN-200 family with DDR/R components (Ouchi \& Ouchi, 281 2008). BRCA1 interacts with the Pyrin domain of IFI16 favoring DNA- 282 damage-induced apoptosis (Aglipay et al., 2003). Likewise, p202 inter- 283 acts via the conserved MFHATVAT region within the HIN domain of mu- 284 rine homolog of human 53 binding protein 1 (53BP1) both in vitro and 285 in vivo (Datta et al., 1996). Interestingly, the authors demonstrated that 286 p202 inhibits the transcriptional activity of p53; the underlying mecha- 287 nism warrants further investigation. Despite the lack of a human homo- 288 $\log$ for p202, a potential interaction between 53BP1 and human HIN- 289 200 members may also be valid because the conservative MFHATVAT 290 sequence is involved (Cridland et al., 2012). Based on these findings, 291 we conducted a bioinformatics analysis and found that several PRRs 292 interact with components of the DRR/R machinery (Fig. 3).

\subsection{From ImmR to $D D R / R$ activation: let the main story begin}

Within this frame, there is a growing body of evidence on the activa- 295 tion of the DDR/R pathway by microbial infection in humans. Takaoka 296 et al. (2003) clearly proved that IFN $\alpha / \beta$ signaling promotes p53 in 297 turn evoking apoptosis that is critical for antiviral immunity, thus show- 298 ing a novel link between IFNs and p53 in antiviral immunity and tumor 299 suppression. The authors showed that infection of mouse embryo fibro- 300 blasts (MEFs) and the human hepatic cancer cell line HepG2 with differ- 301 ent viruses including vesicular stomatitis virus (VSV), Newcastle disease 302 virus (NDV), and herpes simplex virus (HSV) induces ATM-mediated 303 phosphorylation of p53 at Ser-18 (mouse equivalent of human p53 304

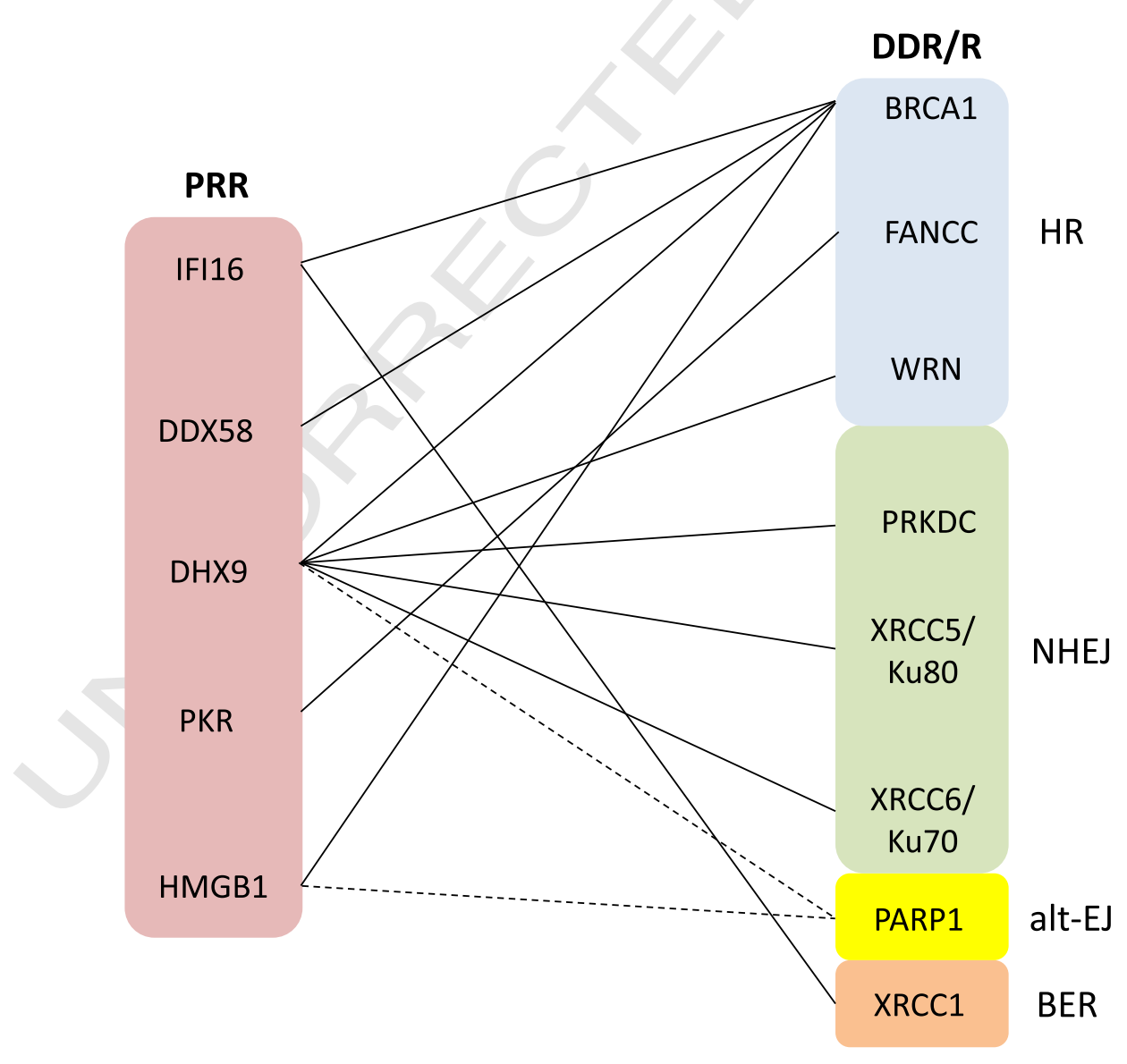

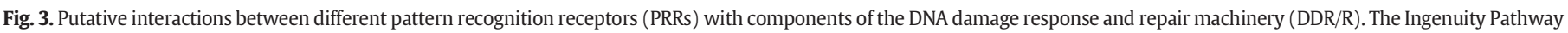

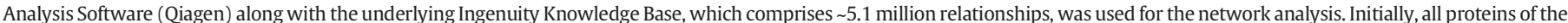

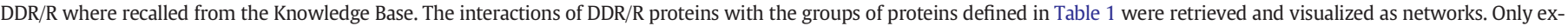

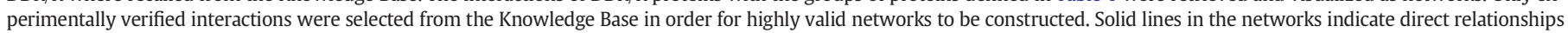
whereas dashed lines indicate indirect ones. 
Ser-15) and Ser-15, respectively. Of note, within this setting, p53 induction was accompanied only by Mdm2 and Puma but not by $p 21$ and Noxa transcription, implying a differential activation of p53-inducible genes after viral infection, thus warranting further studies. In line with the above mentioned data, prolonged expression of IFN $\beta$ in normal human diploid fibroblasts and of IFN $\gamma$ in human umbilical endothelial cells (HUVEC) induces the DDR-p53 axis in a p16 ${ }^{\mathrm{INK} 4 \mathrm{~A}}$-independent manner, in addition to the accumulation of $\gamma$-H2AX foci along with the phosphorylated forms of ATM-Ser1981, checkpoint kinase 2 (Chk2)-Thr68, and p53-Ser15 with ensuing senescence (Kim et al., 1999; Moiseeva et al., 2006). Interestingly, both studies demonstrated that the DNA damage signaling pathway was stimulated by an increase in reactive oxygen species (ROS), because treatment with the antioxidant N-acetyl-cysteine (NAC) inhibited DDR/R activation. Notably, despite activating the ATM-Chk2-p53 pathway, Guo et al. (2010) did not observe phosphorylation of $\mathrm{H} 2 \mathrm{~A}$ at Ser139 in response to $\mathrm{H}_{2} \mathrm{O}_{2}$ treatment in human primary fibroblasts, thus implying that oxidative stress triggers a DDR that is below the threshold needed to activate the "canonical" DDR/ $\mathrm{R}$ route. Instead, treatment with bleomycin, a genuine radiomimetic drug that induces complex DSBs, results in H2A phosphorylation (Regulus et al., 2007). Hence, oxidative stress potentially induces both "canonical" and "non-canonical” DDR/R signaling (Ogrunc et al., 2014). Canonical signaling is favored when triggered by IFNs, although discrepancies between the various settings may exist. Furthermore, stimulation of the downstream effector of IFN-IFNR axis, STAT1, induces the ATM-Chk2CDC25A and ATM-Nijmegen breakage syndrome 1 (NBS1) pathways by modulating the expression of MDC1 and 53BP1, triggering the $S$ phase and the G2-M checkpoint (Townsend et al., 2005). Moreover, the DNA repair protein FANCC facilitates the trafficking of STAT1 to the IFN $\gamma$ R1 docking site (Pang et al., 2000).

\subsubsection{How do viruses trigger $D D R / R$ in the host?}

Several DNA and RNA viruses trigger DDR/R in the host (Table 2) (reviewed by Georgakilas et al., 2010; Lilley et al., 2013; McFadden \& Luftig, 2013; Xiaofei \& Kowalik, 2014). Although the underlying mechanisms are still obscure, viral infection may stimulate DDR both directly and indirectly by the following mechanisms: a) the recognition of viral DNA as damaged DNA, such as the exposed (unintegrated) viral DNA ends that could resemble DSBs; $b$ ) the presence of DNA breaks within the viral genome; $c$ ) the induction of host DNA damage during viral infection (e.g., retroviral DNA integration); d) the identification of aberrant viral DNA structures; e) the expression of viral oncoproteins

\footnotetext{
t2.1 Table 2

t2.2 Viruses triggering the DNA damage response and repair t2.3 machinery (DRR/R). All viruses presented therein potent Q2 tially activate ATM (Lilley et al., 2013). There is evidence t2.5 supporting the fact that HIV-1 stimulates both ATM and t2.6 ATR. Besides induction of ATM, B19V as well as HTLV1 t2.7 may also activate DNA-PKcs (Xiaofei \& Kowalik, 2014). t2.8 It is well documented that EBV, KSHV, HPV, HCV, HTLV1, t2.9 HIV-1, and SV40 promote human carcinogenesis t2.10 (Georgakilas et al., 2010).

t2.11 Epstein Barr Virus (EBV)

t2.12 Herpes Simplex Virus 1, 2 (HSV-1, HSV-2)

t2.13 Kaposi's Sarcoma-associated Herpes Virus (KSHV)

t2.14 Murine gamma Herpes Virus 68 ( $\gamma$ HV68),

t2.15 Human Papilloma Virus 8, 16 (HPV8, 16)

t2.16 Adeno-Associated Virus (AAV)

t2.17 Polyomavirus

t2.18 Human Cytomegalovirus (HCMV)

t2.19 Hepatitis C Virus (HCV)

t2.20 Human parvovirus B19 (B19V)

t2.21 Rift Valley Fever Virus (RVFV)

t2.22 Human T-cell lymphotrophic Virus type 1 (HTLV1)

t2.23 Human Immunodeficiency Virus 1 (HIV-1)

t2.24 Simian Virus 40 (SV40)
}

leading to a hyperproliferative phase, which may in turn cause DNA rep- 346 lication stress, favoring the generation of single-strand breaks (SSBs) 347 and DSBs; and f) PRR-IFN-dependent axis as previously described 348 (Wilkinson \& Weller, 2003; Sinclair et al., 2006; McFadden \& Luftig, Q14Q15 2013; Xiaofei \& Kowalik, 2014). With respect to aberrant viral DNA 350 structures in particular, the rolling-circle structure as well as the newly 351 produced linear products and the presence of replication intermediates 352 often with a nonlinear, branched structure synthesized during lytic rep- 353 lication may be recognized as SSBs or DSBs. In addition to these features, 354 increased expression of the newly described PRR adaptor $\beta$-catenin in 355 thymocytes induces DDR/R, favoring senescence independently of p53 356 and apoptosis dependent on p53 (Xu et al., 2008). In addition, the cross Q16 talk between DDR/R machinery and ImmR is further strengthened by 358 the dual role of MRE11 and Ku70 both as PRRs sensing cytoplasmic 359 DNA and as DDR/R components (Fig. 2).

\subsection{Lessons from viruses, part 2: interplay with $D D R / R$ machinery}

361

Perhaps, one of the strongest proofs of the tight association between 362 ImmR and DDR machinery stems from the various strategies employed 363 by viruses to take control of DDR (Lilley et al., 2007; McFadden \& 364 Luftig, 2013). Viruses abrogate the activity of critical components of 365 $\mathrm{DDR} / \mathrm{R}$, including the MRE11 complex, usually by mislocalizing them 366 and/or targeting them for proteasome-mediated degradation, implying 367 a potential "bright" side of DDR/R stimulation. Indeed, DDR/R can be en- 368 visaged as part of the innate immunity of the host against several viruses. 369 The Epstein-Barr virus (EBV) is a good example of this connection. Infec- 370 tion of B lymphocytes with EBV leads to a transient hyperproliferative 371 phase that coincides with c-Myc up-regulation and robust DDR activa- 372 tion, followed by slower cell divisions (Nikitin et al., 2010). Inhibition 373 of ATM or Chk2 during this initial period increases B cell proliferation 374 and enhances their transformation, whereas ATM or Chk2 suppression 375 had minimal effect after this initial phase, denoting the antitumor activ- 376 ity of DDR/R activation during this acute oncogenic stress period. In light 377 of our recent work demonstrating a functional cross talk between DDR/R 378 and p14 alternate reading frame (p14ARF) antitumor barriers (Velimezi 379 et al., 2013), the status of p14ARF after ATM silencing in the initial phase 380 is of interest. Subsequent upregulation of the Epstein-Barr virus nuclear 381 antigen 3C (EBNA3C) results in reduced c-Myc expression, attenuated 382 $\mathrm{DDR} / \mathrm{R}$ activity, and repressed $\mathrm{p} 16^{\mathrm{INK} 4 \mathrm{~A}}$ and $\mathrm{p} 14^{\mathrm{ARF}}$ expression, favoring 383 the establishment of latency (Jiang et al., 2014). It is highly interesting 384 that this ubiquitous herpes virus infecting $>90 \%$ of adults causes malig- 385 nancy only in a limited number of human hosts. The increased incidence 386 of EBV-related malignancies in immunocompromised patients suggests 387 that the interplay between EBV and the host cellular and systemic re- 388 sponses possibly determines the final outcome of this symbiosis. To 389 this end, studies have maintained that disruption of T cell activity leads 390 EBV-transformed cells to escape (Hislop et al., 2007).

391

DDR/R activity may also possess a "dark" side, facilitating viral infec- 392 tion. HIV-1 infection triggers ATM-dependent DDR/R, favoring the effi- 393 cient repair of the integrase-induced DNA damage, ultimately leading 394 to the survival of host cells (Lau et al., 2005). Inhibition of ATM activity 395 suppresses HIV-1 replication because the integrase-related DNA dam- 396 age cannot be efficiently restored (Lau et al., 2005; Nunnari et al., 2005). Q17

Noticeably, a key step in the activation of the two major RNA sensors 398 RIG1 and MDA5 is the dephosphorylation of their CARD domain by pro- 399 tein phosphatase $1 \alpha$ (PP1 $\alpha$ ) and PP1 $\gamma$ (Wies et al., 2013). Of note, acti- Q18 vation of ATM in response to DNA damage leads to stimulation of PP1 401 (Tang et al., 2008). Therefore, DDR/R may activate PP1 directly (includ- 402 ing the integrase-induced DNA damage) or indirectly manner (like the 403 RLR-IFN $\alpha / \beta$ axis) when cells are infected with RNA viruses, which aug- 404 ments RLR activity forming a positive feedback loop that promotes the 405 ImmR. Two recent works depict two identical mechanisms wherein 406 the antiviral response is suppressed by the $\mathrm{V}$ protein of measles virus 407 via downregulation of the PP1-mediated dephosphorylation of RLRs in 408 human DCs (Davis et al., 2014; Mesman et al., 2014). In addition, during 409 
lytic replication, several viruses including EBV hijack the DDR/R machinery to promote their own replication, suggesting a yin-yang virus-host relationship according to the different stages of the viral life cycle (Li \& Hayward, 2011; Grywalska et al., 2013). In the lytic stage, DDR/R may be activated in two ways: a) during the generation of a prolonged pseudo-S-phase environment where the downstream activity of DDR/R is mitigated and $b$ ) during replication of the viral DNA itself. In both cases, DDR/R activity may foster viral replication contributing to faithful DNA replication and packaging. Recently, Laguette et al. (2014) demonstrated that HIV-1 viral protein R (Vpr) induces the Holliday junction resolution pathway relying on Synthetic lethal $\mathrm{X}$ (of unknown function) 4 (SLX4)-MUS81-essential meiotic endonuclease 1 (EME1), leading to FANCD2 foci accumulation and G2/M arrest. Activation of the SLX4 complex suppresses the spontaneous production of Type I IFN. The latter finding reveals a novel interaction between the DDR machinery and innate immunity suggesting that HIV-1 DNA can escape immunosurveillance mechanisms when processed through Vpr-SLX4-MUS81-EME-1. Interestingly, apart from viruses, two wellknown bacterial pathogens known to cause common human infections, namely Escherichia coli and Helicobacter pylori, trigger DDR/R in host cells (Nougayréde et al., 2006; Toller et al., 2011).

\subsection{Ionizing radiation: from $D D R / R$ to $I m m R$}

So far, we examined how immune insults trigger DDR/R. In the following, we focus on the reciprocal relationship of how DDR/R activates host immunity. First, we discuss the immunogenic function of ionizing radiation (IR).

IR induces complex DNA damage comprising a variety of closely spaced DNA lesions such as DSBs, SSBs, oxidized bases, and abasic (AP) sites (Georgakilas et al., 2013). This type of damage is expected to induce DDR and a variety of DNA repair pathways (Fig. 1A). This multi-pathway induction of DNA damage may first involve a danger signal for labeling this damage as a type of "special stress" above the regular DDR thresholds (Nikitaki et al., 2015), thereafter triggering the systemic effects and participating in secondary signaling based on inflammatory (cytokines and chemokines) or oxidative molecules (ROS/reactive nitrogen species (RNS), oxidized proteins, lipids, etc.) (Georgakilas et al., in press).

Radio-immunotherapeutic approaches are promising new curative anticancer treatments (de la Cruz-Merino et al., 2014; Vatner et al., 2014; Golden et al., 2015; Pilones et al., 2015). In addition to being directly cytotoxic, IR has also been traditionally considered as immunosuppressive. However, several findings over the past years suggest that it may promote host immune effector mechanisms, favoring antitumor immunity (Haikerwal et al., 2015). Almost two decades ago, Hallahan et al. (1989) demonstrated that exposure to X-rays increases the levels of the pro-inflammatory cytokine TNF $\alpha$ in human sarcoma cells, thus enhancing the lethality of radiation. Since then, a number of studies have corroborated the immunostimulatory (immunogenic) role of IR therapy. Interestingly, low doses of IR ( $0.5 \mathrm{~Gy})$ can exert an immunosuppressive effect in some cases, revealing the crucial role of the level and type of DNA damage as a control switch for the type of effect of IR on the immune system (Scheithauer et al., 2014). For an in-depth analysis of this topic, the reader is advised to refer to the aforementioned recent reviews. Within this context, ablative local radiotherapy induces Type I INF signaling when IFN $\beta$ is upregulated by the tumor microenvironment (Burnette et al., 2011). The latter enhances the cross-priming ability of tumorinfiltrating DCs, thus triggering antitumor immunity and in turn tumor regression. On investigating this issue further, Deng et al. (2014) showed that IR activates the cGAS-STING-IRF3-IFNB axis in DCs favoring crosspriming to $\mathrm{CD} 8+\mathrm{T}$ cells. This suggests that DCs sense the DNA produced by irradiated tumor cells. Indeed, the authors demonstrated that DNA from irradiated tumor cells activates cGAS in DCs during a cell-cell contact-mediated process. Noticeably, IR triggers the expression of major histocompatibility complex (MHC) class I, which boosts T cytotoxic lymphocytic adoptive transfer, restricting tumor growth in vivo in mouse colon adenocarcinoma (Reits et al., 2006). Treatment with 474 rapamycin blocked the cell surface expression of MHC-I as a response 475 to IR treatment in the later phase, suggesting the involvement of mam- 476 malian target of rapamycin (mTOR). Indeed, two other studies have 477 shown that IR promotes mTOR activity, which is greatly enhanced in 478 MEFs and in the human colon carcinoma cell line HCT116 in the absence 479 of adenosine monophosphate-activated protein kinase (AMPK), an up- 480 stream negative regulator of mTOR (Braunstein et al., 2009; Zannella 481 et al., 2011). It is worth noting that IR activates AMPK in an ATM- 482 dependent manner, inhibiting excessive mTOR expression in both nor- 483 mal and cancerous environments, leading to cell cycle arrest and favor- 484 ing cell survival (Sanli et al., 2010; Zannella et al., 2011; Sanli et al., 485 2014). In addition to the lately established immunomodulatory role of 486 mTOR these findings (Cobbold, 2013) highlight the importance of the Q22 AMPK-mTOR signaling pathway in radiation biology with potential ther- 488 apeutic applications.

\subsection{Bystander or non-targeted effects enter the game}

The effect of IR is not limited to the cells, tissues, and organs subject 491 to irradiation; it also acts "out of field" within the same organism. The 492 radiation-induced bystander or non-targeted effects are well accepted, 493 although the underlying mechanisms are still obscure especially 494 in vivo (Hatzi et al., 2015; Georgakilas et al., in press). Irradiated cells 495 send signals to non-exposed neighboring cells such as damage- 496 mediated or protective responses that include DNA damage formation, 497 apoptosis, senescence, terminal differentiation, as well as radioadaptive 498 responses (Prise \& O'Sullivan, 2009; Martin et al., 2011). Bonner's group Q23 examined the dynamics of DSBs in irradiated and bystander cells in 500 three-dimensional (3-D) human tissue models (Sedelnikova et al., 501 2007). Maximal $\gamma$-H2AX foci formation was observed 30 min after irra- 502 diation in the former, whereas the incidence of $\gamma$-H2AX foci reached a 503 maximum by $12-24 \mathrm{~h}$ after irradiation in the latter, followed by in- 504 creased apoptosis, micronucleus formation, senescence, and loss of nu- 505 clear DNA methylation. The bystander effect is mediated through two 506 key routes: a) by direct cell-cell contact via gap junctions allowing 507 molecules weighing up to $1.0-1.5 \mathrm{kDa}$ to pass through and $\mathrm{b}$ ) by release 508 of soluble factors including RONS and cytokines such as TNF $\alpha, 509$ transforming growth factor-beta 1 (TGFß1), IL-1ß, IL-6, IL-8, and IL-33 510 (Najafi et al., 2014; Havaki et al., 2015). In addition, activated macro- 511 phages are recruited to the irradiated sites, thus promoting cytokine 512 production and in turn oxidative stress further. Interestingly, experi- 513 mental evidence points to the saturation of bystander responses, 514 which indicates that no additional effect occurs above a certain dose, in- 515 stead reaching a plateau (Nagasawa et al., 2002). The latter contrasts Q2 with the direct effect of IR, where the response increases with elevated 517 radiation dose. However, even in this case, the relative biological effect 518 (RBE) increases up to $100-200 \mathrm{keV} / \mu \mathrm{m}$ and starts decreasing, possibly 519 because the additional energy deposited does not cause further damage 520 per se (Prise \& O'Sullivan, 2009). Monte Carlo damage simulation Q25 (MCDS), which relies on repeated random sampling, is frequently 522 used to reproduce clustered DNA damage (closely spaced DNA lesions), 523 including DSBs and SSBs, in irradiated tissues (Carlson et al., 2008). For a 524 population of cells uniformly inflicted by irradiation, the induction and 525 repair of DSBs can be measured by determining the rate of change of 526 the average number of potentially rejoinable DSBs per cell at time $t 527$ with the following equation (Carlson et al., 2008):

$\frac{\mathrm{dL}(\mathrm{t})}{\mathrm{dt}}=f_{R} \sum \dot{D}(t)-\left(\lambda+\eta f_{R} \overline{Z_{F}} \sum\right) \mathrm{L}(\mathrm{t})-\eta L(t) L(t)$.

L average number of DSBs in a cell

$\dot{D}(\mathrm{t}) \quad$ absorbed doserate

$\mathrm{f}_{R} \sum \dot{D}(t) d t$

potentiallt rejoinable DSBs occuring in a cell during $\mathrm{dt}$
532 533 
$\lambda L(t) \quad$ the first-order DBS repair process, where the rate constant $\lambda$ is the sum of $\lambda_{R}$ (rate of DBS repair) and $\lambda_{F}$ (rate of damage $\eta f_{R} \overline{Z_{F}} \sum L(t)$ fixation)

intratrack (along on track) misrepair

$\eta L^{2}(t) \quad$ intertrack (along different tracks) misrepair

Although difficult, a mathematical formula can be developed to determine the rate of DSBs in bystander cells in the near future. Considering that the irradiated and bystander cells have similar effects of irradiation, but different time and extent, the equation should include the following parameters: a) the rate of DSBs in the irradiated cells and b) the underlying mechanisms mediating the bystander effect. The former has already been addressed, whereas the latter warrants further investigation as it is challenging.

\subsection{How does $D D R / R$ induce ImmR?}

In the following section, we discuss the underlying mechanisms linking DDR activity with ImmR.

\subsubsection{NF- $\kappa B$ : linking $D D R / R$ activity with ImmR}

Brzostek-Racine et al. (2011) demonstrated a clear connection between DDR/R activation and IFN production, despite IR being a prototypic DDR/R inducer (Han \& Yu, 2011) (Fig. 2). The authors showed that treatment of human cell lines with various DNA-damaging agents induce IRF7 and IRF1, leading to elevated levels of IFN- $\alpha$ and IFN- $\lambda 1$ in an NF- $\kappa$ Bdependent manner. MEFs that lack nuclear factor kappa B essential modulator (NEMO), one of the regulatory subunits of the IKK complex, could not upregulate IFN- $\alpha$ and IFN- $\lambda 1$ after etoposide treatment. Activation of NEMO allows NF- $\kappa B$ dimers to translocate to the nucleus favoring gene transcription (Pasparakis, 2009). An interesting role of NEMO is that it serves as the molecular linkage between ATM and NF- $\kappa$ B signaling after genotoxic stress, revealing a novel function of ATM in the cytoplasm, mediating NF-KB activation in response to DSBs (Fig. 2) (Li et al., 2001; Wu et al., 2006, reviewed in Miyamoto, 2011). Thus, NEMO (phosphorylated at Ser85) triggers an inside-out signaling pathway when shuttling between the nucleus and the cytoplasm, leading to an ImmR because of DDR activity (Fig. 2B). The ATM-NF- $\kappa$ B cross talk is further analyzed in Section 3. Moreover, UV-mediated activation of NF- $\kappa \mathrm{B}$ is compromised in primary skin fibroblasts isolated from patients with xeroderma pigmentosum (Muotri et al, 2006), thus reiterating the strong interaction between the DDR/R machinery and NF- $\kappa B$, the master regulator of inflammation. Within this frame, the critical role of p38 mitogen-activated protein kinase (MAPK) signaling pathway should be recognized. p38MAPK responds to a variety of external and internal stimuli including DDR/R activity, which in turn modulates several genes involved in the inflammatory response (Cuadrado \& Nebreda, 2010). The latter is frequently mediated by the positive regulation of NF-KB activity.

\subsubsection{Activation of DDR triggers NKG2DL and DNAML expression}

In 2005, Gasser et al. (Nature 2005) demonstrated that constitutive activation of DDR/R in human dermal foreskin fibroblasts upregulates NKG2D ligands (NKG2DL). Pharmacological inhibition of ATM, ataxia telangiectasia and Rad3 related (ATR), and checkpoint kinase 1 (Chk1) prevented their overexpression in nontumor cell lines. Moreover, NKG2DL expression was reduced when ATM was silenced in a murine ovarian cancer cell line, whereas no difference was observed with ATR short interfering RNA (siRNA) in this particular setting. Likewise, treatment of multiple myeloma (MM) cell lines with low doses of chemotherapeutic agents elevates the status of NKG2D and DNAX accessory molecule-1 (DNAM-1)/CD226 ligands in an ATM/ATR-dependent manner (Soriani et al., 2009). Of note, NKG2D and DNAM-1 ligands were upregulated in MM cells expressing a senescence phenotype. NKG2D is an activating and costimulatory receptor that belongs to a family of lectinlike Type II transmembrane proteins expressed in humans as a homodimer on NK cells, $\gamma \delta \mathrm{T}$ cells, and a subset of CD8 + and CD4+ T cells
(Burgess et al., 2008). DNAM-1 is another activating immune receptor 597 that belongs to the Ig superfamily, expressed in humans at the cell sur- 598 face of NK and NKT cells; CD8+, CD4+, and $\gamma \delta$ T lymphocytes; and mac- 599 rophages (de Andrade et al., 2014). MICA, MICB, UL binding protein 1-6 600 (ULBP1-6), and RAE1 as well as CD112/nectin-2 and CD155/PVR (polio- 601 virus receptor) are the human ligands for NKG2D and DNAM-1, respec- 602 tively. NKG2D and DNAM- 1 ligands are usually expressed poorly by 603 healthy cells, but they are up-regulated on the surface of infected, trans- 604 formed, or otherwise "stressed" cells of various cell types (Zingoni et al., 605 2013; Cerboni et al., 2014) (Fig. 2). Ligation with the NKG2D and 606 DNAM-1 receptors triggers innate and adaptive immunity, leading to 607 enhanced cytokine production and cytotoxicity, favoring cell lysis of 608 the incipient cells. Several viruses have evolved the ability to downreg- 609 ulate NKG2D and DNAM-1 ligands (Cerboni et al., 2014). Moreover, cer- 610 tain tumors reduce the levels of NKG2DL or DNAM-1L at the cell surface 611 and release soluble NKG2DL via proteolytic shedding or phospholipace 612 C cleavage, exosome secretion, and alternative splicing to promote im- 613 mune escape (Chitadze et al., 2013; de Andrade Immunol, 2014). There- Q27 fore, it is not surprising that NKG2D- and DNAM-1-deficient mice are 615 susceptible to tumorigenesis (reviewed in Raulet \& Guerra, 2009). Of 616 note, the acquisition of an EMT phenotype in the Snail-HT29 M6 colon 617 carcinoma cell line is associated with an upregulation of NKG2DL, 618 followed by enhanced lysis of cancer cells by NK cells (Lopez-Soto Q28 et al., 2013). In a conceptual twist, human cancer cells in several 620 common carcinomas express the NKG2D immunoreceptor themselves, 621 which confers a growth advantage by triggering the PI3K-AKT-mTOR 622 axis (Benitez et al., 2011). The latter reveals a complex role for 623 NKG2D/NKG2DL during tumorigenesis, which should be taken into ac- 624 count in future therapeutic applications.

\subsubsection{Persistent DDR activation}

promotes the accumulation of cytoplasmic DNA

627

Hence, in addition to the evidence of DDR/R machinery stimulation 628 soon after viral infection, the activation of DDR/R from the earliest 629 stages of carcinogenesis (Bartkova et al., 2005; Gorgoulis et al., 2005a, Q29 2005b) suggests a critical role of the DDR-NKG2D/DNAM-1 axis as a 631 prompt immunosurveillance mechanism (Fig. 2). The recent finding 632 that activation of the DDR cascade induces the expression of NKG2DL 633 and RAE1, in a STING-TBK1-IRF3-dependent manner in lymphoma 634 cell lines, further elucidates the underlying pathways linking DDR/R 635 with ImmR (A.R. Lam et al., 2014; E. Lam et al., 2014). Of note, the Q30 same group very recently depicted that induction of DDR in normal 637 and various cancerous settings favors the presence of cytosolic single- 638 stranded DNA (ssDNA) and dsDNA (Shen et al., 2015). Accumulation 639 of cytosolic DNA promotes the expression of Type I IFNs, contributing 640 to the immunogenicity of tumor cells. Overexpression of RNASE H1, 641 which hydrolyzes RNA from RNA:DNA hybrids, as well as Trex1, a 642 major mammalian 3' DNA exonuclease, reduces the levels of cytoplas- 643 mic DNA, thus inhibiting Type I IFN-mediated rejection. By contrast, 644 Trex1-deficient cells exhibit ATM-dependent checkpoint activation 645 (Yang et al., 2007). According to Yang et al. (2007), Trex1 degrades 646 ssDNA generated from the aberrant processing of replication intermedi- 647 ates, thereby suppressing abnormal DDR/R activity. Mutations in TREX1, 648 resulting in a dysfunctional nuclease enzyme, have been identified in 649 Aicardi-Goutières Syndrome (AGS) (Aicardi \& Goutieres, 2000). AGS 650 shares common features with the autoimmune syndrome systemic 651 lupus erythematosus (SLE). Trex1 deficiency possibly promotes a path- 652 ological ImmR via aberrant DDR/R activation. However, some questions 653 remain unanswered: How does the loss of Trex1 trigger autoimmunity? 654 This may be partly explained by the accumulation of ectopic nucleic 655 acids in the cytoplasm, which ultimately leads to the upregulation of 656 NKG2D and DNAM-1 ligands. Further, NKG2DL may be activated by his- 657 tone deacetylase inhibitors, demethylating agents, all-trans-retinoic 658 acid, HER2/HER3 signaling, and IL-18 (which can be induced after 659 inflammasome activation as mentioned earlier) (reviewed by Chitadze 660 et al., 2013). 


\subsubsection{Activation of $p 53$ favors immunosurveillance}

Conflicting data on the role of p53 in the immunosurveillance mechanism exist. Although previous studies described that p53 was not required for NKGDL upregulation (Gasser et al., 2005), two other studies demonstrated the presence of functional p53-responsive elements in ULBP1-2 (Li et al., 2011; Textor et al., 2011). Conversely, the expression of miR-34 represses ULBP2 in a p53-dependent manner (Heinemann et al., 2012). Further, restoration of p53 in mouse liver carcinomas promotes tumor regression because senescence activity and a robust ImmR interact cooperatively (Xue et al., 2007). Reactivation of p53 increased the expression of several inflammatory modulators by tumor cells including ICAM-1 (CD54), LFA-1 as well as MICA, ULBP2, and CD155, accompanied by the recruitment of neutrophils, macrophages, and NK cells, thus promoting tumor elimination (Xue et al., 2007; Krizhanovsky et al., 2008). The presence of a functional p53-responsive element in ICAM-1 conferring inducibility to p53, as observed in our laboratory, further supports a direct immunosurveillance role of wild-type p53 (Fig. 2) (Gorgoulis et al., 2003; Gorgoulis et al., 2005a, 2005b). Of course, we should bear in mind that p53 reactivation triggers senescence, which in turn produces an inflammatory response called SASP (Rodier \& Campisi, 2011). Overall, p53 is found to favor immunosurveillance in different settings both directly and indirectly (Collado \& Serrano, 2010; Gorgoulis \& Halazonetis, 2010; Salama et al., 2014). However, the extent of their action in parallel or separately in eradicating tumors needs to be addressed.

\subsection{Senescence-associated secretory}

phenotype: another paradigm of DDR/R-ImmR cross talk

The persistent activation of the DDR/R machinery favors the secretion of inflammatory cytokines, including IL-6 and IL-8 (Rodier et al., 2009). Activation of ATM, NBS1, and Chk2 is essential for cytokine production, whereas p53 activity is dispensable. The term Senescenceassociated secretory phenotype (SASP) encompasses several of these inflammatory elements, as they are also associated with the senescence phenotype. Hence, DDR activity triggers inflammation, again demonstrating that DDR/R and ImmR form a functional network with highly connected associations. The state of chronic inflammation observed in several pathological settings, including neoplasias and autoimmune diseases, may be partially attributed to persistent DDR activation. The senescence inflammatory response (SIR) is a unique type of senescence-related inflammation that overlaps with the SASP signature (Lasry \& Ben-Neriah, in press), thereby conforming to the term "parainflammation" introduced by Medzhitov (2008). SIR/parainflammation represents a state of lowgrade inflammation, an intermediate between homeostasis and overt inflammation. However, the control of SIR by persistent DDR and the sequence of events in relation with SASP remain elusive. SASP components in the cell act both autonomously and non-autonomously, favoring communication between damaged cells and their neighboring cells. The net effect of the non-cell-autonomous activity depends on the cell and tissue context. SASP favors senescence in normal or low-grade premalignant cells but it boosts tumorigenesis in high-grade premalignant or malignant cells (Gorgoulis \& Halazonetis, 2010). SIR exerts a "yin-yang" effect, with a pro- or antitumorigenic activity based on the cell context (Pribluba et al., 2013).

\subsection{A common denominator behind different diseases}

Overall, the DDR/R and ImmR are clearly part of a tightly regulated mechanism protecting (multi)cellular integrity from both exogenous and endogenous threats. Thus, a unifying model emerges with DDR/R, PRR, and inflammatory/immune mediators (including INFs and ILs) being activated in concert as a response to D/PAMPs within a particular time frame (Fig. 5). Aberrant activation disrupts cellular and systemic homeostasis, often leading to chronic and potentially fatal diseases. Hence, this model underlines the common routes activated during malignancies, connective tissue diseases, and infectious diseases. Stimu- 724 lation of the INF signaling pathway in a TLR-dependent and TLR- 725 independent manner contributes to autoimmunity (Moutsopoulos \& Q33 Hooks, 1983; Meyer, 2009; Conigliaro et al., 2010; Delgado-Vega et al., Q34 2010; Crow, 2014; Kato \& Fujita, 2014; Lemos et al., 2014; Smith \& 728 Jefferies, 2014; Land, 2015). Similarly, the TLR pathway plays a signifi- 729 cant role in inflammation-associated carcinogenesis (Mairov et al., Q35 2013). Recently, Funabiki et al. (2014) demonstrated that lupus-like 731 features developed spontaneously with a mutant MDA5 gain of function 732 (GOF) that activated the corresponding signaling in the absence of the 733 appropriate ligand. In the past, we demonstrated a marked association 734 of particular NOD2/CARD15 variants with sarcoidosis as well as with ul- 735 cerative colitis and Crohn's disease, two chronic inflammatory condi- 736 tions that pose an elevated risk of colorectal carcinoma (Gazouli et al., Q36 2004; Gazouli et al., 2005; Gazouli et al., 2006). In addition, DDR has 738 been proven to be involved in the pathogenesis of autoimmune diseases 739 (Schild-Poulter et al., 2008; Davies et al., 2012; Solier \& Pommier, 2014; Q37 Gunther et al., 2015). Examples from bedside experience support the 741 common molecular background behind the different pathologies men- 742 tioned previously. Fever is one of the most common manifestations of 743 several diseases. It is a prominent sign that reflects the activation of a 744 common route leading to the release of pyrogens irrespective of the ini- 745 tial trigger. Based on our previous analysis, activation of both sensors, 746 PRR and DDR/R, may lead to the production of pyrogenic substances in- 747 cluding IL-1 $\beta$, TNF- $\alpha$, IL-6, and INF- $\alpha$ (Dinarello, 1999). This explains Q38 why fever of unknown origin (FUO) is a major challenge for physicians, 749 as the underlying cause may fall under one of the following three enti- 750 ties capable of activating the PRR-DDR/R-inflammatory mediator cir- 751 cuit: neoplasms, collagen vascular diseases, or infections (Becker \& 752 $\mathrm{Wu}, 2010$ ). In addition, one of the characteristics of DNA repair- 753 deficient syndromes is elevated expression of immune and inflammato- 754 ry genes (Ermolaeva \& Schumacher, 2014). Werner syndrome (WS), a 755 progeroid disorder caused by a deficiency in a RecQ-type DNA helicase 756 (encoded by WRN), exhibits an increased inflammatory status (Turaga 757 et al., 2009). Moreover, prolonged DDR/R activation has been linked 758 with diabetes mellitus (Shimizu et al., 2014). DNA damage promotes in- 759 creased inflammation, which in turn interferes with insulin signaling as 760 well as reduced regenerative ability, impaired metabolism, and sup- 761 pressed endocrine function provoking insulin resistance. Paraneoplastic 762 syndromes (PSs) can represent another example, from daily practice, 763 supporting the DDR/R-ImmR cross talk. PSs are disorders attributed to 764 benign or malignant neoplasms remote from the direct local or metasta- 765 tic effects and are considered to be immune mediated (Darnell \& Posner, 766 2003). The oncogene-induced DNA replication stress pathway, which 767 leads to deregulated DDR/R activation and in turn favors genomic insta- 768 bility (Halazonetis et al., 2008), may increase the levels of certain 769 cytokines including IL-6, IL-5, granulocyte colony-stimulating factor 770 (G-CSF), and granulocyte/macrophage colony-stimulating factor (GM- 771 CSF), as well as the production of paraneoplastic autoantibodies ob- 772 served in PSs. This hypothesis remains to be confirmed in the future. 773 In the following section, we present an interesting connection between 774 ATM and NF- $\kappa$ B, further supporting the DDR/R-ImmR interplay.

\section{The ATM apical DDR/R kinase as a hub of the DDR/R-ImmR network}

It is well known that the main function of ATM is to coordinate the 778 DDR/R network (Jackson \& Bartek, 2009). However, ATM also responds 779 to a wider variety of stressogenic stimuli, bringing about cellular reac- 780 tions that aim to preserve cellular homeostasis (Shiloh \& Ziv, 2013). 781 Within this context, ATM seems to modulate NF-kB activity in a multi- 782 faceted manner.

One of the best characterized ATM-NF- KB interactions occurs in the 784 cytoplasm where ATM assembles with IKK $\gamma$ (NEMO) dimers, activating 785 IKB kinases (IKK $\alpha$ and IKK $\beta$ ) and in turn triggering NF-KB-dependent 786 gene expression (Miyamoto, 2011). This type of ATM signaling 787 
constitutes a nuclear to cytoplasmic ("inside-out") innate pathway, as mentioned previously (Fig. 2), and it is part of the endogenous DAMP mechanism that is triggered independently of membrane and cytosolic receptors (Fang et al., 2014). Nevertheless, ATM has also been shown to coordinate NF- $\kappa \mathrm{B}$-mediated signaling initiated by membrane and cytosolic receptors ("outside-in"), predominantly by modulating NF-кBdependent activation of early pro-inflammatory cytokines upon TNF stimulation (Fang et al., 2014).

The cross talk between ATM and NF-kB has been demonstrated in both normal and malignant cells. For example, in the differentiation of pre-B cells, ATM-NEMO mediates the stimulation of NF- $\kappa \mathrm{B}$ during DSB-induced $V(D) J$ recombination of the immunoglobulin loci (Bredemeyer et al., 2008), whereas the same axis is constitutively activated in patients suffering from primary myelodysplastic syndrome (MDS) and acute myeloid leukemia (Miyamoto, 2011). Persistent activation of NF- $\mathrm{KB}$ is observed in many types of cancer, but the underlying mechanism remains obscure (Chatuverdi et al., 2011). Given that genomic instability is an "enabling" hallmark of cancer, it is possible that the DDR/R network could fill this mechanistic gap in certain cases (Negrini et al., 2010). In line with this notion, evidence from human cancer cell lines has shown the significance of $\mathrm{NF}-\kappa \mathrm{B}$ in processes such as homologous recombination (HR)-mediated repair as well as nonhomol- 809 ogous end joining (NHEJ) repair of DSBs, thereby potentially explaining 810

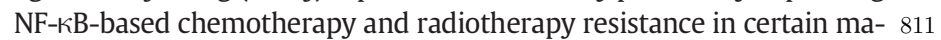
lignancies (Lim et al., 2002; Volcic et al., 2012).

An intriguing link between ATM and NF- $\kappa$ B was revealed based on 813 an earlier study showing that mouse skin cells bypassed senescence 814 and became more invasive upon ATM inhibition (Bartkova et al., 815 2006). Prompted by this finding, we set out to investigate the mechanis- 816 tic basis of this outcome. As invasiveness is associated with increased 817 metalloproteinase activity in most instances (Hadler-Olsen et al., 818 2013), we measured, for example, the generic matrix metalloproteinase 819 (MMP) activity in ATM-depleted cells and found it increased (Fig. 4A). 820 From the various MMPs assessed, we discovered that the enhanced ge- 821 neric MMP activity was driven by increased transcriptionally-based 822 MMP-3 (stromelysin-1) expression (Fig. 4B, C). On conducting a bioin- 823 formatic analysis of the mouse MMP-3 promoter, we noticed, among 824 various regulatory elements, an NF-kB-binding site (Fig. 4D), which is 825 reported to be responsive and evolutionarily conserved in mammals 826 (Gilmore, 2006). To test whether ATM could control MMP-3, via NF- 827 $\mathrm{\kappa B}$, we examined the subcellular localization and phosphorylation sta- 828 tus of the latter. Notably, ATM silencing was followed by a shift of the 829
A.

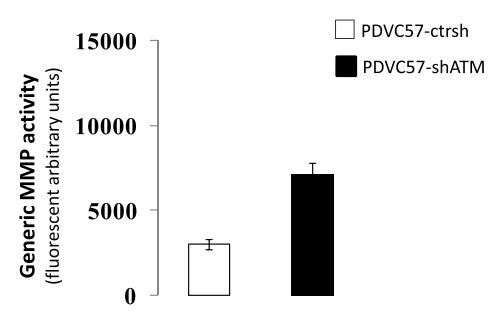

B.

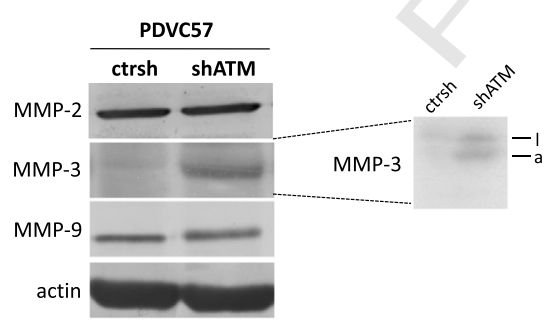

C.

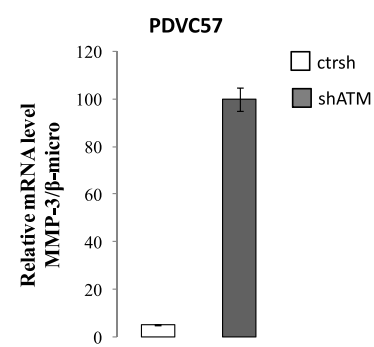

D.

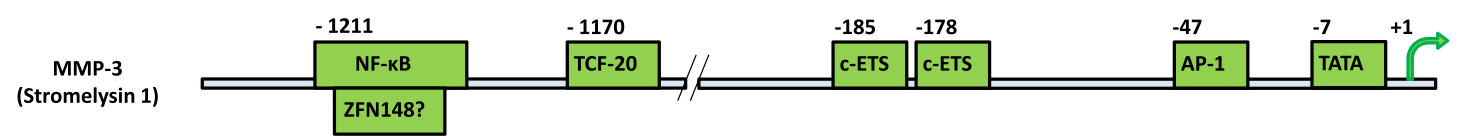

G.

E.

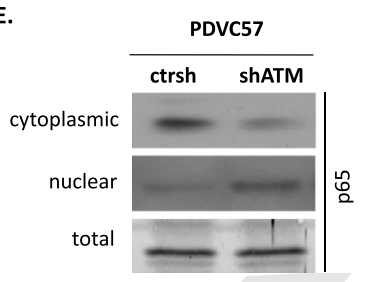

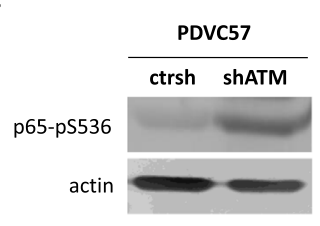

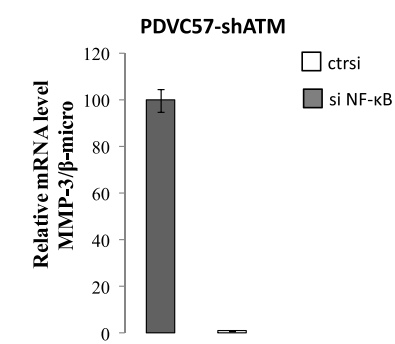
$\square$ ctrsi si NF-kB H.

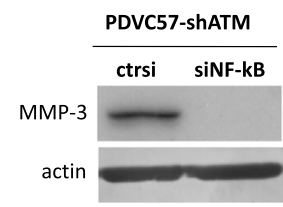

I.

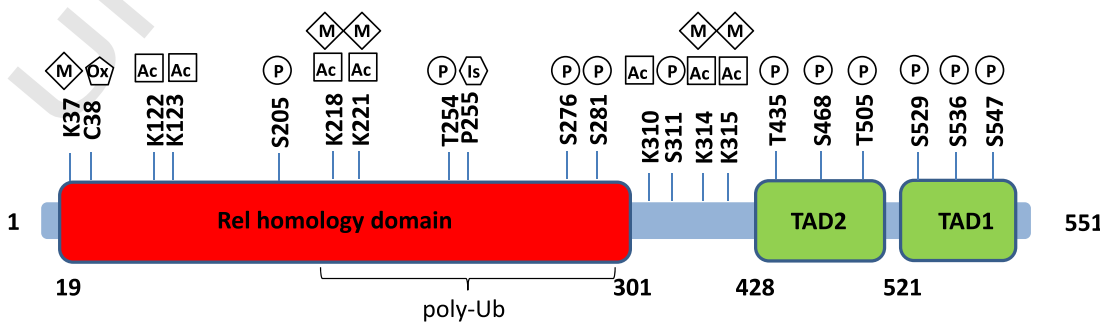

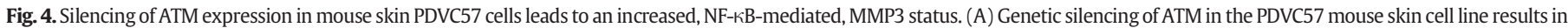

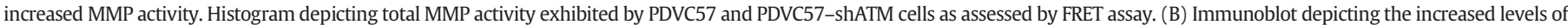
MMP-3 (stromelysin 1) produced by PDVC57-shATM cells. Inset showing that PDVC57-shATM cells secrete higher levels of MMP-3 in the culture supernatant. 1: latent form of MMP-3; a: active form of MMP-3. (C) Histogram showing that PDVC57-shATM cells express increased transcription levels of MMP-3. (D) Structural organization of the MMP-3 promoter. Note the presence of a NF-KB-responsive element. ( $\mathrm{E}$ and F) Silencing of ATM in the PDVC57 cells increases NF-KB activity as assessed by nuclear translocation (E) and S536 phosphorylation (F) of the p65 subunit. ( $\mathrm{G}$ and $\mathrm{H}$ ) siRNA silencing of the $\mathrm{p} 65$ subunit decreases MMP-3 expression in the ATM-deficient PDVC57 cells, at the mRNA $(\mathrm{G})$ and protein $(\mathrm{H})$ levels. (I) Structural presentation of the RelA/p65 protein subunit along with characterized positions of posttranslational modifications. Material and methods are provided in Supplemental Data. 
RelA/p65 subunit from the cytoplasm to the nucleus (Fig. 4E), with a concomitant increase in NF-kB phosphorylation levels at Ser 536 (Fig. 4F), whereas silencing of NF- $\kappa B$ evoked a remarkable reduction in MMP-3 levels (Fig. 4G, H). Although most studies have shown ATM to activate NF- $\kappa \mathrm{B}$, it must be noted that cellular context, in the form of either a cell type or a species, could dictate the outcome of the protein network interplay. NF- $\kappa B$ is posttranslationally modified to a great extent, and these modifications control its transcriptional activities or stability in the cytoplasm and the nucleus (Fig. 4I) (Perkins, 2006; Huang et al., 2010). In this context, phosphorylation at Ser 536 is a wellestablished activating modification that enhances its global transcriptional capabilities in response to a variety of stimuli. However, other phosphorylations have a more limited or temporal effect on its transcriptional repertoire. Characteristically, ATM has been reported to directly bind and phosphorylate NF- $\kappa \mathrm{B}$, upon genotoxic stress, at Ser 547 leading to transactivation of a small number of genes (Sabatel et al., 2012). This ATM-dependent NF-кB-stimulating route is unrelated to the NEMO-mediated mechanism (Wu et al., 2006). In our cellular setting, silencing, and not activation, of ATM triggered NF- $\kappa$ B activity, suggesting that ATM either does not stimulate NF-kB or exerts a constrained effect, similar to that reported from the phosphorylation of NF-kB at Ser 547 (Sabatel et al., 2012).

Altogether, these studies and results clearly demonstrate that ATM and NF- $\kappa B$ cross talk as two of the most important players in DDR/R and ImmR, respectively, and ATM appears to act to be a vital center that harmonizes cell autonomous defense(s) within a wider systematic response.

\section{Questions and perspectives from the DDR/R-ImmR link in human diseases}

Until now, with the exception of immune disorders linked to NHEJ defects, the DDR/R pathways were mainly examined with respect to cell-cycle-related defects, such as cancers, whereas the deregulated ImmR network was mainly studied related to infectious diseases and autoimmune disorders. From the concepts provided in this study, a common role of these interlinked networks in disease pathogenesis and development can be envisioned. For example, the recently proposed oncogene-induced model for cancer development can be embedded in a broader model (Fig. 5) that includes the ImmR and 867 other noncancer-related disorders. In line with this, the recently revised 868 "Hallmarks of Cancer" include genomic instability and tumor- 869 promoting inflammation as enabling hallmarks and immune evasion 870 as an emerging hallmark (Hanahan \& Weinberg, 2011). From this as- 871 pect, patients suffering from cell-cycle-deregulated defects concurrent- 872 ly with autoimmune disorders, with different pathologies and separate 873 treatment, may ultimately have a common denominator. This unifying 874 view raises certain issues so that effective therapeutic tools can be 875 developed.

A "yin-yang" relationship exists between the immune system and 877 the most common human diseases. The immunosurveillance theory pro- 878 posed by Burnet (1957), and by Thomas (1959) about the same time, 879 supported the tumor-protecting role of the immune system. In 2002, 880 Dunn et al. (2002) proposed the three Es of cancer immunoediting, 881 namely elimination, equilibrium, and escape. The first E corresponds to 882 immunosurveillance; the second, which lasts longer than the others, to 883 a period of Darwinian selection favoring the less immunogenic tumor 884 cells; and the third to the last phase where the immunologically sculpted 885 transformed cells breach the host immunity. The DDR/R pathway seems 886 to follow a similar route. Replication-stress-mediated DDR/R activates 887 the antitumor barriers of apoptosis and senescence to protect the host 888 at the precancerous stage, whereas key tumor suppressors such as p53 889 are eliminated during the "battle," favoring genomic instability and ma- 890 lignant clonal expansion. Thus, the DDR/R network loses its "bright" side, 891 transforming into a "dark servant" that supports cancer survival 892 (Bartkova et al., 2005; Gorgoulis et al., 2005a, 2005b; Halazonetis et al., Q43 2008). Of course, the level and type of DNA damage may act as a regulat- 894 ing switch in this case. Considering the cross talk between the DDR/R and 895 the ImmR networks, the following question arises: does the DDR/R ma- 896 chinery interfere with each " $E$ "? If so, then what is its effect at the turning 897 point when the immune system is overcome by malignant transforma- 898 tion? Within this frame and considering that genomic instability triggers 899 PRR activity (Nagi et al., 2014), what is the role of PRRs in the initial 900 phases of cancer development? The expression of PRRs in both immune 901 and nonimmune cells highlights the significance of examining these re- 902 lationships in different cellular compartments such as the stroma. Re- 903 cently, ARF was shown to act as a complementary and delayed barrier 904 to carcinogenesis, responding to escalating oncogenic stress and being 905

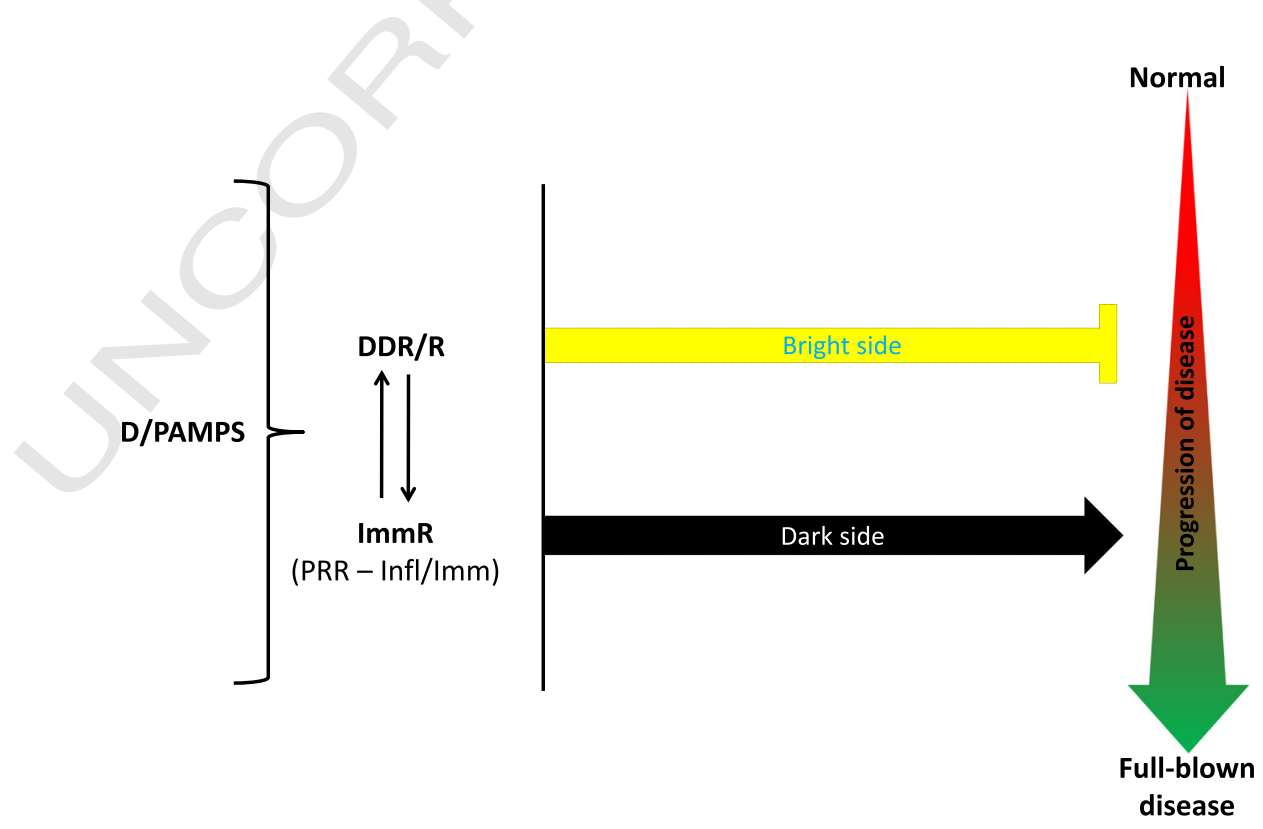

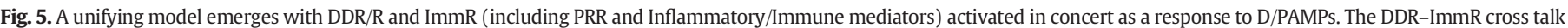

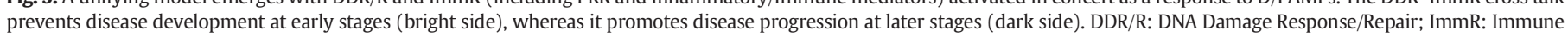
Response; D/PAMPs: Damage/Pathogen-Associated Molecular Patterns. 
906 robustly activated when the DDR/R kinase ATM is disabled. In view of 907 this, it is interesting to examine the effect of ARF, along with the DDR/ $908 \mathrm{R}$, in relation to the ImmR during cancer development (Evangelou 909 et al., 2013; Velimezi et al., 2013).

From the evidence presented so far, it follows that the DDR/R and ImmR pathways can be proposed as representing two branches of a common network that, in many cases, underlies both neoplastic and immunological disorders. However, the way these branches act in cancer and immune-related diseases may differ. For example, if immunoregulation of pro-inflammatory $\mathrm{T}_{\mathrm{h} 1}$ activity is disrupted (Ellyard et al., 2007) failure of homeostasis of the immune system and in turn selftolerance results, leading to what Paul Ehrlich termed as "horror autotoxicus" (harmful immune reactions against self). In general, such a state is antitumorigenic, as immunoregulation of $\mathrm{T}_{\mathrm{h} 2}$ activity is mediated by type 2 immunity including $\mathrm{T}_{\mathrm{h} 2}$, and by $\mathrm{M} 2$ macrophages, which play a pro-cancerous role as potent immunosuppressive cells (Fig. 1Bii). In a similar vein, blockage of the immune-checkpoint receptors cytotoxic T lymphocyte-associated antigen 4 (CTLA4) and programmed death ligand 1 (PDL1/CD274/B7-H1) has promising results in various types of cancer by boosting antitumor immunity (Pardoll, 2012) (Fig. 1Biii). Likewise, CLTA4 $^{-/-}$as well as PDL1 ${ }^{-/-}$mice develop spontaneous autoimmune pathologies (Tivol et al., 1995; Ansari et al., 2003; Fife et al., 2006; Keir et al., 2006; Fife et al., 2009). However, the latter course of action is not always clear. For instance, the role of regulatory $T$ cells $\left(T_{\text {regs }}\right)$ in human neoplasia remains to be clarified. There is evidence supporting an adverse effect of $\mathrm{T}_{\text {regs }}$ in fatal malignancies, such as ovarian and pancreatic cancer, but their role in colorectal cancer remains obscure 4 (Müzes et al., 2008; Pages et al., 2010). Within this context, the role of the DDR/R network in the pathogenesis of autoimmune diseases needs to be investigated. Gunther et al. (2015)) recently demonstrated a functional role of Trex1 in the initiation of autoimmunity in AGS, implying that the DDR/R network emerges as a new player in the autoimmunity field. Whether prolonged DDR/R activity can trigger PRR signaling and vice versa also remains unanswered.

The outcome of these emerging potentially pathogenic links should always be evaluated within a spatiotemporal frame. IL-4, a prototype mediator of the $\mathrm{T}_{\mathrm{h} 2}$ response that favors experimental autoimmune myocarditis, is an interesting example related to organ/cell specificity, whereas IFN $\gamma$ produced by $\mathrm{T}_{\mathrm{h} 1}$ cells limits this pathology. Contrary observations have been made in other sites and settings, such as experimental autoimmune encephalomyelitis and type 1 diabetes, with respect to the $T_{h 1} / T_{h 2}$ immunoregulatory function (Afanasyeva et al., 2001). Within the frame of topology, the two immune-privileged organs, namely the testis and thymus, can also additionally support the $\mathrm{DDR} / \mathrm{R}-\mathrm{ImmR}$ concept. The natural development of germ cells and lymphocytes is highly dependent on the continuous function of the DDR/R network, which could lead to host immunity under non-tolerant conditions possibly by upregulating the NKG2D and DNAM ligands (Jackson \& Bartek, 2009; Fijak et al., 2011; Nunes-Alves et al., 2013). Similarly, this may also explain the features shared by both the cancer microenvironment and the immune-privileged sites (Swartz \& Lund, 2012). Cancer cells exhibit an unremitting cycle of DSB formation and repair, which could render them susceptible to the immune system if the protective shield of immune tolerance was absent (Halazonetis et al., 2008; Hanahan \& Weinberg, 2011). Time, the second element of the "spatiotemporal" parameter, determines the situation in many cases. For instance, prolonged activity of activated macrophages, conventionally classified as antitumor cells, favors tumor promotion through the production of ROS and RNS (Biswas \& Mantovani, 2010; Lawrence \& Natoli, 2011; Murray \& Wynn, 2011). Similarly, a “timing”-dependent dual role of $\mathrm{p} 38 \alpha$ signaling, a key pathway implicated in immunity, inflammation, and recently DDR/R (Phong et al., 2010), was shown during colorectal carcinogenesis (Gupta et al., 2014, 2015). p38 $\alpha$ suppresses tumorigenicity at the initial developmental stages of colon cancer, while subsequently fostering tumor progression by promoting proliferation and inhibiting apoptosis of cancer cells. Recently, the activation of mutant H-Ras in mouse epidermis was report to trigger a different re- 972 sponse in aged mice compared with young mice (Golomb et al., 2015, 973 in press). In aged mice, H-Ras activation resulted in a neoplastic pheno- Q46 type that correlated with senescence, most probably via DDR/R activa- 975 tion (Di Micco et al., 2006; Gorgoulis et al., 2006, 2010), and an ImmR Q47 that was more extensive than in young mice, in addition to delayed 977 tissue recovery. The aged mice showed an increase in pro- 978 inflammatory mediators along with a robust anti-inflammatory re- 979 sponse tending towards $\mathrm{T}_{\mathrm{h} 2}$ polarization, accompanied by the upregula- 980 tion of PDL1(CD274). Investigating the mediators implicated in the 981 DDR/R-PRR-inflammatory/immune signaling network after exerting 982 the same insult in both young and old counterparts will further our un- 983 derstanding of (multi)cellular responses during aging.

Another parameter to be considered is the type of insult that dictates 985 and orchestrates the proper defense mechanism. Taking for example 986 the immunological branch of the DDR/R-ImmR network, elimination 987 of phagocytosed microbes is promoted by a committed $\mathrm{T}_{\mathrm{h} 1}$ response, 988 whereas $T_{\mathrm{h} 2}$ polarization favors the defense against helminthic infec- 989 tions (Fig. 1Bii) (Jankovic et al., 2001). Likewise, the DDR/R limb reacts 990 in a manner similar to that presented in detail in Fig. 1A. Nevertheless, 991 if and how both branches of the DDR/R-ImmR network are coordinated 992 in response to the same exogenous or endogenous insults remain to be 993 examined.

994

All of these parameters provide plasticity to the interaction between 995 the DDR/R pathway and the ImmR, sculpturing the end effects. Most im- 996 portantly, this cross talk promotes inflammation, an emerging charac- 997 teristic feature of cancer as mentioned earlier (Hanahan \& Weinberg, 998 2011). Although inflammation is considered a protective host response 999 to danger signals, maintaining harmony in both growing and adult ani- 1000 mals according to Metchnikoff (Tauber, 2003), aberrant activation of the 1001 inflammatory response disrupts (multi)cellular homeostasis, favoring 1002 the pathogenesis of chronic diseases including neoplasms and autoim- 1003 mune diseases (Karin \& Greten, 2005; de Visser et al., 2006; Tzioufas Q48 et al., 2012; Elinav et al., 2013; Holmdahl et al., 2014). In tumor biology, 1005 chronic inflammation does not merely foster tumor initiation, but it 1006 might also be an "active component of the cancerous play," favored by 1007 full-blown cancers, in order to support their self-aggrandizement. The 1008 latter may be achieved by promoting several cancer hallmarks including 1009 genomic instability, angiogenesis, invasion, metastasis, and possibly im- 1010 mune evasion, by favoring T cell exhaustion, and potentially others such 1011 as deregulated metabolism. In cancer, abnormal activity of PRR and DDR 1012 can promote an inflammatory reaction; the physiological counterpart of 1013 this counterpart is still unknown. Therefore, what are the key features of 1014 cancer-associated inflammation? Some of these features may be ex- 1015 plained by the concept of parainflammation/SIR (Medzhitov, 2008; 1016 Lasry \& Ben-Neriah, in press) and the "over-healing wound" hypothesis 1017 (Schäfer \& Werner, 2008). Cooks and colleagues recently proved the 1018 significance of the DDR/R-ImmR functional interplay in this scenario 1019 by the promotion of chronic inflammation and colitis-associated carci- 1020 nogenesis by certain p53 mutant proteins through prolonged NF-кB ac- 1021 tivation (Cooks et al., 2013; Cooks et al., 2014a, 2014b). Taking into Q49 consideration that TP53 mutations are among the most frequent in 1023 human malignancies (Olivier et al., 2004; Oren \& Rotter, 2010), the 1024 GOF activity of p53 mutants (mt) p53 may play a significant role in 1025 supporting the unique inflammatory environment of different malig- 1026 nancies. It is also worth noting that loss of wild-type p53 activity by it- 1027 self causes a critical breach in cellular homeostasis (Vousden \& Prives, 1028 2009). This is proved by its protective role against inflammatory stress 1029 (Cooks et al., 2014a, 2014b). Hence, when considering the GOF of mt Q50 p53 in addition to the wild-type p53 loss, a highly inflammation- 1031 prone environment is favored. The p53 "symphonic orchestra" is also 1032 known for performing a lesser-known function, described by Herkel 1033 et al. (2001) a decade ago, which further supports the functional con- 1034 nection between DDR/R and autoimmune disorders. Patients with SLE 1035 produce Ab's against the carboxy-terminal DNA-binding domain of 1036 p53, whereas patients with tumors produce anti-p53 Ab's that 1037 
1038 recognize the amino terminus (Lubin et al., 1993). This could possibly be 1039 explained by the varying exposure to p53 in malignancies versus auto1040 immune diseases, including SLE (Herkel, et al., 2001). It is worth consid1041 ering that the Ab's against p53 are usually related to mutant p53 in 1042 tumors (Davidoff et al., 1992), whereas no p53 mutations are found 1043 and anti-p53 Ab's are directed against wild-type p53 in SLE (Kovacs 1044 et al., 1997). Yet, the functional consequences of the anti-p53 Ab's in dif1045 ferent settings need to be clarified. This becomes even more challenging 1046 because of the ongoing trials with drugs targeting p53, either with reac1047 tivation of mutant p53 (Lambert et al., 2009) or with activation of wild1048 type p53 (Brown et al., 2009). Noticeably, murine double minute 2 1049 (MDM2) blockage with nutlin-3 attenuates inflammation in various 1050 settings, through suppression of NF- $\kappa B$ signaling (Liu et al., 2009; 1051 Hashimoto et al., 2011; Mulay et al., 2012), suggesting that the potential 1052 therapeutic effect of this drug is mediated by regulating both p531053 dependent and p53-independent pathways (Thomasova et al., 2012).

1054 MicroRNAs (miRNAs) have also emerged as modulators of the DDR/ 1055 R-ImmR interplay, which are also considered critical players in 1056 inflammation-associated pathologies (Kapsogeorgou et al., 2011; 1057 Singh et al., 2013). This type of noncoding RNAs is indispensable for T 1058 cell homeostasis implicated in the development of $\mathrm{T}_{\text {regs }}$ (Yan et al., 1059 2014). Strong evidence supports their involvement in inflammationQ51 driven cancer (Schetter et al., 2010). Because miRNAs have been 1061 shown to be more abundant at common fragile sites (CFSs), 1062 representing the preferential target sites for oncogene-mediated repliQ52 cation stress from the earliest stages of cancer (Gorgoulis et al., 2005a, 1064 2005b; Halazonetis et al., 2008; Tsantoulis et al., 2008; Aqeilan, 2014; 1065 Georgakilas et al., 2014; Ozeri-Galai et al., 2014), the extent to which 1066 DDR/R-mediated miRNA deregulation affects immune signaling can 1067 be investigated further. Similarly, miRNAs target the 3'-untranslated 1068 region (UTR) of NKG2DL including MICA, MICB, and ULBP1-3, reduc1069 ing their cell surface expression and leading to evasion of malignant 1070 or virus-infected cells from immunosurveillance (Jasinski-Bergner 1071 et al., 2014). Furthermore, p53 enhances the posttranscriptional 1072 maturation of miRNAs, particularly those that suppress growth 1073 (Suzuki et al., 2009).

1074 The players and biochemical interactions that surface from examin1075 ing the interplay between the DDR/R and ImmR modules not only boost 1076 future therapeutic applications but also increase the modes of new ther1077 apeutic interventions, targeted more optimistically and with lesser side 1078 effects than the existing one. For instance, it was recently shown that 1079 the vasculature of solid tumors selectively expresses FasL (CD95L), 1080 which kills effector CD8 + T cells, thus establishing immune tolerance. 1081 Blockage of vascular endothelial growth factor A (VEGF-A) attenuated 1082 endothelial FasL expression, leading to an increase in the influx of 1083 CD8 + cells and in turn tumor growth suppression (Motz et al., 2014). 1084 An alternative approach could be based on FasL induction by the DDR/ 1085 R pathway (Mo \& Beck, 1999). If VEGF-A cannot be targeted directly 1086 (Breccia et al., 2014), then a differential option by inhibiting ATM can 1087 be followed. This would lead to downregulation of FasL and concurrent1088 ly ARF induction by hindering ATM activity (Velimezi et al., 2013), 1089 which can eventually suppress VEGF-A, as previously reported 1090 (Kotsinas et al., 2014). Therefore, the latter therapeutic strategy may 1091 offer a better result because it targets three pathogenic factors (ATM, 1092 FasL, and VEGF-A) instead of the two (FasL and VEGF-A) inhibited in 1093 the former strategy. It is worth noting that several of the data produced 1094 were obtained from mice models, and they must be extrapolated to 1095 humans and vice versa with caution (as an example, see Suppl. Fig. 1).

Q53 As the ImmR has a memory of its own (Fig. 1Bi) (Crotty, 2011) it ap1097 pears that DNA can also "remember" its damage. The latter was report1098 ed in yeast, with the evidence showing the marked influence of DDR/R 1099 on the state of a cell for many generations (Burrill \& Silver, 2011). If 1100 this holds true in humans, then the DDR/R-ImmR functional interplay 1101 has further implications for potential therapeutic applications, as cells 1102 with "DNA damage memory" will be much more resistant to DNA1103 damaging interventions.
Overall, the DDR/R-ImmR concept broadens our insight into the 1104 pathogenesis of many diseases that were previously considered "unre- 1105 lated," with the emergence of common underlying mechanisms. Previ- 1106 ously isolated biomedical fields are now being linked by commonalities 1107 detected between different entities, allowing us to join forces for a better 1108 and more prosperous world. Besides, previous studies have already pro- 1109 vided us with the concept of (multi)-cellular organisms espousing the 1110 motto of the Three Musketeers: "unus pro omnibus, omnes pro uno." 1111

Supplementary data to this article can be found online at http://dx. 1112 doi.org/10.1016/j.pharmthera.2015.06.011.

\section{Conflict of interest}

The authors declare no conflict of interest.

\section{Uncited references}

Ablasser et al., 2009

Aguilera et al., 2014

Ahmed et al., 2014

Alayev and Holz, 2013

Albrecht et al., 2005

Alcami and Koszinowski, 2000

Alexopoulou et al., 2001

Andreou and Klostermeier, 2013

Ariumi et al., 2007

Baniyash, 2004

Baniyash et al., 2014

Barbe et al., 2014

Barber, 2011

Bartek and Lukas, 2007

Bedoya et al., 2013

Bell et al., 2003

Belyakov et al., 2001

Beutler, 2009

Bogerd et al., 2014

Bollard et al., 2012

Boyle et al., 2014

Bregnard et al., 2014

Brenner, 1990

Buchbinder and McDermott, 2014

Bulavin et al., 2001

Burckstummer et al., 2009

Caldecott, 2008

Calin et al., 2004

Campisi, 2005

Campisi, 2014

Campisi and d'Adda di Fagagna, 2007

Cao et al., 2010

Ceeraz et al., 2014

Chiu et al., 2009

Choubey and Gutterman, 1997

Clauson et al., 2013

Connolly and Bowie, 2014

Coscoy and Raulet, 2007

Coussens and Werb, 2002

Cramer et al., 2008

Crespo et al., 2013

Crook and Liu, 2014

Croxford et al., 2013

Cullen, 2013

Curotto de Lafaille and Lafaille, 2009

Dahl et al., 2005

Dalpke and Helm, 2012

D'Amours and Jackson, 2002

Davis and Chen, 2013
1116

1117

1118

1119

1120

1121

1122

1123

1124

1125

1126

1127

1128

1129

1130

1131

1132

1133

1134

1135

1136

1137

1138

1139

1140

1141

1142

1143

1144

1145

1146

1147

1148

1149

1150

1151

1152

1153

1154

1155

1156

1157

1158

1159

1160

1161

1162

1163

1164 
de Zoete et al., 2014

DeFilippis et al., 2010

Dey et al., 2002

Dianov and Hubscher, 2013

Dinarello et al., 2013

Dong, 2004

Duelli et al., 2007

Evans and Hearing, 2005

Fell and Schild-Poulter, 2012

Fernandes-Alnemri et al., 2009

Ferrero-Miliani et al., 2007

Fragoulis and Moutsopoulos, 2010

Franceschi et al., 2000

Frit et al., 2014

Fu et al., 1999

Fuertes et al., 2008

Fullam and Schroder, 2013

Galon et al., 2006

Galon et al., 2012

Gasiunas et al., 2014

Gasser and Raulet, 2006

Gause et al., 2013

Ghosal and Chen, 2013

Gillies et al., 2012

Golden and Apetoh, 2015

Gozzard and Maddison, 2011

Grant et al., 2015

Griebel et al., 2014

Guven Maiorov et al., 2013

Ha et al., 2006

Hardwick and Luisi, 2013

Heil et al., 2004

Hemmi et al., 2000

Hengge et al., 2002a

Hengge et al., 2002b

Herbert et al., 1997

Heroes et al., 2013

Higgs et al., 2014

Hiscott, 2014

Hlatky et al., 2002

Hoeffel et al., 2007

Hoeijmakers, 2001

Hoglund, 2006

Hohensinner et al., 2011

Holley and Chatterjee, 1996

Hopfner, 2014

Hornung et al., 2009

Horvath and Barrangou, 2010

House et al., 2014

Hsiao and Stewart, 2008

Huang and Li, 2013

Hurchla et al., 2005

Jacobs and Damania, 2012

Jakobsen and Paludan, 2014

Jaumot and Hancock, 2001

Jinushi et al., 2012

Jiricny, 2006

Jones et al., 2010

Kang et al., 2012

Karpova et al., 2002

Kato et al., 2006

Kawai and Akira, 2010

Kefalakes et al., 2009

Kim and Ahmed, 2010

Kolakofsky et al., 2012

Kondo et al., 2013
Krishna and Aravind, 2010

Kudoh et al., 2005

Kwak et al., 2003

Kwun et al., 2014

Lai, 1992

Lamarche et al., 2010

Lamkanfi and Dixit, 2009

Lammens et al., 2011

Leger-Ravet et al., 1991

Leith, 1993

Li et al., 2014

Li et al., 2012

Linder and Jankowsky, 2011

Liontos et al., 2007

Liontos et al., 2009

Lu et al., 2014

Lupfer et al., 2014

Ma et al., 2011

Mackern-Oberti et al., 2014

Maddur et al., 2012

Manche et al., 1992

Marcus et al., 2014

McBride et al., 2004

Miao et al., 2010

Min et al., 1996

Mitchell et al., 2014

Mitoma et al., 2013

Miyake and Kaisho, 2014

Miyake et al., 2013

Montes et al., 2008

Moody and Laimins, 2009

Mosser and Edwards, 2008

Murzin, 1993

Muzes et al., 2012

Myong et al., 2009

Nagasawa and Little, 1992

Naito et al., 1998

Niederkorn, 2006

Novick et al., 2013

Nurnberger et al., 2004

Okita et al., 2012

Okubo et al., 2003

O'Neill, 2009

Oshiumi et al., 2010

Ostrand-Rosenberg and Sinha, 2009

Patil et al., 2013

Patterson and Werling, 2013

Pawelek and Chakraborty, 2008

Peters et al., 2013

Peti et al., 2013

Pettengill et al., 2014

Pham et al., 2013

Philpott et al., 2014

Pichlmair et al., 2006

Polo and Jackson, 2011

Powell et al., 2011

Qian et al., 2014

Qin and Xu, 2014

Radic, 2014

Raj et al., 2001

Ramakrishnan et al., 2013

Randow et al., 2013

Reed, 2011

Reinhardt and Schumacher, 2012

Rigby et al., 2014

Rivera-Calzada et al., 2007 
Rupnik et al., 2008

Sabbah et al., 2009

Saccani et al., 2002

Salminen et al., 2012

Savage et al., 2014

Schlee, 2013

Schramm and Hernandez, 2002

Schreiber and Piehler, 2015

Schwartz et al., 2001

Semenenko and Stewart, 2004

Semenenko and Stewart, 2006

Seya, 2014

Shatnyeva et al., 2015

Shaw and Liu, 2014

She et al., 2001

She et al., 2000

Shiloh, 2003

Shirata et al., 2005

Shu et al., 2014

Silverstein, 2001

Singh et al., 2014

Sinha et al., 2013

Smilek et al., 2014

Soto-Pantoja et al., 2014

Steel et al., 2012

Stern et al., 2010

Stolz et al., 2011

Stracker et al., 2002

Stracker et al., 2009

Sun et al., 2013

Takaoka et al., 2007

Tang and Gasser, 2013

Teh and Gray, 2014

Tian et al., 2015

Tilton et al., 2011

Tsakiri et al., 2013

Unterholzner et al., 2010

Vabret and Blander, 2013

van Montfoort et al., 2014

Van Nguyen et al., 2007

Vanden Berghe et al., 1998

Veeranki and Choubey, 2012

Vermeulen et al., 2003

Vincent, 2012

Vissers et al., 2012

Vologodskii, 2007

Walker et al., 2001

Wang, Gao, Pan and Zhang, 2014

Wang, 2006

Wang, Liu and Wang, 2014

Warren et al., 2010

Weitzman et al., 2004

Williams, 1999

Wood et al., 2009

Wu et al., 2004

Yanai et al., 2009

Yang et al., 2010

Yang et al., 2008

Yoneyama et al., 2005

Yoo et al., 2014

Zarogoulidis et al., 2014

Zhang et al., 1994

Zhang et al., 2011

Zheng and Bevilacqua, 2004

Zhu et al., 2014

Zuliani et al., 2012

\section{Acknowledgments}

1363

We would like to thank Christos P. Zampetidis for helping prepare 1364 the manuscript. This research has been cofinanced by the European 1365 Union (European Social Fund - ESF) and Greek national funds through 1366 the Operational Program "Education and Lifelong Learning" of the Na- 1367 tional Strategic Reference Framework (NSRF), Research Funding Pro- 1368 gram: Heracleitus II, and through the Operational NSRF-THALES 1369 (Grant number 379435) Investing in knowledge society through the 1370 European Social Fund. A.G.G is supported by an EU Marie Curie Reinte- 1371 gration Grant MC-CIG-303514, cofinanced by the European Union 1372 (European Social Fund-ESF) and Greek national funds through the Op- 1373 erational Program "Educational and Lifelong Learning" of the National 1374 Strategic Reference Framework (NSRF) Research Funding Program: 1375 THALES (Grant number MIS 379346) and COST Action CM1201 "Biomi- 1376 metic Radical Chemistry." This work is dedicated to the memory of 1377 Maria Ph. Foustanou-Koutra.

1378

\section{References}

Aachoui, Y., Sagulenko, V., Miao, E. A., \& Stacey, K. J. (2013). Inflammasome-mediated 1380 pyroptotic and apoptotic cell death, and defense against infection. Curr Opin 1381 Microbiol 16(3), 319-326. 1382

Abbas, A. K., Lichtman, A. H., \& Pillai, S. (2010). Activation of T lymphocytes. Cellular and 1383 Molecular Immunology (6th ed.). Philadelphia: Saunders-Elsevier. 1384

Ablasser, A., Bauernfeind, F., Hartmann, G., Latz, E., Fitzgerald, K. A., \& Hornung, V. (2009). 1385 RIG-I-dependent sensing of poly(dA:DT) through the induction of an RNA polymer- 1386 ase III-transcribed RNA intermediate. Nat Immunol 10(10), 1065-1072. 1387

Afanasyeva, M., Wang, Y., Kaya, Z., Park, S., Zilliox, M. J., Schofield, B. H., et al. (2001). Ex- 1388 perimental autoimmune myocarditis in $\mathrm{A} / \mathrm{J}$ mice is an interleukin-4-dependent dis- 1389 ease with a Th2 phenotype. Am J Pathol 159(1), 193-203.

1390

Aglipay, J. A., Lee, S. W., Okada, S., Fujiuchi, N., Ohtsuka, T., Kwak, J. C., et al. (2003). A 1391 member of the pyrin family, IFI16, is a novel BRCA1-associated protein involved in 1392 the p53-mediated apoptosis pathway. Oncogene 22(55), 8931-8938. 1393

Aguilera, M., Darby, T., \& Melgar, S. (2014). The complex role of inflammasomes in the 1394 pathogenesis of inflammatory bowel diseases - lessons learned from experimental 1395 models. Cytokine Growth Factor Rev 25(6), 715-730. 1396

Ahmed, M. M., Guha, C., Hodge, J. W., \& Jaffee, E. (2014). Immunobiology of radiotherapy: 1397 New paradigms. Radiat Res 182(2), 123-125. 1398

Aicardi, J., \& Goutieres, F. (2000). Systemic lupus erythematosus or Aicardi-Goutieres syn- 1399 drome? Neuropediatrics 31(3), $113 . \quad 1400$

Alayev, A., \& Holz, M. K. (2013). mTOR signaling for biological control and cancer. J Cell 1401 Physiol 228(8), 1658-1664. 1402

Albrecht, M., Choubey, D., \& Lengauer, T. (2005). The HIN domain of IFI-200 proteins con- 1403 sists of two OB folds. Biochem Biophys Res Commun 327(3), 679-687. 1404

Alcami, A., \& Koszinowski, U. H. (2000). Viral mechanisms of immune evasion. Trends 1405 Microbiol 8(9), 410-418.

Alexopoulou, L., Holt, A. C., Medzhitov, R., \& Flavell, R. A. (2001). Recognition of double- 1407 stranded RNA and activation of NF-kappaB by toll-like receptor 3. Nature 1408 413(6857), 732-738. 1409

Andreou, A. Z., \& Klostermeier, D. (2013). The DEAD-box helicase eIF4A: Paradigm or the 1410 odd one out? RNA Biol 10(1), 19-32.

Ansari, M. J., Salama, A. D., Chitnis, T., Smith, R. N., Yagita, H., Akiba, H., et al. (2003). The 1412 programmed death-1 (PD-1) pathway regulates autoimmune diabetes in nonobese 1413 diabetic (NOD) mice. J Exp Med 198(1), 63-69. 1414

Aqeilan, R. I. (2014). Role of common fragile sites and corresponding genes in cancer de- 1415 velopment. Cell Mol Life Sci 71(23), 4487-4488. 1416

Ariumi, Y., Kuroki, M., Abe, K., Dansako, H., Ikeda, M., Wakita, T., et al. (2007). DDX3 1417 DEAD-box RNA helicase is required for hepatitis C virus RNA replication. J Virol 1418 81(24), 13922-13926. 1419

Baniyash, M. (2004). TCR zeta-chain downregulation: Curtailing an excessive inflamma- 1420 tory immune response. Nat Rev Immunol 4(9), 675-687. 1421

Baniyash, M., Sade-Feldman, M., \& Kanterman, J. (2014). Chronic inflammation and can- 1422 cer: Suppressing the suppressors. Cancer Immunol Immunother 63(1), 11-20. 1423

Barbe, F., Douglas, T., \& Saleh, M. (2014). Advances in nod-like receptors (NLR) biology. 1424 Cytokine Growth Factor Rev 25(6), 681-697. 1425

Barber, G. N. (2011). Innate immune DNA sensing pathways: STING, AIMII and the regu- 1426 lation of interferon production and inflammatory responses. Curr Opin Immunol 1427 23(1), 10-20. 1428

Bartek, J., \& Lukas, J. (2007). DNA damage checkpoints: From initiation to recovery or ad- 1429 aptation. Curr Opin Cell Biol 19(2), 238-245. 1430

Bartkova, J., Horejsi, Z., Koed, K., Kramer, A., Tort, F., Zieger, K., et al. (2005). DNA damage Q59 response as a candidate anti-cancer barrier in early human tumorigenesis. Nature 1432 434(7035), 864-870. 1433

Bartkova, J., Rezaei, N., Liontos, M., Karakaidos, P., Kletsas, D., Issaeva, N., et al. (2006). 1434 Oncogene-induced senescence is part of the tumorigenesis barrier imposed by DNA 1435 damage checkpoints. Nature 444(7119), 633-637. 1436

Bauer, S., Kirschning, C. J., Hacker, H., Redecke, V., Hausmann, S., Akira, S., et al. (2001). 1437 Human TLR9 confers responsiveness to bacterial DNA via species-specific CpG motif 1438 recognition. Proc Natl Acad Sci U S A 98(16), 9237-9242. 
Becker, J. H., \& Wu, S. C. (2010). Fever-an update. J Am Podiatr Med Assoc 100(4), 281-290. edoya, S. K., Lam, B., Lau, K., \& Larkin, J., III (2013). Th17 cells in immunity and autoimmunity. Clin Dev Immunol 2013, 986789.

Bell, J. K., Mullen, G. E., Leifer, C. A., Mazzoni, A., Davies, D. R., \& Segal, D. M. (2003). Leucine-rich repeats and pathogen recognition in toll-like receptors. Trends Immunol 24(10), 528-533.

Belyakov, O. V., Malcolmson, A. M., Folkard, M., Prise, K. M., \& Michael, B. D. (2001). Direct evidence for a bystander effect of ionizing radiation in primary human fibroblasts. $\mathrm{Br} J$ Cancer 84(5), 674-679.

Benitez, A. C., Dai, Z., Mann, H. H., Reeves, R. S., Margineantu, D. H., Gooley, T. A., et al. (2011). Expression, signaling proficiency, and stimulatory function of the NKG2D lymphocyte receptor in human cancer cells. Proc Natl Acad Sci U S A 108(10), 4081-4086.

Beutler, B. A. (2009). TLRs and innate immunity. Blood 113(7), 1399-1407.

Biswas, S. K., \& Mantovani, A. (2010). Macrophage plasticity and interaction with lymphocyte subsets: Cancer as a paradigm. Nat Immunol 11(10), 889-896.

Bogerd, H. P., Skalsky, R. L., Kennedy, E. M., Furuse, Y., Whisnant, A. W., Flores, O., et al. (2014). Replication of many human viruses is refractory to inhibition by endogenous cellular microRNAs. J Virol 88(14), 8065-8076.

Bollard, C. M., Rooney, C. M., \& Heslop, H. E. (2012). T-cell therapy in the treatment of post-transplant lymphoproliferative disease. Nat Rev Clin Oncol 9(9), 510-519. oyko, A., \& Kovalchuk, I. (2011). Genetic and epigenetic effects of plant-pathogen interactions: An evolutionary perspective. Mol Plant 4(6), 1014-1023.

Boyle, J. P., Parkhouse, R., \& Monie, T. P. (2014). Insights into the molecular basis of the NOD2 signalling pathway. Open Biol 4(12)http://dx.doi.org/10.1098/rsob.140178.

raunstein, S., Badura, M. L., Xi, Q., Formenti, S. C., \& Schneider, R. J. (2009). Regulation of protein synthesis by ionizing radiation. Mol Cell Biol 29(21), 5645-5656.

Breccia, M., Molica, M., \& Alimena, G. (2014). How tyrosine kinase inhibitors impair metabolism and endocrine system function: A systematic updated review. Leuk Res 38(12), 1392-1398.

regnard, C., Benkirane, M., \& Laguette, N. (2014). DNA damage repair machinery and HIV escape from innate immune sensing. Front Microbiol 5, 176.

Brenner, D. J. (1990). Track structure, lesion development, and cell survival. Radiat Res 124(1 Suppl.), S29-S37.

rown, C. J., Lain, S., Verma, C. S., Fersht, A. R., \& Lane, D. P. (2009). Awakening guardian angels: Drugging the p53 pathway. Nat Rev Cancer 9(12), 862-873.

Brzostek-Racine, S., Gordon, C., Van Scoy, S., \& Reich, N. C. (2011). The DNA damage response induces IFN. J Immunol 187(10), 5336-5345.

Buchbinder, E. I., \& McDermott, D. F. (2014). Interferon, interleukin-2, and other cytokines. Hematol Oncol Clin North Am 28(3), 571-583.

Bulavin, D. V., Higashimoto, Y., Popoff, I. J., Gaarde, W. A., Basrur, V., Potapova, O., et al. (2001). Initiation of a G2/M checkpoint after ultraviolet radiation requires p38 kinase. Nature 411(6833), 102-107.

Burckstummer, T., Baumann, C., Bluml, S., Dixit, E., Durnberger, G., Jahn, H., et al. (2009). An orthogonal proteomic-genomic screen identifies AIM2 as a cytoplasmic DNA sensor for the inflammasome. Nat Immunol 10(3), 266-272.

Burgess, S. J., Maasho, K., Masilamani, M., Narayanan, S., Borrego, F., \& Coligan, J. E. (2008). The NKG2D receptor: Immunobiology and clinical implications. Immunol Res 40(1), 18-34.

Burnet, M. (1957). Cancer; a biological approach. I. the processes of control. Br Med J 1(5022), 779-786.

Burnette, B. C., Liang, H., Lee, Y., Chlewicki, L., Khodarev, N. N., Weichselbaum, R. R., et al. (2011). The efficacy of radiotherapy relies upon induction of type i interferondependent innate and adaptive immunity. Cancer Res 71(7), 2488-2496.

Burrill, D. R., \& Silver, P. A. (2011). Synthetic circuit identifies subpopulations with sustained memory of DNA damage. Genes Dev 25(5), 434-439.

Caldecott, K. W. (2008). Single-strand break repair and genetic disease. Nat Rev Genet $9(8), 619-631$.

Calin, G. A., Sevignani, C., Dumitru, C. D., Hyslop, T., Noch, E., Yendamuri, S., et al. (2004). Human microRNA genes are frequently located at fragile sites and genomic regions involved in cancers. Proc Natl Acad Sci U S A 101(9), 2999-3004.

Campisi, J. (2005). Senescent cells, tumor suppression, and organismal aging: Good citizens, bad neighbors. Cell 120(4), 513-522.

Campisi, J. (2014). Cell biology: The beginning of the end. Nature 505(7481), 35-36

Campisi, J., \& d'Adda di Fagagna, F. (2007). Cellular senescence: When bad things happen to good cells. Nat Rev Mol Cell Biol 8(9), 729-740.

Cao, J. N., Gollapudi, S., Sharman, E. H., Jia, Z., \& Gupta, S. (2010). Age-related alterations of gene expression patterns in human CD8+ T cells. Aging Cell 9(1), 19-31. Monte Carlo DNA damage simulations and deterministic repair models to examine putative mechanisms of cell killing. Radiat Res 169(4), 447-459.

avlar, T., Ablasser, A., \& Hornung, V. (2012). Induction of type I IFNs by intracellular DNAsensing pathways. Immunol Cell Biol 90(5), 474-482.

Ceeraz, S., Nowak, E. C., Burns, C. M., \& Noelle, R. J. (2014). Immune checkpoint receptors in regulating immune reactivity in rheumatic disease. Arthritis Res Ther 16(5), 469.

Cerboni, C., Fionda, C., Soriani, A., Zingoni, A., Doria, M., Cippitelli, M., et al. (2014). The DNA damage response: A common pathway in the regulation of NKG2D and DNAM-1 ligand expression in normal, infected, and cancer cells. Front Immunol 4, 508.

Chatzinikolaou, G., Karakasilioti, I., \& Garinis, G. A. (2014). DNA damage and innate immunity: Links and trade-offs. Trends Immunol 35(9), 429-435.

Cheng, S. C., Joosten, L. A., \& Netea, M. G. (2014). The interplay between central metabolism and innate immune responses. Cytokine Growth Factor Rev 25(6), 707-713.

Chitadze, G., Bhat, J., Lettau, M., Janssen, O., \& Kabelitz, D. (2013). Generation of soluble NKG2D ligands: Proteolytic cleavage, exosome secretion and functional implications. Scand J Immunol 78(2), 120-129.

Chiu, Y. H., Macmillan, J. B., \& Chen, Z. J. (2009). RNA polymerase III detects cytosolic DNA and induces type I interferons through the RIG-I pathway. Cell 138(3), 576-591.
Choubey, D., \& Gutterman, J. U. (1997). Inhibition of E2F-4/DP-1-stimulated transcription 1526 by p202. Oncogene 15(3), 291-301.

Choubey, D., Li, S. J., Datta, B., Gutterman, J. U., \& Lengyel, P. (1996). Inhibition of E2F- 1528 mediated transcription by p202. EMBO J 15(20), 5668-5678. 1529

Ciccia, A., \& Elledge, S. J. (2010). The DNA damage response: Making it safe to play with $\mathbf{Q 6 0}$ knives. Mol Cell 40(2), 179-204.

Clauson, C., Scharer, O. D., \& Niedernhofer, L. (2013). Advances in understanding the com- 1532 plex mechanisms of DNA interstrand cross-link repair. Cold Spring Harb Perspect Med 1533 3(10), a012732.

Collado, M., \& Serrano, M. (2010). Senescence in tumours: Evidence from mice and Q61 humans. Nat Rev Cancer 10(1), 51-57.

Conigliaro, P., Perricone, C., Benson, R. A., Garside, P., Brewer, J. M., Perricone, R., et al. 1537 (2010). The type I IFN system in rheumatoid arthritis. Autoimmunity 43(3), 220-225. 1538

Connolly, D. J., \& Bowie, A. G. (2014). The emerging role of human PYHIN proteins in in- 1539 nate immunity: Implications for health and disease. Biochem Pharmacol 92(3), 1540 405-414.

Cooks, T., Harris, C. C., \& Oren, M. (2014). Caught in the cross fire: P53 in inflammation. 1542 Carcinogenesis 35(8), 1680-1690.

Cooks, T., \& Oren, M. (2010). NFKB and p53: A life and death affair. Cell Cycle 9, 947-952. 1544

Cooks, T., Pateras, I. S., \& Gorgoulis, V. G. (2014). When mutant p53 fires up. Cancer Cell 1545 Microenviron 1, e135.

Cooks, T., Pateras, I. S., Tarcic, O., Solomon, H., Schetter, A. J., Wilder, S., et al. (2013). Mu- 1547 tant p53 prolongs NF-kappaB activation and promotes chronic inflammation and 1548 inflammation-associated colorectal cancer. Cancer Cell 23(5), 634-646. 1549

Coppe, J. P., Patil, C. K., Rodier, F., Sun, Y., Munoz, D. P., Goldstein, J., et al. (2008). 1550 Senescence-associated secretory phenotypes reveal cell-nonautonomous func- 1551 tions of oncogenic RAS and the p53 tumor suppressor. PLoS Biol 6(12), 1552 2853-2868.

Coscoy, L., \& Raulet, D. H. (2007). DNA mismanagement leads to immune system over- 1554 sight. Cell 131(5), 836-838.

Coussens, L. M., \& Werb, Z. (2002). Inflammation and cancer. Nature 420(6917), 860-867. 1556

Cramer, P., Armache, K. J., Baumli, S., Benkert, S., Brueckner, F., Buchen, C., et al. (2008). 1557 Structure of eukaryotic RNA polymerases. Annu Rev Biophys 37, 337-352. 1558

Crespo, J., Sun, H., Welling, T. H., Tian, Z., \& Zou, W. (2013). T cell anergy, exhaustion, se- 1559 nescence, and stemness in the tumor microenvironment. Curr Opin Immunol 25(2), 1560 214-221.

Cridland, J. A., Curley, E. Z., Wykes, M. N., Schroder, K., Sweet, M. J., Roberts, T. L., et al. 1562 (2012). The mammalian PYHIN gene family: Phylogeny, evolution and expression. 1563 BMC Evol Biol 12, 140.

Crook K. R. \& Liu, P. (2014) Role of myeloid-derived suppressor cells in autoimmune dis- 1565 ease. World J Immunol 4(1), 26-33.

Crotty, S. (2011). Follicular helper CD4 T cells (TFH). Annu Rev Immunol 29, 621-663. 1567

Crow, M. K. (2014). Type I interferon in the pathogenesis of lupus. J Immunol 192(12), 1568 5459-5468.

Croxford, J. L., Tang, M. L., Pan, M. F., Huang, C. W., Kamran, N., Phua, C. M., et al. (2013). 1570 ATM-dependent spontaneous regression of early emu-myc-induced murine B-cell 1571 leukemia depends on natural killer and T cells. Blood 121(13), 2512-2521. 1572

Cuadrado, A., \& Nebreda, A. R. (2010). Mechanisms and functions of p38 MAPK signalling. Q62 Biochem J 429(3), 403-417.

Cullen, B. R. (2013). Current Topics in Microbiology and Immunology. In B. R. Cullen (Ed), 1575 Intrinsic Immunity. Berlin: Springer-Verlag.

Curotto de Lafaille, M. A., \& Lafaille, J. J. (2009). Natural and adaptive foxp3+ regulatory T 1577 cells: More of the same or a division of labor? Immunity 30(5), 626-635.

Dahl, J., You, J., \& Benjamin, T. L. (2005). Induction and utilization of an ATM signaling 1579 pathway by polyomavirus. J Virol 79(20), 13007-13017.

Dalpke, A., \& Helm, M. (2012). RNA mediated toll-like receptor stimulation in health and 158 disease. RNA Biol 9(6), 828-842.

D'Amours, D. \& Jackson, S. P. (2002). The Mre11 complex: At the cross and checkpoint signalling. Nat Rev Mol Cell Biol 3(5), 317-327.

Darnell, R. B., \& Posner, J. B. (2003). Paraneoplastic syndromes involving the nervous sys- Q63 tem. N Engl J Med 349(16), 1543-1554.

Datta, B., Li, B., Choubey, D., Nallur, G., \& Lengyel, P. (1996). P202, an interferon-inducible 1587 modulator of transcription, inhibits transcriptional activation by the P53 tumor sup- 1588 pressor protein, and a segment from the P53-binding protein 1 that binds to P202 1589 overcomes this inhibition. J Biol Chem 271(44), 27544-27555.

Davidoff, A. M., Iglehart, J. D., \& Marks, J. R. (1992). Immune response to p53 is dependent 1591 upon p53/HSP70 complexes in breast cancers. Proc Natl Acad Sci US A 89(8), 3439-3442. 1592

Davies, R. C., Pettijohn, K., Fike, F., Wang, J., Nahas, S. A., Tunuguntla, R., et al. (2012). De- 1593 fective DNA double-strand break repair in pediatric systemic lupus erythematosus. 1594 Arthritis Rheum 64(2), 568-578.

Davis, A. J., \& Chen, D. J. (2013). DNA double strand break repair via non-homologous end- 1596 joining. Transl Cancer Res 2(3), 130-143. 1597

Davis, M. E., Wang, M. K., Rennick, L. J., Full, F., Gableske, S., Mesman, A. W., et al. (2014). 1598 Antagonism of the phosphatase PP1 by the measles virus V protein is required for in- 1599 nate immune escape of MDA5. Cell Host Microbe 16(1), 19-30. Andrade, L. F., Smyth, M. J., \& Martinet, L. (2014). DNAM-1 control of natural killer 1601
cells functions through nectin and nectin-like proteins. Immunol Cell Biol 92(3), 1602 237-244.

. Illescas-Vacas, A , Grueso-Lopez, A, Barco-Sanchez, A \& MiguezSanchez, C.Cancer Immunotherapies Spanish Group (GETICA). (2014). Radiation for 1605 awakening the dormant immune system, a promising challenge to be explored. 1606 Front Immunol 5, 102.

de Visser, K. E., Eichten, A., \& Coussens, L. M. (2006). Paradoxical roles of the immune sys- 1608 tem during cancer development. Nat Rev Cancer 6(1), 24-37.

de Zoete, M. R. Palm, N. W. Zhu, S., \& Flavell, R. A. (2014). Inflammasomes. Cold Spring 1610 Harb Perspect Biol 6(12), a016287. 
DeFilippis, V. R., Alvarado, D., Sali, T., Rothenburg, S., \& Fruh, K. (2010). Human cytomegalovirus induces the interferon response via the DNA sensor ZBP1. J Virol 84(1), 585-598.

Delgado-Vega, A. M., Alarcon-Riquelme, M. E., \& Kozyrev, S. V. (2010). Genetic associations in type I interferon related pathways with autoimmunity. Arthritis Res Ther 12(Suppl. 1), S2

Deng, L., Liang, H., Xu, M., Yang, X., Burnette, B., Arina, A., et al. (2014). STING-dependent cytosolic DNA sensing promotes radiation-induced type I interferon-dependent antitumor immunity in immunogenic tumors. Immunity 41(5), 843-852.

Dey, D., Dahl, J., Cho, S., \& Benjamin, T. L. (2002). Induction and bypass of p53 during productive infection by polyomavirus. J Virol 76(18), 9526-9532.

Dianov, G. L., \& Hubscher, U. (2013). Mammalian base excision repair: The forgotten archangel. Nucleic Acids Res 41(6), 3483-3490.

Di Micco, R., Fumagalli, M., Cicalese, A., Piccinin, S., Gasparini, P., Liuse, C., et al. (2006). Oncogene-induced senescence is a DNA damage response triggered by DNA hyperreplication. Nature 444, 638-642.

Dinarello, C. A. (1999). Cytokines as endogenous pyrogens. J Infect Dis 179(Suppl. 2) S294-S304.

Dinarello, C. A., Novick, D., Kim, S., \& Kaplanski, G. (2013). Interleukin-18 and IL-18 binding protein. Front Immunol 4, 289.

Dong, X. (2004). Pathogen-induced systemic DNA rearrangement in plants. Trends Plant Sci 9(2), 60-61.

Duan, X., Ponomareva, L., Veeranki, S., Panchanathan, R., Dickerson, E., \& Choubey, D. (2011). Differential roles for the interferon-inducible IFI16 and AIM2 innate immune sensors for cytosolic DNA in cellular senescence of human fibroblasts. Mol Cancer Res 9(5), 589-602.

Duelli, D. M., Padilla-Nash, H. M., Berman, D., Murphy, K. M., Ried, T., \& Lazebnik, Y. (2007). A virus causes cancer by inducing massive chromosomal instability through cell fusion. Curr Biol 17(5), 431-437.

Dunn, G. P., Bruce, A. T., Ikeda, H., Old, L. J., \& Schreiber, R. D. (2002). Cancer immunoediting From immunosurveillance to tumor escape. Nat Immunol 3(11), 991-998.

Elinav, E., Nowarski, R., Thaiss, C. A., Hu, B., Jin, C., \& Flavell, R. A. (2013). Inflammationinduced cancer: Crosstalk between tumours, immune cells and microorganisms. Nat Rev Cancer 13(11), 759-771.

Ellyard, J. I., Simson, L., \& Parish, C. R. (2007). Th2-mediated anti-tumour immunity: Friend or foe? Tissue Antigens 70(1), 1-11.

Ermolaeva, M. A., \& Schumacher, B. (2014). Systemic DNA damage responses: Organisma adaptations to genome instability. Trends Genet 30(3), 95-102.

Evangelou, K., Bartkova, J., Kotsinas, A., Pateras, I. S., Liontos, M., Velimezi, G., et al. (2013). The DNA damage checkpoint precedes activation of ARF in response to escalating oncogenic stress during tumorigenesis. Cell Death Differ 20(11), 1485-1497.

Evans, J. D., \& Hearing, P. (2005). Relocalization of the Mre11-Rad50-Nbs1 complex by the adenovirus E4 ORF3 protein is required for viral replication.J Virol 79(10), 6207-6215.

Fang, L., Choudhary, S., Zhao, Y., Edeh, C. B., Yang, C., Boldogh, I., et al. (2014). ATM regulates NF-kappaB-dependent immediate-early genes via RelA ser 276 phosphorylation coupled to CDK9 promoter recruitment. Nucleic Acids Res 42(13), 8416-8432.

Faure, M., \& Lafont, F. (2013). Pathogen-induced autophagy signaling in innate immunity. J Innate Immun 5(5), 456-470.

Fell, V. L., \& Schild-Poulter, C. (2012). Ku regulates signaling to DNA damage response pathways through the Ku70 von Willebrand A domain. Mol Cell Biol 32(1), 76-87.

Fensterl, V., \& Sen, G. C. (2009). Interferons and viral infections. Biofactors 35(1), 14-20.

Fernandes-Alnemri, T., Yu, J. W., Datta, P., Wu, J., \& Alnemri, E. S. (2009). AIM2 activates the inflammasome and cell death in response to cytoplasmic DNA. Nature 458(7237), 509-513.

Ferrero-Miliani, L., Nielsen, O. H., Andersen, P. S., \& Girardin, S. E. (2007). Chronic inflammation: Importance of NOD2 and NALP3 in interleukin-1beta generation. Clin Exp Immunol 147(2), 227-235.

Fife, B. T., Guleria, I., Gubbels Bupp, M., Eagar, T. N., Tang, Q., Bour-Jordan, H., et al. (2006). Insulin-induced remission in new-onset NOD mice is maintained by the PD-1-PD-L1 pathway. J Exp Med 203(12), 2737-2747.

Fife, B. T., Pauken, K. E., Eagar, T. N., Obu, T., Wu, J., Tang, Q., et al. (2009). Interactions between PD-1 and PD-L1 promote tolerance by blocking the TCR-induced stop signal. Nat Immunol 10(11), 1185-1192.

Fijak, M., Bhushan, S., \& Meinhardt, A. (2011). Immunoprivileged sites: The testis. Methods Mol Biol 677, 459-470.

Fragoulis, G. E., \& Moutsopoulos, H. M. (2010). IgG4 syndrome: Old disease, new perspective. J Rheumatol 37(7), 1369-1370.

Franceschi, C., Bonafe, M., Valensin, S., Olivieri, F., De Luca, M., Ottaviani, E., et al. (2000) Inflamm-aging. an evolutionary perspective on immunosenescence. Ann N Y Acad Sci 908, 244-254.

Frit, P., Barboule, N., Yuan, Y., Gomez, D., \& Calsou, P. (2014). Alternative end-joining pathway(s): Bricolage at DNA breaks. DNA Repair 17, 81-97.

Fu, Y., Comella, N., Tognazzi, K., Brown, L. F., Dvorak, H. F., \& Kocher, O. (1999). Cloning of DLM-1, a novel gene that is up-regulated in activated macrophages, using RNA differential display. Gene 240(1), 157-163.

Fuertes, M. B., Girart, M. V., Molinero, L. L., Domaica, C. I., Rossi, L. E., Barrio, M. M., et al. (2008). Intracellular retention of the NKG2D ligand MHC class I chain-related gene A in human melanomas confers immune privilege and prevents NK cell-mediated cytotoxicity. J Immunol 180(7), 4606-4614.

Fullam, A., \& Schroder, M. (2013). DExD/H-box RNA helicases as mediators of anti-viral innate immunity and essential host factors for viral replication. Biochim Biophys Acta 1829(8), 854-865.

Funabiki, M., Kato, H., Miyachi, Y., Toki, H., Motegi, H., Inoue, M., et al. (2014). Autoimmune disorders associated with gain of function of the intracellular sensor MDA5. Immunity 40(2), 199-212.
Galon, J., Costes, A., Sanchez-Cabo, F., Kirilovsky, A., Mlecnik, B., Lagorce-Pages, C., et al. 1698 (2006). Type, density, and location of immune cells within human colorectal tumors 1699 predict clinical outcome. Science 313(5795), 1960-1964.

Galon, J., Pages, F., Marincola, F. M., Angell, H. K., Thurin, M., Lugli, A., et al. (2012). Cancer 1701 classification using the immunoscore: A worldwide task force. J Transl Med 10 (205- 1702 5876-10-205).

Gasiunas, G., Sinkunas, T., \& Siksnys, V. (2014). Molecular mechanisms of CRISPR- 1704 mediated microbial immunity. Cell Mol Life Sci 71(3), 449-465. 1705

Gasser, S., Orsulic, S., Brown, E. J., \& Raulet, D. H. (2005). The DNA damage pathway reg- 1706 ulates innate immune system ligands of the NKG2D receptor. Nature 436(7054), 1707 1186-1190. 1708

Gasser, S., \& Raulet, D. H. (2006). The DNA damage response arouses the immune system. 1709 Cancer Res 66(8), 3959-3962.

Gause, W. C., Wynn, T. A., \& Allen, J. E. (2013). Type 2 immunity and wound healing: Evo- 1711 lutionary refinement of adaptive immunity by helminths. Nat Rev Immunol 13(8), 1712 607-614.

Georgakilas, A. G., Mosley, W. G., Georgakila, S., Ziech, D., \& Panayiotidis, M. I. (2010). 1714 Viral-induced human carcinogenesis: An oxidative stress perspective. Mol Biosyst 6, 1715 1162-1172.

Georgakilas, A. G., O'Neill, P., \& Stewart, R. D. (2013). Induction and repair of clustered 1717 DNA Lesions: What do we know so far? Radiat Res 180, 100-109. 1718

Georgakilas, A. G., Pavlopoulou, A., Louka, M., Nikitaki, Z., Vorgias, C. E., Bagos, P. G., et al. 1719 (2015). Emerging molecular networks common in ionizing radiation, immune and in- 1720 flammatory responses by employing bioinformatics approaches. Cancer Lett (in press). Q64

Georgakilas, A. G., Tsantoulis, P., Kotsinas, A., Michalopoulos, I., Townsend, P., \& Gorgoulis, 1722 V. G. (2014). Are common fragile sites merely structural domains or highly organized 1723 "functional" units susceptible to oncogenic stress? Cell Mol Life Sci 71(23), 4519-4544. 1724 Ghosal, G., \& Chen, J. (2013). DNA damage tolerance: A double-edged sword guarding the 1725 genome. Transl Cancer Res 2(3), 107-129.

Gillies, R. J., Verduzco, D., \& Gatenby, R. A. (2012). Evolutionary dynamics of carcinogen- 1727 esis and why targeted therapy does not work. Nat Rev Cancer 12(7), 487-493. 1728

Gilmore, T. D. (2006). Introduction to NF-КB: Players, pathways, perspectives. Oncogene 1729 25, 6680-6684 1730

Golden, E. B., \& Apetoh, L. (2015). Radiotherapy and immunogenic cell death. Semin 1731 Radiat Oncol 25(1), 11-17. 1732

Golomb, L., Sagiv, A., Pateras, I. S., Maly, A., Krizhanovsky, V., Gorgoulis, V. G., et al. (2015). 1733 Age-associated inflammation connects RAS-induced senescence to stem cell dysfunc- 1734 tion and epidermal malignancy. Cell Death Differ 2015, 1-11. 1735

Gorgoulis, V. G., \& Halazonetis, T. D. (2010). Oncogene-induced senescence: The bright 1736 and dark side of the response. Curr Opin Cell Biol 22(6), 816-827. 1737

Gorgoulis, V. G., Pratsinis, H., Zacharatos, P., Demoliou, C., Sigala, F., Asimacopoulos, P. J., Q65 et al. (2005). p53-dependent ICAM-1 overexpression in senescent human cells iden- 1739 tified in atherosclerotic lesions. Lab Invest 85(4), 502-511. 1740

Gorgoulis, V. G., Vassiliou, L. V., Karakaidos, P., Zacharatos, P., Kotsinas, A., Liloglou, T., et al. 1741 (2005). Activation of the DNA damage checkpoint and genomic instability in human 1742 precancerous lesions. Nature 434(7035), 907-913. 1743

Gorgoulis, V. G., Zacharatos, P., Kotsinas, A., Kletsas, D., Mariatos, G., Zoumpourlis, V., et al. 1744 (2003). p53 activates ICAM-1 (CD54) expression in an NF-kappaB-independent man- 1745 ner. EMBO J 22(7), 1567-1578. 1746

Gozzard, P., \& Maddison, P. (2011). Republished: Which antibody and which cancer in 1747 which paraneoplastic syndromes? Postgrad Med J 87(1023), 60-70. 1748

Grant, C. R., Liberal, R., Mieli-Vergani, G., Vergani, D., \& Longhi, M. S. (2015). Regulatory T- 1749 cells in autoimmune diseases: Challenges, controversies and-yet-unanswered ques- 1750 tions. Autoimmun Rev 14(2), 105-116.

Griebel, T., Maekawa, T., \& Parker, J. E. (2014). NOD-like receptor cooperativity in effector- 1752 triggered immunity. Trends Immunol 35(11), 562-570. 1753

Grywalska, E., Markowicz, J., Grabarczyk, P., Pasiarski, M., \& Rolinski, J. (2013). Epstein- 1754 barr virus-associated lymphoproliferative disorders. Postepy Hig Med Dosw (Online) 1755 67, 481-490. 1756

Gunther, C., Kind, B., Reijns, M. A., Berndt, N., Martinez-Bueno, M., Wolf, C., et al. (2015). 1757 Defective removal of ribonucleotides from DNA promotes systemic autoimmunity. J 1758 Clin Invest 125(1), 413-424.

Guo, Z., Deshpande, R., \& Paull, T. T. (2010). ATM activation in the presence of oxidative 1760 stress. Cell Cycle 9(24), 4805-4811.

Gupta, J., del Barco Barrantes, I., Igea, A., Sakellariou, S., Pateras, I. S., Gorgoulis, V. G., et al. 666 (2014). Dual function of p38alpha MAPK in colon cancer: Suppression of colitis- 1763 associated tumor initiation but requirement for cancer cell survival. Cancer Cell 1764 25(4), 484-500.

Gupta, J., Igea, A., Papaioannou, M., Lopez-Casas, P. P., Llonch, E., Hidalqo, M., et al. (2015). 1766 Pharmacological inhibition of p38 MAPK reduces tumor growth in patient-derived 1767 xenografts from colon tumors. Oncotarget 6(11), 8539-8551.

Guven Maiorov, E., Keskin, O., Gursoy, A., \& Nussinov, R. (2013). The structural network of 1769 inflammation and cancer: Merits and challenges. Semin Cancer Biol 23(4), 243-251. 1770

Ha, S. C., Van Quyen, D., Hwang, H. Y., Oh, D. B., Brown, B. A., II, Lee, S. M., et al. (2006). Bio- 1771 chemical characterization and preliminary X-ray crystallographic study of the domains 1772 of human ZBP1 bound to left-handed Z-DNA. Biochim Biophys Acta 1764(2), 320-323. 1773 Hadler-Olsen, E., Winberg, J. O., \& Uhlin-Hansen, L. (2013). Matrix metalloproteinases in 1774 cancer: Their value as diagnostic and prognostic markers and therapeutic targets. 1775 Tumour Biol 34(4), 2041-2051.

Haikerwal, S. J., Hagekyriakou, J., MacManus, M., Martin, O. A., \& Haynes, N. M. (2015). 1777 Building immunity to cancer with radiation therapy. Cancer Lett.

Halazonetis, T. D. Gorgoulis, V. G., \& Bartek, J. (2008). An oncogene-induced DNA damage 1779 model for cancer development. Science 319(5868), 1352-1355.

Hallahan, D. E., Spriggs, D. R., Beckett, M. A., Kufe, D. W., \& Weichselbaum, R. R. (1989). 1781 Increased tumor necrosis factor alpha mRNA after cellular exposure to ionizing radi- 1782 ation. Proc Natl Acad Sci U S A 86(24), 10104-10107. 
Han, W., \& Yu, K. N. (2011). Ionizing radiation, DNA double strand break and mutation. In K. B. Urbano (Ed.), Advances in Genetic Research (pp. 197-210). New York: Nova Science Publishers Inc.

anahan, D., \& Weinberg, R. A. (2011). Hallmarks of cancer: The next generation. Cell 144(5), 646-674

Hardwick, S. W., \& Luisi, B. F. (2013). Rarely at rest: RNA helicases and their busy contributions to RNA degradation, regulation and quality control. RNA Biol 10(1), 56-70.

Hashimoto, T., Ichiki, T., Ikeda, J., Narabayashi, E., Matsuura, H., Miyazaki, R., et al. (2011). Inhibition of MDM2 attenuates neointimal hyperplasia via suppression of vascular proliferation and inflammation. Cardiovasc Res 91(4), 711-719.

atzi, V. I., Laskaratou, D. A., Mavragani, I. V., et al. (2015). Non-targeted radiation effects in vivo: A critical glance of the future in radiobiology. Cancer Lett 356(1), 34-42.

Havaki, S., Kotsinas, A., Chronopoulos, E., Kletsas, D., Georgakilas, A., \& Gorgoulis, V. G. (2015). The role of oxidative DNA damage in radiation induced bystander effect. Cancer Lett 356(1), 43-51.

Heil, F., Hemmi, H., Hochrein, H., Ampenberger, F., Kirschning, C., Akira, S., et al. (2004). Species-specific recognition of single-stranded RNA via toll-like receptor 7 and 8 . Science 303(5663), 1526-1529.

Heinemann, A., Zhao, F., Pechlivanis, S., Eberle, J., Steinle, A., Diederichs, S., et al. (2012). Tumor suppressive microRNAs miR-34a/c control cancer cell expression of ULBP2, a stress-induced ligand of the natural killer cell receptor NKG2D. Cancer Res 72(2), 460-471.

Hemmi, H., Takeuchi, O., Kawai, T., Kaisho, T., Sato, S., Sanjo, H., et al. (2000). A toll-like receptor recognizes bacterial DNA. Nature 408(6813), 740-745.

Hengge, U. R., Ruzicka, T., Tyring, S. K., Stuschke, M., Roggendorf, M., Schwartz, R. A., et al. (2002a). Update on Kaposi's sarcoma and other HHV8 associated diseases. Part 1: Epidemiology, environmental predispositions, clinical manifestations, and therapy. Lancet Infect Dis 2(5), 281-292.

Hengge, U. R., Ruzicka, T., Tyring, S. K., Stuschke, M., Roggendorf, M., Schwartz, R. A., et al. (2002b). Update on Kaposi's sarcoma and other HHV8 associated diseases. Part 2: Pathogenesis, Castleman's disease, and pleural effusion lymphoma. Lancet Infect Dis 2(6), 344-352

Herbert, A., Alfken, J., Kim, Y. G., Mian, I. S., Nishikura, K., \& Rich, A. (1997). A Z-DNA binding domain present in the human editing enzyme, double-stranded RNA adenosine deaminase. Proc Natl Acad Sci U S A 94(16), 8421-8426.

Herkel, J., Mimran, A., Erez, N., Kam, N., Lohse, A. W., Marker-Hermann, E., et al. (2001) Autoimmunity to the $\mathrm{p} 53$ protein is a feature of systemic lupus erythematosus (SLE) related to anti-DNA antibodies. J Autoimmun 17(1), 63-69.

Heroes, E., Lesage, B., Gornemann, J., Beullens, M., Van Meervelt, L., \& Bollen, M. (2013). The PP1 binding code: A molecular-lego strategy that governs specificity. FEBS J 280(2), 584-595.

Hertel, L., Rolle, S., De Andrea, M., Azzimonti, B., Osello, R., Gribaudo, G., et al. (2000). The retinoblastoma protein is an essential mediator that links the interferon-inducible 204 gene to cell-cycle regulation. Oncogene 19(32), 3598-3608.

Higgs, M. R., Chouteau, P., \& Lerat, H. (2014). 'Liver let die': Oxidative DNA damage and hepatotropic viruses. J Gen Virol 95(Pt 5), 991-1004.

Hiscott, J. (2014). Introduction to innate sensing and response to pathogens (part 2). Cytokine Growth Factor Rev 25(6), 629-630.

Hislop, A. D., Taylor, G. S., Sauce, D., \& Rickinson, A. B. (2007). Cellular responses to viral infection in humans: Lessons from Epstein-Barr virus. Annu Rev Immunol 25, 587-617.

Hlatky, L., Sachs, R. K., Vazquez, M., \& Cornforth, M. N. (2002). Radiation-induced chromosome aberrations: Insights gained from biophysical modeling. Bioessays 24(8), 714-723.

Hoeffel, G., Ripoche, A. C., Matheoud, D., Nascimbeni, M., Escriou, N., Lebon, P., et al. (2007). Antigen crosspresentation by human plasmacytoid dendritic cells. Immunity 27(3), 481-492.

Hoeijmakers, J. H. (2001). Genome maintenance mechanisms for preventing cancer. Nature 411(6835), 366-374.

Hoglund, P. (2006). DNA damage and tumor surveillance: One trigger for two pathways. SCi STKE 2006(317), pe2.

Hohensinner, P. J., Goronzy, J. J., \& Weyand, C. M. (2011). Telomere dysfunction, autoimmunity and aging. Aging Dis 2(6), 524-537.

Holley, W. R., \& Chatterjee, A. (1996). Clusters of DNA induced by ionizing radiation: Formation of short DNA fragments. I. Theoretical modeling. Radiat Res 145(2), 188-199.

Holmdahl, R., Malmstrom, V., \& Burkhardt, H. (2014). Autoimmune priming, tissue attack and chronic inflammation - the three stages of rheumatoid arthritis. Eur J Immuno 44(6), 1593-1599.

Hopfner, K. P. (2014). RIG-I holds the CARDs in a game of self versus nonself. Mol Cell 55(4), 505-507.

Hornung, V., Ablasser, A., Charrel-Dennis, M., Bauernfeind, F., Horvath, G., Caffrey, D. R. et al. (2009). AIM2 recognizes cytosolic dsDNA and forms a caspase-1-activating inflammasome with ASC. Nature 458(7237), 514-518.

Horvath, P., \& Barrangou, R. (2010). CRISPR/Cas, the immune system of bacteria and archaea. Science 327(5962), 167-170.

House, N. C., Koch, M. R., \& Freudenreich, C. H. (2014). Chromatin modifications and DNA repair: Beyond double-strand breaks. Front Genet 5, 296.

Hsiao, Y., \& Stewart, R. D. (2008). Monte Carlo simulation of DNA damage induction by xrays and selected radioisotopes. Phys Med Biol 53(1), 233-244.

Huang, Y., \& Li, L. (2013). DNA crosslinking damage and cancer - a tale of friend and foe. Transl Cancer Res 2(3), 144-154.

Hurchla, M. A., Sedy, J. R., Gavrieli, M., Drake, C. G., Murphy, T. L., \& Murphy, K. M. (2005) $\mathrm{B}$ and $\mathrm{T}$ lymphocyte attenuator exhibits structural and expression polymorphisms and is highly induced in anergic CD4+ T cells. J Immunol 174(6), 3377-3385.

Isaacs, A., Cox, R. A., \& Rotem, Z. (1963). Foreign nucleic acids as the stimulus to make interferon. Lancet 2(7299), 113-116.
Ishikawa, H., \& Barber, G. N. (2011). The STING pathway and regulation of innate immune 1870 signaling in response to DNA pathogens. Cell Mol Life Sci 68(7), 1157-1165.

Ivashkiv, L. B., \& Donlin, L. T. (2014). Regulation of type I interferon responses. Nat Rev 1872 Immunol 14(1), 36-49. 1873

Jackson, S. P., \& Bartek, J. (2009). The DNA-damage response in human biology and dis- Q70 ease. Nature 461(7267), 1071-1078. 1875

Jacobs, S. R., \& Damania, B. (2012). NLRs, inflammasomes, and viral infection.J Leukoc Biol 1876 92(3), 469-477. 1877

Jakobsen, M. R., \& Paludan, S. R. (2014). IFI16: At the interphase between innate DNA 1878 sensing and genome regulation. Cytokine Growth Factor Rev 25(6), 649-655. 1879

Janeway, C. A., Jr. (1989). Pillars article: Approaching the asymptote? evolution and rev- 1880 olution in immunology. cold spring harb symp quant biol, 1989. 54: 1-13. J 1881 Immunol 191(9), 4475-4487.

Jankovic, D., Liu, Z., \& Gause, W. C. (2001). Th1- and Th2-cell commitment during infec- 1883 tious disease: Asymmetry in divergent pathways. Trends Immunol 22(8), 450-457. 1884

Jasinski-Bergner, S., Mandelboim, O., \& Seliger, B. (2014). The role of microRNAs in the Q71 control of innate immune response in cancer. J Natl Cancer Inst 106(10). 1886

Jaumot, M., \& Hancock, J. F. (2001). Protein phosphatases 1 and 2A promote raf-1 activa- 1887 tion by regulating 14-3-3 interactions. Oncogene 20(30), 3949-3958. 1888

Jiang, S., Willox, B., Zhou, H., Holthaus, A. M., Wang, A., Shi, T. T., et al. (2014). Epstein-barr 1889 virus nuclear antigen 3C binds to BATF/IRF4 or SPI1/IRF4 composite sites and recruits 1890 Sin3A to repress CDKN2A. Proc Natl Acad Sci U S A 111(1), 421-426. 1891

Jinushi, M., Chiba, S., Baghdadi, M., Kinoshita, I., Dosaka-Akita, H., Ito, K., et al. (2012). 1892 ATM-mediated DNA damage signals mediate immune escape through integrin- 1893 alphavbeta3-dependent mechanisms. Cancer Res 72(1), 56-65. 1894

Jiricny, J. (2006). The multifaceted mismatch-repair system. Nat Rev Mol Cell Biol 7(5), 1895 335-346.

Johnstone, R. W., Wei, W., Greenway, A., \& Trapani, J. A. (2000). Functional interaction be- 1897 tween p53 and the interferon-inducible nucleoprotein IFI 16. Oncogene 19(52), 1898 6033-6042.

Jones, J. W., Kayagaki, N., Broz, P., Henry, T., Newton, K., O'Rourke, K., et al. (2010). Absent 1900 in melanoma 2 is required for innate immune recognition of francisella tularensis. 1901 Proc Natl Acad Sci U S A 107(21), 9771-9776. 1902

Kachroo, A., \& Robin, G. P. (2013). Systemic signaling during plant defense. Curr Opin Plant 1903 Biol 16(4), 527-533.

Kang, H. G., Hyong, W. C., von Einem, S., Manosalva, P., Ehlers, K., Liu, P. P., et al. (2012). 1905 CRT1 is a nuclear-translocated MORC endonuclease that participates in multiple 1906 levels of plant immunity. Nat Commun 3, 1297.

Kapsogeorgou, E. K., Gourzi, V. C., Manoussakis, M. N., Moutsopoulos, H. M., \& Tzioufas, A. 1908 G. (2011). Cellular microRNAs (miRNAs) and Sjogren's syndrome: Candidate regula- 1909 tors of autoimmune response and autoantigen expression. J Autoimmun 37(2), 1910 129-135.

Karin, M., \& Greten, F. R. (2005). NF-kappaB: Linking inflammation and immunity to can- 1912 cer development and progression. Nat Rev Immunol 5(10), 749-759. 1913

Karpova, A. Y., Trost, M., Murray, J. M., Cantley, L. C., \& Howley, P. M. (2002). Interferon reg- 1914 ulatory factor-3 is an in vivo target of DNA-PK. Proc Natl Acad Sci U S A 99(5), 1915 2818-2823.

Kato, H., \& Fujita, T. (2014). Autoimmunity caused by constitutive activation of cytoplas- Q72 mic viral RNA sensors. Cytokine Growth Factor Rev 25(6), 739-743. 1918

Kato, H., Takeuchi, O., Sato, S., Yoneyama, M., Yamamoto, M., Matsui, K., et al. (2006). Dif- 1919 ferential roles of MDA5 and RIG-I helicases in the recognition of RNA viruses. Nature 1920 441(7089), 101-105.

Kawai, T., \& Akira, S. (2010). The role of pattern-recognition receptors in innate immuni- 1922 ty: Update on toll-like receptors. Nat Immunol 11(5), 373-384. 1923

Kawasaki, T., Kawai, T., \& Akira, S. (2011). Recognition of nucleic acids by pattern- 1924 recognition receptors and its relevance in autoimmunity. Immunol Rev 243(1), 61-73. 1925

Keating, S. E., Baran, M., \& Bowie, A. G. (2011). Cytosolic DNA sensors regulating type I in- 1926 terferon induction. Trends Immunol 32(12), 574-581.

Kefalakes, H., Stylianides, T. J., Amanakis, G., \& Kolios, G. (2009). Exacerbation of inflam- 1928 matory bowel diseases associated with the use of nonsteroidal anti-inflammatory 1929 drugs: Myth or reality? Eur J Clin Pharmacol 65(10), 963-970.

Keir, M. E., Liang, S. C., Guleria, I., Latchman, Y. E., Qipo, A., Albacker, L. A., et al. (2006). Tis- 1931 sue expression of PD-L1 mediates peripheral T cell tolerance. J Exp Med 203(4), 1932 883-895.

Kersse, K., Bertrand, M. J., Lamkanfi, M., \& Vandenabeele, P. (2011). NOD-like receptors 1934 and the innate immune system: Coping with danger, damage and death. Cytokine 1935 Growth Factor Rev 22(5-6), 257-276.

Kim, P. S., \& Ahmed, R. (2010). Features of responding T cells in cancer and chronic infec- 1937 tion. Curr Opin Immunol 22(2), 223-230.

Kim, S., Bauernfeind, F., Ablasser, A., Hartmann, G., Fitzgerald, K. A., Latz, E., et al. (2010). 1939 Listeria monocytogenes is sensed by the NLRP3 and AIM2 inflammasome. Eur J 1940 Immunol 40(6), 1545-1551.

Kim, T., Kim, T. Y., Song, Y. H., Min, I. M., Yim, J., \& Kim, T. K. (1999). Activation of interfer- 1942 on regulatory factor 3 in response to DNA-damaging agents. J Biol Chem 274(43), 1943 30686-30689.

Kolakofsky, D., Kowalinski, E., \& Cusack, S. (2012). A structure-based model of RIG-I acti- 1945 vation. RNA 18(12), 2118-2127.

Kondo, T., Kobayashi, J., Saitoh, T., Maruyama, K. Ishii, K. J., Barber, G. N., et al. (2013). DNA 1947 damage sensor MRE11 recognizes cytosolic double-stranded DNA and induces type I 1948 interferon by regulating STING trafficking. Proc Natl Acad Sci US A 110(8), 2969-2974. 1949

Kotsinas, A., Papanagnou, P., Evangelou, K., Trigas, G. C., Kostourou, V., Townsend, P., et al. 1950 (2014). ARF: A versatile DNA damage response ally at the crossroads of development 1951 and tumorigenesis. Front Genet 5, 236.

Kovacs, B., Patel, A., Hershey, J. N., Dennis, G. J., Kirschfink, M., \& Tsokos, G. C. (1997). An- 1953 tibodies against p53 in sera from patients with systemic lupus erythematosus and 1954 other traumatic diseases. Arthritis Rheum 40(5), 980-982. 
Kovalchuk, I., Kovalchuk, O., Kalck, V., Boyko, V., Filkowski, J., Heinlein, M., et al. (2003). Pathogen-induced systemic plant signal triggers DNA rearrangements. Nature 423(6941), 760-762.

Krishna, S. S., \& Aravind, L. (2010). The bridge-region of the ku superfamily is an atypical zinc ribbon domain. J Struct Biol 172(3), 294-299.

Krizhanovsky, V., Yon, M., Dickins, R. A., Hearn, S., Simon, J., Miething, C., et al. (2008). Senescence of activated stellate cells limits liver fibrosis. Cell 134(4), 657-667.

Kudoh, A., Fujita, M., Zhang, L., Shirata, N., Daikoku, T., Sugaya, Y., et al. (2005). Epsteinbarr virus lytic replication elicits ATM checkpoint signal transduction while providing an S-phase-like cellular environment. J Biol Chem 280(9), 8156-8163.

wak, J. C., Ongusaha, P. P., Ouchi, T., \& Lee, S. W. (2003). IFI16 as a negative regulator in the regulation of p53 and p21(Waf1). J Biol Chem 278(42), 40899-40904.

Kwun, H. J., Toptan, T., Ramos da Silva, S., Atkins, J. F., Moore, P. S., \& Chang, Y. (2014). Human DNA tumor viruses generate alternative reading frame proteins through repeat sequence recoding. Proc Natl Acad Sci U S A 111(41), E4342-E4349.

Laguette, N., Bregnard, C., Hue, P., Basbous, J., Yatim, A., Larroque, M., et al. (2014). Premature activation of the SLX4 complex by vpr promotes G2/M arrest and escape from innate immune sensing. Cell 156(1-2), 134-145.

Lai, M. M. (1992). RNA recombination in animal and plant viruses. Microbiol Rev 56(1), 61-79. Lam, A. R., Le Bert, N., Ho, S. S., Shen, Y. J., Tang, M. L., Xiong, G. M., et al. (2014). RAE1 ligands for the NKG2D receptor are regulated by STING-dependent DNA sensor pathways in lymphoma. Cancer Res 74, 2193-2203.

Lam, E., Stein, S., \& Falck-Pedersen, E. (2014). Adenovirus detection by the cGAS/STING/ TBK1 DNA sensing cascade. J Virol 88(2), 974-981.

Lamarche, B. J., Orazio, N. I., \& Weitzman, M. D. (2010). The MRN complex in doublestrand break repair and telomere maintenance. FEBS Lett 584(17), 3682-3695.

Lambert, J. M., Gorzov, P., Veprintsev, D. B., Soderqvist, M., Segerback, D., Bergman, J., et al. (2009). PRIMA-1 reactivates mutant p53 by covalent binding to the core domain. Cancer Cell 15(5), 376-388.

Lamkanfi, M. (2011). Emerging inflammasome effector mechanisms. Nat Rev Immunol 11(3), 213-220.

mkanfi, M., \& Dixit, V. M. (2009). Inflammasomes: Guardians of cytosolic sanctity. Immunol Rev 227(1), 95-105.

Lammens, K., Bemeleit, D. J., Mockel, C., Clausing, E., Schele, A., Hartung, S., et al. (2011). The Mre11:Rad50 structure shows an ATP-dependent molecular clamp in DNA double-strand break repair. Cell 145(1), 54-66.

and, W. G. (2015). The role of damage-associated molecular patterns in human diseases: Part I - promoting inflammation and immunity. Sultan Qaboos Univ Med J 15(1), e9-e21.

langefeld, T., Mohamed, W., Ghai, R., \& Chakraborty, T. (2009). Toll-like receptors and NOD-like receptors: Domain architecture and cellular signalling. Adv Exp Med Biol 653, 48-57.

Lasry, A., \& Ben-Neriah, Y. (2015). Senescence-associated inflammatory responses: Aging and cancer perspectives. Trends Immunol (in press).

Lau, A., Swinbank, K. M., Ahmed, P. S., Taylor, D. L., Jackson, S. P., Smith, G. C., et al. (2005). Suppression of HIV-1 infection by a small molecule inhibitor of the ATM kinase. Nat Cell Biol 7(5), 493-500.

awrence, T., \& Natoli, G. (2011). Transcriptional regulation of macrophage polarization: Enabling diversity with identity. Nat Rev Immunol 11(11), 750-761.

Leger-Ravet, M. B., Peuchmaur, M., Devergne, O., Audouin, J., Raphael, M., Van Damme, J., et al. (1991). Interleukin-6 gene expression in Castleman's disease. Blood 78(11), 2923-2930.

Leith, J. T. (1993). Correspondence re: H. Nagasawa and J. B. Little, induction of sister chromatid exchanges by extremely low doses of alpha-particles. Cancer res., 52: 63946396, 1992. Cancer Res 53(9), 2188.

Lemos, H., Huang, L., McGaha, T. L., \& Mellor, A. L. (2014). Cytosolic DNA sensing via the stimulator of interferon genes adaptor: Yin and yang of immune responses to DNA. Eur J Immunol 44(10), 2847-2853.

i, H., Lakshmikanth, T., Garofalo, C., Enge, M., Spinnler, C., Anichini, A., et al. (2011). Pharmacological activation of $\mathrm{p} 53$ triggers anticancer innate immune response through induction of ULBP2. Cell Cycle 10(19), 3346-3358.

i, H. B., Jin, C., Chen, Y., \& Flavell, R. A. (2014). Inflammasome activation and metabolic disease progression. Cytokine Growth Factor Rev 25(6), 699-706.

Li, N., Banin, S., Ouyang, H., Li, G. C., Courtois, G., Shiloh, Y., et al. (2001). ATM is required for IkappaB kinase (IKKk) activation in response to DNA double strand breaks. J Biol Chem 276(12), 8898-8903.

i, R., \& Hayward, S. D. (2011). The ying-yang of the virus-host interaction: Control of the DNA damage response. Future Microbiol 6(4), 379-383.

i, Y., Chen, R., Zhou, Q., Xu, Z., Li, C., Wang, S., et al. (2012). LSm14A is a processing bodyassociated sensor of viral nucleic acids that initiates cellular antiviral response in the early phase of viral infection. Proc Natl Acad Sci U S A 109(29), 11770-11775.

illey, C. E., Schwartz, R. A., \& Weitzman, M. D. (2007). Using or abusing: Viruses and the cellular DNA damage response. Trends Microbiol 15(3), 119-126.

Lim, J. W., Kim, H., \& Kim, K. H. (2002). Expression of Ku70 and Ku80 mediated by NFkappa B and cyclooxygenase-2 is related to proliferation of human gastric cancer cells. J Biol Chem 277(48), 46093-46100.

inder, P., \& Jankowsky, E. (2011). From unwinding to clamping - the DEAD box RNA helicase family. Nat Rev Mol Cell Biol 12(8), 505-516.

iontos, M., Koutsami, M., Sideridou, M., Evangelou, K., Kletsas, D., Levy, B., et al. (2007) Deregulated overexpression of hCdt1 and hCdc6 promotes malignant behavior Cancer Res 67(22), 10899-10909.

Liontos, M., Niforou, K., Velimezi, G., Vougas, K., Evangelou, K., Apostolopoulou, K., et al. (2009). Modulation of the E2F1-driven cancer cell fate by the DNA damage response machinery and potential novel E2F1 targets in osteosarcomas. Am J Pathol 175(1), 376-391.

Liu, G., Park, Y. J., Tsuruta, Y., Lorne, E., \& Abraham, E. (2009). p53 attenuates ipopolysaccharide-induced NF-kappaB activation and acute lung injury. J Immunol 182(8), 5063-5071.
Lopez-Soto, A., Huergo-Zapico, L., Galvan, J. A., Rodrigo, L., de Herreros, A. G., Astudillo, A., 2042 et al. (2013). Epithelial-mesenchymal transition induces an antitumor immune re- 2043 sponse mediated by NKG2D receptor. I Immunol 190(8), 4408-4419. 2044

Lu, H., Lu, N., Weng, L., Yuan, B., Liu, Y. J., \& Zhang, Z. (2014). DHX15 senses double- 076 stranded RNA in myeloid dendritic cells. J Immunol 193(3), 1364-1372. 2046

Lubin, R., Schlichtholz, B., Bengoufa, D., Zalcman, G., Tredaniel, J., Hirsch, A., et al. (1993). 2047 Analysis of p53 antibodies in patients with various cancers define B-cell epitopes of 2048 human p53: Distribution on primary structure and exposure on protein surface. 2049 Cancer Res 53(24), 5872-5876.

Lucht, J. M., Mauch-Mani, B., Steiner, H. Y., Metraux, J. P., Ryals, J., \& Hohn, B. (2002). Path- 2051 ogen stress increases somatic recombination frequency in arabidopsis. Nat Genet 2052 30(3), 311-314.

Ludlow, L. E., Johnstone, R. W., \& Clarke, C. J. (2005). The HIN-200 family: More than 205 interferon-inducible genes? Exp Cell Res 308(1), 1-17. 2055

Luna, E., Bruce, T. J., Roberts, M. R., Flors, V., \& Ton, J. (2012). Next-generation systemic ac- 2056 quired resistance. Plant Physiol 158(2), 844-853.

Lupfer, C., Thomas, P. G., \& Kanneganti, T. D. (2014). Nucleotide oligomerization and bind- 2058 ing domain 2-dependent dendritic cell activation is necessary for innate immunity 2059 and optimal CD8 + T cell responses to influenza A virus infection. J Virol 88(16), 2060 8946-8955.

Ma, Y., Aymeric, L., Locher, C., Kroemer, G., \& Zitvogel, L. (2011). The dendritic cell-tumor 2062 cross-talk in cancer. Curr Opin Immunol 23(1), 146-152. 2063

Mackern-Oberti, J. P., Vega, F., Llanos, C., Bueno, S. M., \& Kalergis, A. M. (2014). Targeting 2064 dendritic cell function during systemic autoimmunity to restore tolerance. Int J Mol 2065 Sci 15(9), 16381-16417.

Maddur, M. S., Miossec, P., Kaveri, S. V., \& Bayry, J. (2012). Th17 cells: Biology, pathogen- 2067 esis of autoimmune and inflammatory diseases, and therapeutic strategies. Am J 2068 Pathol 181(1), 8-18.

Manche, L, Green, S. R. Schmedt, C. \& Mathews, M. B. (1992). Interactions between 2070 double-stranded RNA regulators and the protein kinase DAI. Mol Cell Biol 12(11), 2071 5238-5248. (2014). Recognition of tumors by the innate immune system and natural killer 2074 cells. Adv Immunol 122, 91-128.

2075

Mariathasan, S., \& Monack, D. M. (2007). Inflammasome adaptors and sensors: Intracellu- 2076 lar regulators of infection and inflammation. Nat Rev Immunol 7(1), 31-40. 2077

Maringer, K., \& Fernandez-Sesma, A. (2014). Message in a bottle: Lessons learned from 2078 antagonism of STING signalling during RNA virus infection. Cytokine Growth Factor 2079 Rev 25(6), 669-679.

Martin, O. A., Redon, C. E. Dickey, J. S., Nakamura, A. J. \& Bonner, W. M. (2011). Para- 2081 inflammation mediates systemic DNA damage in response to tumor growth. 2082 Commun Integr Biol 4(1), 78-81.

McBride, W. H., Chiang C. S. Olson, J. L., Wang C. C. Hong J. H., Pajonk, F. et al (2004). A 2084 sense of danger from radiation. Radiat Res 162(1), 1-19.

McFadden, K., \& Luftig, M. A. (2013). Interplay between DNA tumor viruses and the host 2086 DNA damage response. Curr Top Microbiol Immunol 371, 229-257. 2087

McKenna, K., Beignon, A. S., \& Bhardwaj, N. (2005). Plasmacytoid dendritic cells: Linking 2088 innate and adaptive immunity. J Virol 79(1), 17-27.

Medzhitov, R. (2008). Origin and physiological roles of inflammation. Nature 454(7203), 2090 428-435.

Mesman, A. W., Zijlstra-Willems, E. M., Kaptein, T. M., de Swart, R. L., Davis, M. E., Ludlow, M., 2092 et al. (2014). Measles virus suppresses RIG-I-like receptor activation in dendritic cells 2093 via DC-SIGN-mediated inhibition of PP1 phosphatases. Cell Host Microbe 16(1), 31-42. 2094

Meyer, O. (2009). Interferons and autoimmune disorders. Joint Bone Spine 76(5), 2095 464-473.

Miao, E. A., Leaf, I. A., Treuting, P. M., Mao, D. P., Dors, M., Sarkar, A., et al. (2010). Caspase- 2097 1-induced pyroptosis is an innate immune effector mechanism against intracellular 2098 bacteria. Nat Immunol 11(12), 1136-1142.

Min, W., Ghosh, S., \& Lengyel, P. (1996). The interferon-inducible p202 protein as a mod- 2100 ulator of transcription: Inhibition of NF-kappa B, c-fos, and c-jun activities. Mol Cell 2101 Biol 16(1), 359-368.

Mitchell, A. J., Roediger, B., \& Weninger, W. (2014). Monocyte homeostasis and the 2103 plasticity of inflammatory monocytes. Cell Immunol 291(1-2), 22-31.

Mitoma, H., Hanabuchi, S., Kim, T., Bao, M., Zhang, Z, Sugimoto, N. et al, (2013). The 2105 DHX33 RNA helicase senses cytosolic RNA and activates the NLRP3 inflammasome. 2106 Immunity 39(1), 123-135

Miyake, K., \& Kaisho, T. (2014). Homeostatic inflammation in innate immunity. Curr Opin 2108 Immunol 30, 85-90. 2109

Miyake, M., Lawton, A., Goodison, S., Urquidi, V., Gomes-Giacoia, E., Zhang, G., et al. 2110 (2013). Chemokine (C-X-C) ligand 1 (CXCL1) protein expression is increased in ag- 2111 gressive bladder cancers. BMC Cancer 13 (322-2407-13-322). 2112

Miyamoto, S. (2011). Nuclear initiated NF-kappaB signaling: NEMO and ATM take center 077 stage. Cell Res 21(1), 116-130. 2114

Mo, Y. Y., \& Beck, W. T. (1999). DNA damage signals induction of fas ligand in tumor cells. 2115 Mol Pharmacol 55(2), 216-222. 2116

Moiseeva, O., Mallette, F. A., Mukhopadhyay, U. K., Moores, A., \& Ferbeyre, G. (2006). DNA 2117 damage signaling and p53-dependent senescence after prolonged beta-interferon 2118 stimulation. Mol Biol Cell 17(4), 1583-1592.

2119

ontes, C. L., Chapoval, A. I., Nelson, J., Orhue, V., Zhang, X., Schulze, D. H., et al. (2008). 2120 Tumor-induced senescent T cells with suppressor function: A potential form of 2121 tumor immune evasion. Cancer Res 68(3), 870-879. 2122

Moody, C. A., \& Laimins, L. A. (2009). Human papillomaviruses activate the ATM DNA 2123 damage pathway for viral genome amplification upon differentiation. PLoS Pathog 2124 5(10), e1000605.

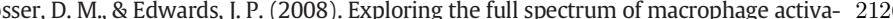
tion. Nat Rev Immunol 8(12), 958-969. 
Motz, G. T., Santoro, S. P., Wang, L. P., Garrabrant, T., Lastra, R. R., Hagemann, I. S., et al. (2014). Tumor endothelium FasL establishes a selective immune barrier promoting tolerance in tumors. Nat Med 20(6), 607-615.

Mulay, S. R., Thomasova, D., Ryu, M., \& Anders, H. J. (2012). MDM2 (murine double minute-2) links inflammation and tubular cell healing during acute kidney injury in mice. Kidney Int 81(12), 1199-1211.

unoz-Espin, D., \& Serrano, M. (2014). Cellular senescence: From physiology to pathology. Nat Rev Mol Cell Biol 15(7), 482-496.

Muotri, A. R., Bottero, V., Tergaonkar, V., \& Correa, R. G. (2006). UV-mediated NF-kappaB activation is abolished in deficient XPC/D primary fibroblasts. Cell Cycle 5(10), 1085-1089.

Murray, P. J., \& Wynn, T. A. (2011). Protective and pathogenic functions of macrophage subsets. Nat Rev Immunol 11(11), 723-737.

Murzin, A. G. (1993). OB(oligonucleotide/oligosaccharide binding)-fold: Common structural and functional solution for non-homologous sequences. EMBO J 12(3), 861-867.

Muzes, G., Molnar, B., \& Sipos, F. (2012). Regulatory T cells in inflammatory bowel diseases and colorectal cancer. World J Gastroenterol 18(40), 5688-5694

Myong, S., Cui, S., Cornish, P. V., Kirchhofer, A., Gack, M. U., Jung, J. U., et al. (2009). Cytosolic viral sensor RIG-I is a $5^{\prime}$-triphosphate-dependent translocase on doublestranded RNA. Science 323(5917), 1070-1074.

Nagasawa, H., \& Little, J. B. (1992). Induction of sister chromatid exchanges by extremely low doses of alpha-particles. Cancer Res 52(22), 6394-6396.

Nagi, R. S., Bhat, A. S., \& Kumar, H. (2014). Cancer: A tale of aberrant PRR response. Front Immunol 5, 161.

Naito, Y., Saito, K., Shiiba, K., Ohuchi, A., Saigenji, K., Nagura, H., et al. (1998). CD8+ T cells infiltrated within cancer cell nests as a prognostic factor in human colorectal cancer. Cancer Res 58(16), 3491-3494.

Najafi, M., Fardid, R., Hadadi, G., \& Fardid, M. (2014). The mechanisms of radiationinduced bystander effect. J Biomed Phys Eng 4(4), 163-172.

Nakashima, A., Shima, T., Inada, K., Ito, M., \& Saito, S. (2012). The Balance of the Immune System between T Cells and NK Cells in Miscarriage. Am J Reprod Immunol 67, 304-310.

Negrini, S., Gorgoulis, V. G., \& Halazonetis, T. D. (2010). Genomic instability-an evolving hallmark of cancer. Nat Rev Mol Cell Biol 11(3), 220-228.

Niederkorn, J. Y. (2006). See no evil, hear no evil, do no evil: The lessons of immune privilege. Nat Immunol 7(4), 354-359.

Nikitaki, Z., Hellweg, C., Georgakilas, A. G., \& Ravanat, J. L. (2015). Stress-induced DNA Damage biomarkers: Applications and limitations. Front Chem 3, 35.

Nikitin, P. A., Yan, C. M., Forte, E., Bocedi, A., Tourigny, J. P., White, R. E., et al. (2010). An ATM/ Chk2-mediated DNA damage-responsive signaling pathway suppresses Epstein-Barr virus transformation of primary human B cells. Cell Host Microbe 8(6), 510-522.

Novick, D., Kim, S., Kaplanski, G., \& Dinarello, C. A. (2013). Interleukin-18, more than a Th1 cytokine. Semin Immunol 25(6), 439-448.

Nunes-Alves, C., Nobrega, C., Behar, S. M., \& Correia-Neves, M. (2013). Tolerance has its limits: How the thymus copes with infection. Trends Immunol 34(10), 502-510.

Nurnberger, T., Brunner, F., Kemmerling, B., \& Piater, L. (2004). Innate immunity in plants and animals: Striking similarities and obvious differences. Immunol Rev 198, 249-266.

Ogrunc, M., Di Micco, R., Liontos, M., Bombardelli, L., Mione, M., Fumagalli, M., et al. (2014). Oncogene-induced reactive oxygen species fuel hyperproliferation and DNA damage response activation. Cell Death Differ 21(6), 998-1012.

Okita, R., Mougiakakos, D., Ando, T., Mao, Y., Sarhan, D., Wennerberg, E., et al. (2012). HER2/HER3 signaling regulates NK cell-mediated cytotoxicity via MHC class I chain-related molecule A and B expression in human breast cancer cell lines. Immunol 188(5), 2136-2145.

Okubo, E., Lehman, J. M., \& Friedrich, T. D. (2003). Negative regulation of mitotic promoting factor by the checkpoint kinase chk1 in simian virus 40 lytic infection. J Virol 77(2) 1257-1267.

Olivier, M. Hussain, S. P., CarondeFromentel, C., Hainaut, P. \& Harris, C. C. (2004). TP53 mutation spectra and load: A tool for generating hypotheses on the etiology of cancer. IARC Sci Publ 157(157), 247-270.

O'Neill, L. A. (2009). DNA makes RNA makes innate immunity. Cell 138(3), 428-430.

Oren, M., \& Rotter, V. (2010). Mutant p53 gain-of-function in cancer. Cold Spring Harb Perspect Biol 2(2), a001107.

Oshiumi, H., Sakai, K., Matsumoto, M.. \& Seya, T. (2010). DEAD/H BOX 3 (DDX3) helicase binds the RIG-I adaptor IPS-1 to up-regulate IFN-beta-inducing potential. Eur J Immunol 40(4), 940-948.

Ostrand-Rosenberg, S., \& Sinha, P. (2009). Myeloid-derived suppressor cells: Linking inflammation and cancer. J Immunol 182(8), 4499-4506.

Ouchi, M., \& Ouchi, T. (2008). Role of IFI16 in DNA damage and checkpoint. Front Biosci 13, 236-239.

Ozeri-Galai, E., Tur-Sinai, M., Bester, A. C., \& Kerem, B. (2014). Interplay between genetic and epigenetic factors governs common fragile site instability in cancer. Cell Mol Life Sci 71(23), 4495-4506.

Pages, F., Galon, J., Dieu-Nosjean, M. C., Tartour, E., Sautes-Fridman, C., \& Fridman, W. H. (2010). Immune infiltration in human tumors: A prognostic factor that should not be ignored. Oncogene 29(8), 1093-1102.

Paludan, S. R., \& Bowie, A. G. (2013). Immune sensing of DNA. Immunity 38(5), 870-880,

Pang Q. Fagerlie, S., Christianson, T. A., Keeble, W., Faulkner, G., Diaz, J., et al. (2000). The Fanconi anemia protein FANCC binds to and facilitates the activation of STAT1 by gamma interferon and hematopoietic growth factors. Mol Cell Biol 20(13), 4724-4735.

Pardoll, D. M. (2012). The blockade of immune checkpoints in cancer immunotherapy. Nat Rev Cancer 12(4), 252-264.

Pasparakis, M. (2009). Regulation of tissue homeostasis by NF-kappaB signalling: Implications for inflammatory diseases. Nat Rev Immunol 9(11), 778-788.

Patil, M., Pabla, N., \& Dong, Z. (2013). Checkpoint kinase 1 in DNA damage response and cell cycle regulation. Cell Mol Life Sci 70(21), 4009-4021.
Patterson, N. J.. \& Werling. D. (2013). To con protection: TIR-domain containing proteins 078 (tcp) and innate immune evasion. Vet Immunol Immunopathol 155(3), 147-154. 2215

Pawelek, J. M., \& Chakraborty, A. K. (2008). Fusion of tumour cells with bone marrow- 2216 derived cells: A unifying explanation for metastasis. Nat Rev Cancer 8(5), 2217 377-386. 2218

Perkins, N. D. (2006). Post-translational modifications regulating the activity and function 2219 of the nuclear factor kappa B pathway. Oncogene 25(51), 6717-6730. 2220

Peters, N. E., Ferguson, B. J., Mazzon, M.. Fahy, A. S., Krysztofinska, E., Arribas-Bosacoma, R., 2221 et al. (2013). A mechanism for the inhibition of DNA-PK-mediated DNA sensing by a 2222 virus. PLoS Pathog 9(10), e1003649.

Peti, W., Nairn, A. C., \& Page, R. (2013). Structural basis for protein phosphatase 1 regula- 222 tion and specificity. FEBS J 280(2), 596-611.

Pettengill, M. A., van Haren, S. D., \& Levy, O. (2014). Soluble mediators regulating immu- 2226 nity in early life. Front Immunol 5, 457.

Pham, T. H., Kwon, K. M., Kim, Y. E., Kim, K. K., \& Ahn, J. H. (2013). DNA sensing- 2228 independent inhibition of herpes simplex virus 1 replication by DAI/ZBP1. J Virol 2229 87(6), 3076-3086.

Philpott, D. J., Sorbara, M. T., Robertson, S. J., Croitoru, K., \& Girardin, S. E. (2014). NOD pro- 2231 teins: Regulators of inflammation in health and disease. Nat Rev Immunol 14(1), 9-23. 2232

Phong, M. S., Van Horn, R. D., Li, S., Tucker-Kellogg, G., Surana, U., \& Ye, X. S. (2010). p38 2233 mitogen-activated protein kinase promotes cell survival in response to DNA damage 2234 but is not required for the G(2) DNA damage checkpoint in human cancer cells. Mol 2235 Cell Biol 30(15), 3816-3826.

Pichlmair, A., Schulz, O., Tan, C. P., Naslund, T. I., Liljestrom, P., Weber, F., et al. (2006). RIG- 2237 I-mediated antiviral responses to single-stranded RNA bearing 5'-phosphates. Science 2238 314(5801), 997-1001.

Pilones, K. A., Vanpouille-Box, C., \& Demaria, S. (2015). Combination of radiotherapy and 2240 immune checkpoint inhibitors. Semin Radiat Oncol 25(1), 28-33.

Polo, S. E., \& Jackson, S. P. (2011). Dynamics of DNA damage response proteins at DNA 2242 breaks: A focus on protein modifications. Genes Dev 25(5), 409-433. 2243

Powell, A. E., Anderson, E. C., Davies, P. S., Silk, A. D., Pelz, C., Impey, S., et al. (2011). Fusion 2244 between intestinal epithelial cells and macrophages in a cancer context results in nu- 2245 clear reprogramming. Cancer Res 71(4), 1497-1505. 2246

Pribluba, A., Elyada, E., Wiener, Z., Hamza, H., Goldstein, R. E., Biton, M., et al. (2013). A 2247 senescence-inflammatory switch from cancer-inhibitory to cancer-promoting mech- 2248 anism. Cancer Cell 24, 242-256.

Prise, K. M., \& O'Sullivan, J. M. (2009). Radiation-induced bystander signalling in cancer 2250 therapy. Nat Rev Cancer 9(5), 351-360. 225

Qian, C., Liu, J., \& Cao, X. (2014). Innate signaling in the inflammatory immune disorders. 2252 Cytokine Growth Factor Rev 25(6), 731-738. 2253

Qin, J., \& Xu, Q. (2014). Functions and application of exosomes. Acta Pol Pharm 71(4), 2254 537-543.

Radic, M. (2014). Clearance of apoptotic bodies, NETs, and biofilm DNA: Implications for 2256 autoimmunity. Front Immunol 5, 365.

Raj, K., Ogston, P., \& Beard, P. (2001). Virus-mediated killing of cells that lack p53 activity. 2258 Nature 412(6850), 914-917. 2259

Ramakrishnan, M., Mathur, S. R., \& Mukhopadhyay, A. (2013). Fusion-derived epithelial 2260 cancer cells express hematopoietic markers and contribute to stem cell and migrato- 2261 ry phenotype in ovarian carcinoma. Cancer Res 73(17), 5360-5370. 2262

Ran, Y., Shu, H. B., \& Wang, Y. Y. (2014). MITA/STING: A central and multifaceted mediator 2263 in innate immune response. Cytokine Growth Factor Rev 25(6), 631-639. 2264

Randow, F., MacMicking, J. D., \& James, L. C. (2013). Cellular self-defense: How cell- 2265 autonomous immunity protects against pathogens. Science 340(6133), 701-706. 2266

Raphael, I., Nalawade, S., Eagar, T. N., \& Forsthuber, T. G. (2014). T cell subsets and their 2267 signature cytokines in autoimmune and inflammatory diseases. Cytokine.

Rathinam, V. A., Jiang, Z., Waggoner, S. N., Sharma, S., Cole, L. E., Waggoner, L., et al. 2269 (2010). The AIM2 inflammasome is essential for host defense against cytosolic bacte- 2270 ria and DNA viruses. Nat Immunol 11(5), 395-402.

Rathinam, V. A., Sharma, S., \& Fitzgerald, K. A. (2010). Catenin' on to nucleic acid sensing. 2272 Nat Immunol 11(6), 466-468.

Raulet, D. H., \& Guerra, N. (2009). Oncogenic stress sensed by the immune system: Role of 2274 natural killer cell receptors. Nat Rev Immunol 9(8), 568-580. 2275

Reed, S. H. (2011). Nucleotide excision repair in chromatin: Damage removal at the drop 2276 of a HAT. DNA Repair 10(7), 734-742.

Regulus, P., Duroux, B., Bayle, P. A., Favier, A., Cadet, J., \& Ravanat, J. L. (2007). Oxidation of 2278 the sugar moiety of DNA by ionizing radiation or bleomycin could induce the forma- 2279 tion of a cluster DNA lesion. Proc Natl Acad Sci U S A 104, 14032-14037. 2280

Reinhardt, H. C., \& Schumacher, B. (2012). The p53 network: Cellular and systemic DNA 2281 damage responses in aging and cancer. Trends Genet 28(3), 128-136. 2282

Reits, E. A., Hodge, J. W., Herberts, C. A., Groothuis, T. A., Chakraborty, M., Wansley, E. K., 2283 et al. (2006). Radiation modulates the peptide repertoire, enhances MHC class I ex- 2284 pression, and induces successful antitumor immunotherapy. J Exp Med 203(5), 2285 $1259-1271$.

Rigby, R. E., Webb, L. M., Mackenzie, K. J., Li, Y., Leitch, A., Reijns, M. A., et al. (2014). RNA: 2287 DNA hybrids are a novel molecular pattern sensed by TLR9. EMBO J 33(6), 542-558. 2288

Rivera-Calzada, A., Spagnolo, L., Pearl, L. H., \& Llorca, O. (2007). Structural model of full- 2289 length human Ku70-Ku80 heterodimer and its recognition of DNA and DNA-PKcs. 2290 EMBO Rep 8(1), 56-62.

Rodier, F., \& Campisi, J. (2011). Four faces of cellular senescence. J Cell Biol 192(4), 2292 547-556.

Rodier, F., Coppe, J. P., Patil, C. K., Hoeijmakers, W. A., Munoz, D. P., Raza, S. R., et al. (2009), 2294 Persistent DNA damage signalling triggers senescence-associated inflammatory cyto- 2295 kine secretion. Nat Cell Biol 11(8), 973-979.

Roth, S., Rottach, A., Lotz-Havla, A. S., Laux, V., Muschaweckh, A., Gersting, S. W., et al. 2297 (2014). Rad50-CARD9 interactions link cytosolic DNA sensing to IL-1beta production. 2298 Nat Immunol 15(6), 538-545. 
R455-R457.

Sabatel, H., Di Valentin, E., Gloire, G., Dequiedt, F., Piette, J., \& Habraken, Y. (2012). Phosphorylation of p65(RelA) on ser(547) by ATM represses NF-kappaB-dependent transcription of specific genes after genotoxic stress. PLoS One 7(6), e38246.

Sabbah, A., Chang, T. H., Harnack, R., Frohlich, V., Tominaga, K., Dube, P. H., et al. (2009). Activation of innate immune antiviral responses by Nod2. Nat Immunol 10(10), 1073-1080.

Saccani, S., Pantano, S., \& Natoli, G. (2002). p38-dependent marking of inflammatory genes for increased NF-kappa B recruitment. Nat Immunol 3(1), 69-75.

Salama, R., Sadaie, M., Hoare, M., \& Narita, M. (2014). Cellular senescence and its effector programs. Genes Dev 28(2), 99-114.

Salminen, A., Kauppinen, A., \& Kaarniranta, K. (2012). Emerging role of NF-kappaB signaling in the induction of senescence-associated secretory phenotype (SASP). Cell Signal $24(4), 835-845$

Sangfelt, O., Erickson, S., Castro, J., Heiden, T., Gustafsson, A., Einhorn, S., et al. (1999). Molecular mechanisms underlying interferon-alpha-induced GO/G1 arrest: CKImediated regulation of $\mathrm{G} 1$ cdk-complexes and activation of pocket proteins. Oncogene 18(18), 2798-2810.

Sanli, T., Rashid, A., Liu, C., Harding, S., Bristow, R. G., Cutz, J. C., et al. (2010). Ionizing radiation activates AMP-activated kinase (AMPK): A target for radiosensitization of human cancer cells. Int I Radiat Oncol Biol Phys 78(1), 221-229.

Sanli, T., Steinberg, G. R., Singh, G., \& Tsakiridis, T. (2014). AMP-activated protein kinase (AMPK) beyond metabolism: A novel genomic stress sensor participating in the DNA damage response pathway. Cancer Biol Ther 15(2), 156-169.

Savage, P. A., Leventhal, D. S., \& Malchow, S. (2014). Shaping the repertoire of tumorinfiltrating effector and regulatory T cells. Immunol Rev 259(1), 245-258.

Schäfer, M., \& Werner, S. (2008). Cancer as an overhealing wound: An old hypothesis revisited. Nat Rev Mol Cell Biol 9(8), 628-638.

cheithauer, H., Belka, C., Lauber, K., \& Gaipl, U. S. (2014). Immunological aspects of radiotherapy. Radiat Oncol 9, 185.

chetter, A. J., Heegaard, N. H., \& Harris, C. C. (2010). Inflammation and cancer: Interweaving microRNA, free radical, cytokine and p53 pathways. Carcinogenesis 31(1), 37-49.

Schild-Poulter, C., Su, A., Shih, A., Kelly, O. P., Fritzler, M. J., Goldstein, R., et al. (2008). Association of autoantibodies with ku and DNA repair proteins in connective tissue diseases. Rheumatology 47(2), 165-171.

chlee, M. (2013). Master sensors of pathogenic RNA - RIG-I like receptors. Immunobiology 218(11), 1322-1335.

Schoggins, J. W., Wilson, S. J., Panis, M., Murphy, M. Y., Jones, C. T., Bieniasz, P., et al. (2011). A diverse range of gene products are effectors of the type I interferon antiviral response. Nature 472(7344), 481-485.

Schramm, L., \& Hernandez, N. (2002). Recruitment of RNA polymerase III to its target promoters. Genes Dev 16(20), 2593-2620.

chreiber, G., \& Piehler, J. (2015). The molecular basis for functional plasticity in type I interferon signaling. Trends Immunol 36(3), 139-149.

Schwartz, T., Behlke, J., Lowenhaupt, K., Heinemann, U., \& Rich, A. (2001). Structure of the DLM-1-Z-DNA complex reveals a conserved family of Z-DNA-binding proteins. Nat Struct Biol 8(9), 761-765.

Sedelnikova, O. A., Nakamura, A., Kovalchuk, O., Koturbash, I., Mitchell, S. A., Marino, S. A., et al. (2007). DNA double-strand breaks form in bystander cells after microbeam irradiation of three-dimensional human tissue models. Cancer Res 67(9), 4295-4302.

Semenenko, V. A., \& Stewart, R. D. (2004). A fast Monte Carlo algorithm to simulate the spectrum of DNA damages formed by ionizing radiation. Radiat Res 161(4), 451-457. Semenenko, V. A., \& Stewart, R. D. (2006). Fast Monte Carlo simulation of DNA damage formed by electrons and light ions. Phys Med Biol 51(7), 1693-1706.

Seya, T. (2014). Measles virus takes a two-pronged attack on PP1. Cell Host Microbe 16(1) $1-2$.

Shatnyeva, O. M., Hansen, H. P., Reiners, K. S., Sauer, M., Vyas, M., \& von Strandmann, E. P. (2015). DNA damage response and evasion from immunosurveillance in CLL: New options for NK cell-based immunotherapies. Front Genet 6, 11.

Shaw, N., \& Liu, Z. J. (2014). Role of the HIN domain in regulation of innate responses. Mol Cell Biol 34(1), 2-15.

She, Q. B., Bode, A. M., Ma, W. Y., Chen, N. Y., \& Dong, Z. (2001). Resveratrol-induced activation of $\mathrm{p} 53$ and apoptosis is mediated by extracellular-signal-regulated protein kinases and p38 kinase. Cancer Res 61(4), 1604-1610.

She, Q. B., Chen, N., \& Dong, Z. (2000). ERKs and p38 kinase phosphorylate p53 protein at serine 15 in response to UV radiation. J Biol Chem 275(27), 20444-20449.

Shen, Y. J., Le Bert, N., Chitre, A. A., Xing'Er Koo, C., Nga, X. H., Ho, S. S. W., et al. (2015). Genome-derived cytosolic DNA mediates Type I interferon-dependent rejection of B cell lymphoma cells. Cell Rep 11, 460-473.

Shi, C. S., Shenderov, K., Huang, N. N., Kabat, J., Abu-Asab, M., Fitzgerald, K. A., et al. (2012). Activation of autophagy by inflammatory signals limits IL-1beta production by targeting ubiquitinated inflammasomes for destruction. Nat Immunol 13(3), 255-263.

Shiloh, Y. (2003). ATM and related protein kinases: Safeguarding genome integrity. Nat Rev Cancer 3(3), 155-168.

Shiloh, Y., \& Ziv, Y. (2013). The ATM protein kinase: Regulating the cellular response to genotoxic stress, and more. Nature Reviews. Mol Cell Biol 14(4), 197-210.

Shimizu, I., Yoshida, Y., Suda, M., \& Minamino, T. (2014). DNA damage response and metabolic disease. Cell Metab 20(6), 967-977.

Shirata, N., Kudoh, A., Daikoku, T., Tatsumi, Y., Fujita, M., Kiyono, T., et al. (2005). Activation of ataxia telangiectasia-mutated DNA damage checkpoint signal transduction elicited by herpes simplex virus infection. J Biol Chem 280(34), 30336-30341.

Shu, C., Li, X., \& Li, P. (2014). The mechanism of double-stranded DNA sensing through the cGAS-STING pathway. Cytokine Growth Factor Rev 25(6), 641-648.
Silverstein, A. M. (2001). Autoimmunity versus horror autotoxicus: The struggle for rec- 2386 ognition. Nat Immunol 2(4), 279-281.

Sinclair, A., Yarranton, S., \& Schelcher, C. (2006). DNA-damage response pathways trig- 2388 gered by viral replication. Expert Rev Mol Med 8(5), 1-11.

Singh, R. P., Massachi, I., Manickavel, S., Singh, S., Rao, N. P., Hasan, S., et al. (2013). The 2390 role of miRNA in inflammation and autoimmunity. Autoimmun Rev 12(12), 2391 1160-1165.

Singh, V. V . Dutta, D Ansari, M. A Dutta, S. \& Chandran, B. (2014). Kaposi's sarcoma- 2393 associated herpesvirus induces the ATM and H2AX DNA damage response early dur- 2394 ing de novo infection of primary endothelial cells, which play roles in latency estab- 2395 lishment. J Virol 88(5), 2821-2834.

Sinha, D., Gupta, M. K., Patel, H. K., Ranjan, A., \& Sonti, R. V. (2013). Cell wall degrading 2397 enzyme induced rice innate immune responses are suppressed by the type 3 secre- 2398 tion system effectors XopN, XopQ XopX and XopZ of xanthomonas oryzae pv. oryzae. 2399 PLoS One 8(9), e75867.

2400

Slaughter, A., Daniel, X., Flors, V., Luna, E., Hohn, B., \& Mauch-Mani, B. (2012). Descen- 2401 dants of primed arabidopsis plants exhibit resistance to biotic stress. Plant Physiol 2402 158(2), 835-843.

Smilek, D. E, Ehlers, peutic combinations for autoimmune disease. Dis Model Mech 7(5), 503-513.

Smith, S., \& Jefferies, C. (2014). Role of DNA/RNA sensors and contribution to autoimmu- $\mathbf{Q 8 2}$ nity. Cytokine Growth Factor Rev 25(6), 745-757. 2407

Solier, S., \& Pommier, Y. (2014). The nuclear gamma-H2AX apoptotic ring: Implications 2408 for cancers and autoimmune diseases. Cell Mol Life Sci 71(12), 2289-2297. 2409

Song, H., Kim, K. E., Hur, D., Lim, J. S., Yang, Y., Cho, B. J., et al. (2008). IL-18 enhances 2410 ULBP2 expression through the MAPK pathway in leukemia cells. Immunol Lett 2411 120(1-2), 103-107.

Song, L. L., Alimirah, F., Panchanathan, R., Xin, H., \& Choubey, D. (2008). Expression of an 2413 IFN-inducible cellular senescence gene, IFI16, is up-regulated by p53. Mol Cancer Res 2414 $6(11), 1732-1741$.

Soriani, A., Zingoni, A., Cerboni, C., Iannitto, M. L., Ricciardi, M. R., Di Gialleonardo, V., et al. 2416 (2009). ATM-ATR-dependent up-regulation of DNAM-1 and NKG2D ligands on mul- 2417 tiple myeloma cells by therapeutic agents results in enhanced NK-cell susceptibility 2418 and is associated with a senescent phenotype. Blood 113(15), 3503-3511.

Soto-Pantoja, D. R., Terabe, M., Ghosh, A., Ridnour, L. A., DeGraff, W. G., Wink, D. A., et al. 2420 (2014). CD47 in the tumor microenvironment limits cooperation between antitumor 2421 T-cell immunity and radiotherapy. Cancer Res 74(23), 6771-6783. 2422

Steel, J. C., Waldmann, T. A., \& Morris, J. C. (2012). Interleukin-15 biology and its therapeu- 2423 tic implications in cancer. Trends Pharmacol Sci 33(1), 35-41. 2424

Stern, A., Keren, L., Wurtzel, O., Amitai, G., \& Sorek, R. (2010). Self-targeting by CRISPR: 2425 Gene regulation or autoimmunity? Trends Genet 26(8), 335-340.

2426

Stolz, A., Ertych, N., \& Bastians, H. (2011). Tumor suppressor CHK2: Regulator of DNA 2427 damage response and mediator of chromosomal stability. Clin Cancer Res 17(3), 2428 401-405.

Stracker, T. H., Carson, C. T., \& Weitzman, M. D. (2002). Adenovirus oncoproteins inacti- 2430 vate the Mre11-Rad50-NBS1 DNA repair complex. Nature 418(6895), 348-352. 2431

Stracker, T. H., Usui, T., \& Petrini, J. H. (2009). Taking the time to make important deci- 2432 sions: The checkpoint effector kinases Chk1 and Chk2 and the DNA damage response. 2433 DNA Repair 8(9), 1047-1054. 2434

Sugihara, T., Kaul, S. C., Kato, J., Reddel, R. R., Nomura, H., \& Wadhwa, R. (2001). Pex19p 2435 dampens the p19ARF-p53-p21WAF1 tumor suppressor pathway. J Biol Chem 2436 276(22), 18649-18652.

Sun, L., Wu, J., Du, F., Chen, X., \& Chen, Z. J. (2013). Cyclic GMP-AMP synthase is a cytosolic 2438 DNA sensor that activates the type I interferon pathway. Science 339(6121), 786-791. 2439

Suzuki, H. I., Yamagata, K., Sugimoto, K., Iwamoto, T., Kato, S., \& Miyazono, K. (2009). 2440 Modulation of microRNA processing by p53. Nature 460(7254), 529-533. 2441

Swartz, M. A. \& Lund, A. W. (2012). Lymphatic and interstitial flow in the tumour microen- 2442 vironment: Linking mechanobiology with immunity. Nat Rev Cancer 12(3), 210-219. 2443

Sykes, L., MacIntyre, D. A., Yap, X. J., Ghee Theo, T., \& Bennett, P. R. (2012). The Th1:Th2 2444 Dichotomy of Pregnancy and Preterm Labour. Mediators Inflamm 2012, 967629. 2445

Takaoka, A. Hayakawa, S., Yanai, H., Stoiber, D., Negishi, H., Kikuchi, H., et al. (2003). Inte- 2446 gration of interferon-alpha/beta signalling to p53 responses in tumour suppression 2447 and antiviral defence. Nature 424(6948), 516-523.

Takaoka, A., Wang, Z., Choi, M. K., Yanai, H., Negishi, H., Ban, T., et al. (2007). DAI (DLM-1/ 2449 ZBP1) is a cytosolic DNA sensor and an activator of innate immune response. Nature 2450 448(7152), 501-505.

Tam, J. C., \& Jacques, D. A. (2014). Intracellular immunity: Finding the enemy 2452 within-How cells recognize and respond to intracellular pathogens. J Leukoc Biol 2453 96(2), 233-244.

Tang, M. L., \& Gasser, S. (2013). ATM activation mediates anticancer immunosurveillance 2455 by natural killer and T cells. Oncoimmunology 2(6), e24438. 2456

Tang, M. L., Khan, M. K., Croxford, J. L., Tan, K. W., Angeli, V., \& Gasser, S. (2014). The DNA 2457 damage response induces antigen presenting cell-like functions in fibroblasts. Eur J 2458 Immunol 44(4), 1108-1118.

Tang X. Hui, Z G, Cui, X. L., Garg, R, Kastan, M. B. \& Xu, B. (2008). A novel ATM- 2460 dependent pathway regulates protein phosphatase 1 in response to DNA damage. 2461 Mol Cell Biol 28(8), 2559-2566.

. Metchnikoff and the phagocytosis theory. Nat Rev Mol Cell Biol 4(11), 2463 897-901.

Teh, C. E., \& Gray, D. H. (2014). Can you rely on treg cells on the rebound? Eur J Immunol 2465 44(12), 3504-3507.

Textor, S, Fiegler, N. Arnold, A Porgador, A. Hofmann, T. G, \& Cerwenka, A. (2011) 2467 Human NK cells are alerted to induction of p53 in cancer cells by upregulation of 2468 the NKG2D ligands ULBP1 and ULBP2. Cancer Res 71(18), 5998-6009. 2469

Thomas, L. (1959). In H. S. Lawrence (Ed.), Cellular and Humoral Aspects of Hypersensitivity. 2470 New York: Hoeber-Harper. 
Thomasova, D., Mulay, S. R., Bruns, H., \& Anders, H. J. (2012). p53-independent roles of MDM2 in NF-kappaB signaling: Implications for cancer therapy, wound healing, and autoimmune diseases. Neoplasia 14(12), 1097-1101.

Thompson, L. H. (2012). Recognition, signaling, and repair of DNA double-strand breaks produced by ionizing radiation in mammalian cells: The molecular choreography. Mutat Res 751(2), 158-246.

Tian, H., Gao, Z., Li, H., Zhang, B., Wang, G., Zhang, Q., et al. (2015). DNA damage response A double-edged sword in cancer prevention and cancer therapy. Cancer Lett 358(1), $8-16$.

ilton, C., Clippinger, A. J., Maguire, T., \& Alwine, J. C. (2011). Human cytomegalovirus induces multiple means to combat reactive oxygen species. J Virol 85(23), 12585-12593.

Tivol, E. A., Borriello, F., Schweitzer, A. N., Lynch, W. P., Bluestone, J. A., \& Sharpe, A. H. (1995). Loss of CTLA-4 leads to massive lymphoproliferation and fatal multiorgan tissue destruction, revealing a critical negative regulatory role of CTLA-4. Immunity 3(5), 541-547.

Townsend, P. A., Cragg, M. S., Davidson, S. M., McCormick, J., Barry, S., Lawrence, K. M., et al. (2005). STAT-1 facilitates the ATM activated checkpoint pathway following DNA damage. J Cell Sci 118(Pt 8), 1629-1639.

Tsakiri, E. N., Sykiotis, G. P., Papassideri, I. S., Gorgoulis, V. G., Bohmann, D., \& Trougakos, I. P. (2013). Differential regulation of proteasome functionality in reproductive vs. somatic tissues of drosophila during aging or oxidative stress. FASEB J 27(6), 2407-2420.

Tsantoulis, P. K., Kotsinas, A., Sfikakis, P. P., Evangelou, K., Sideridou, M., Levy, B., et al. (2008). Oncogene-induced replication stress preferentially targets common fragile sites in preneoplastic lesions. A genome-wide study. Oncogene 27(23), 3256-3264.

Turaga, R. V., Paquet, E. R., Sild, M., Vignard, J., Garand, C., Johnson, F. B., et al. (2009). The Werner syndrome protein affects the expression of genes involved in adipogenesis and inflammation in addition to cell cycle and DNA damage responses. Cell Cycle 8(13), 2080-2092.

Tzioufas, A. G., Tatouli, I. P., \& Moutsopoulos, H. M. (2012). Autoantibodies in Sjogren's syndrome: Clinical presentation and regulatory mechanisms. Presse Med 41(9 Pt 2), e451-e460.

Unterholzner, L. (2013). The interferon response to intracellular DNA: Why so many receptors? Immunobiology 218(11), 1312-1321.

Unterholzner, L., Keating, S. E., Baran, M., Horan, K. A., Jensen, S. B., Sharma, S., et al. (2010). IFI16 is an innate immune sensor for intracellular DNA. Nat Immunol 11(11), 997-1004.

Vabret, N., \& Blander, J. M. (2013). Sensing microbial RNA in the cytosol. Front Immunol 4, 468. van Montfoort, N., Olagnier, D., \& Hiscott, J. (2014). Unmasking immune sensing of retroviruses: Interplay between innate sensors and host effectors. Cytokine Growth Factor Rev 25(6), 657-668.

Van Nguyen, T., Puebla-Osorio, N., Pang, H., Dujka, M. E., \& Zhu, C. (2007). DNA damageinduced cellular senescence is sufficient to suppress tumorigenesis: A mouse model.J Exp Med 204(6), 1453-1461.

Vanden Berghe, W., Plaisance, S., Boone, E., De Bosscher, K., Schmitz, M. L., Fiers, W., et al. (1998). p38 and extracellular signal-regulated kinase mitogen-activated protein kinase pathways are required for nuclear factor-kappaB p65 transactivation mediated by tumor necrosis factor. J Biol Chem 273(6), 3285-3290.

Vanlangenakker, N., Vanden Berghe, T., \& Vandenabeele, P. (2012). Many stimuli pull the necrotic trigger, an overview. Cell Death Differ 19(1), 75-86.

Varvarigou, A. A., Thomas, I., Rodi, M., Economou, I., Mantagos, S., \& Mouzaki, A. (2012). Respiratory distress syndrome (RDS) in premature infants is underscored by the magnitude of Th1 cytokine polarization. Cytokine 58, 355-360.

Vatner, R. E., Cooper, B. T., Vanpouille-Box, C., Demaria, S., \& Formenti, S. C. (2014). Combinations of immunotherapy and radiation in cancer therapy. Front Oncol 4, 325

Veeranki, S., \& Choubey, D. (2012). Interferon-inducible p200-family protein IFI16, an innate immune sensor for cytosolic and nuclear double-stranded DNA: Regulation of subcellular localization. Mol Immunol 49(4), 567-571.

Velimezi, G., Liontos, M., Vougas, K., Roumeliotis, T., Bartkova, J., Sideridou, M., et al. (2013). Functional interplay between the DNA-damage-response kinase ATM and ARF tumour suppressor protein in human cancer. Nat Cell Biol 15(8), 967-977.

Vermeulen, L., De Wilde, G., Van Damme, P., Vanden Berghe, W., \& Haegeman, G. (2003). Transcriptional activation of the NF-kappaB p65 subunit by mitogen- and stressactivated protein kinase-1 (MSK1). EMBO J 22(6), 1313-1324.

Vincent, M. (2012). Cancer: A de-repression of a default survival program common to all cells?: A life-history perspective on the nature of cancer. Bioessays 34(1), 72-82.

Vissers, M., Remijn, T., Oosting, M., de Jong, D. J., Diavatopoulos, D. A., Hermans, P. W., et al. (2012). Respiratory syncytial virus infection augments NOD2 signaling in an IFNbeta-dependent manner in human primary cells. Eur J Immunol 42(10), 2727-2735.

Volcic, M., Karl, S., Baumann, B., Salles, D., Daniel, P., Fulda, S., et al. (2012). NF-kappaB regulates DNA double-strand break repair in conjunction with BRCA1-CtIP complexes. Nucleic Acids Res 40(1), 181-195.

Vologodskii, A. (2007). Monte Carlo Simulation of DNA topological properties. In M. I. Monastyrsky (Ed.), Topology in Molecular Biology (pp. 23-41). Berlin: Springer-Verlag. Vousden, K. H., \& Prives, C. (2009). Blinded by the light: The growing complexity of p53. Cell 137(3), 413-431.

Wadhwa, R., Sugihara, T., Hasan, M. K., Taira, K., Reddel, R. R., \& Kaul, S. C. (2002). A major functional difference between the mouse and human ARF tumor suppressor proteins. J Biol Chem 277(39), 36665-36670.

Walker, J. R., Corpina, R. A., \& Goldberg, J. (2001). Structure of the ku heterodimer bound to DNA and its implications for double-strand break repair. Nature 412(6847), 607-614.
Wang, M., Gao, Z., Pan, L., \& Zhang, Y. (2014). Cellular microRNAs and picornaviral infec- 2553 tions. RNA Biol 11(7), 808-816. 2554

Wang, R. F. (2006). Immune suppression by tumor-specific CD4+ regulatory T-cells in 2555 cancer. Semin Cancer Biol 16(1), 73-79. 2556

Wang, T., Liu, G., \& Wang, R. (2014). The intercellular metabolic interplay between tumor 2557 and immune cells. Front Immunol 5, $358 . \quad 2558$

Warren, S. E., Armstrong, A., Hamilton, M. K., Mao, D. P., Leaf, I. A., Miao, E. A., et al. (2010). 2559 Cutting edge: Cytosolic bacterial DNA activates the inflammasome via Aim2. J 2560 Immunol 185(2), 818-821.

Weitzman, M. D., Carson, C. T., Schwartz, R. A., \& Lilley, C. E. (2004). Interactions of viruses 2562 with the cellular DNA repair machinery. DNA Repair 3(8-9), 1165-1173.

Wilkinson, D. E., \& Weller, S. K. (2003). The role of DNA recombination in herpes simplex 2564 virus DNA replication. IUBMB Life 55(8), 451-458. 2565

Williams, B. R. (1999). PKR; a sentinel kinase for cellular stress. Oncogene 18(45), 2566 6112-6120. 2567

Wood, C. D., Thornton, T. M., Sabio, G., Davis, R. A., \& Rincon, M. (2009). Nuclear localiza- 2568 tion of p38 MAPK in response to DNA damage. Int J Biol Sci 5(5), 428-437. 2569

Wu, X., Avni, D., Chiba, T., Yan, F., Zhao, Q., Lin, Y., et al. (2004). SV40 T antigen interacts 2570 with Nbs1 to disrupt DNA replication control. Genes Dev 18(11), 1305-1316. 2571

Wu, Z. H., Shi, Y., Tibbetts, R. S., \& Miyamoto, S. (2006). Molecular linkage between the ki- Q85 nase ATM and NF-kappaB signaling in response to genotoxic stimuli. Science 2573 311(5764), 1141-1146. 2574

Xiaofei, E., \& Kowalik, T. F. (2014). The DNA damage response induced by infection with 2575 human cytomegalovirus and other viruses. Viruses 6(5), 2155-2185. 2576

Xin, H., Curry, J., Johnstone, R. W., Nickoloff, B. J., \& Choubey, D. (2003). Role of IFI 16, a 2577 member of the interferon-inducible p200-protein family, in prostate epithelial cellu- 2578 lar senescence. Oncogene 22(31), 4831-4840.

Xin, H., Pereira-Smith, O. M., \& Choubey, D. (2004). Role of IFI 16 in cellular senescence of 2580 human fibroblasts. Oncogene 23(37), 6209-6217.

Xu, M., Yu, Q., Subrahmanyam, R., Difilippantonio, M. J., Ried, T., \& Sen, J. M. (2008). Beta- 2582 catenin expression results in p53-independent DNA damage and oncogene-induced 2583 senescence in prelymphomagenic thymocytes in vivo. Mol Cell Biol 28(5), 1713-1723. 2584

Xue, W., Zender, L., Miething, C., Dickins, R. A., Hernando, E., Krizhanovsky, V., et al. Q86 (2007). Senescence and tumour clearance is triggered by p53 restoration in murine 2586 liver carcinomas. Nature 445(7128), 656-660.

Yan, S., Yim, L. Y, Lu, L, Lau, C. S. \& Chan, V. S. (2014). MicroRNA regulation in systemic 2588 lupus erythematosus pathogenesis. Immune Netw 14(3), 138-148. 2589

Yanai, H., Ban, T., Wang, Z., Choi, M. K., Kawamura, T., Negishi, H., et al. (2009). HMGB pro- 2590 teins function as universal sentinels for nucleic-acid-mediated innate immune re- 2591 sponses. Nature 462(7269), 99-103. 2592

Yang, P., An, H., Liu, X., Wen, M., Zheng, Y., Rui, Y., et al. (2010). The cytosolic nucleic acid 2593 sensor LRRFIP1 mediates the production of type I interferon via a beta-catenin- 2594 dependent pathway. Nat Immunol 11(6), 487-494. 2595

Yang, X. H., Shiotani, B., Classon, M., \& Zou, L. (2008). Chk1 and claspin potentiate PCNA 2596 ubiquitination. Genes Dev 22(9), 1147-1152. 2597

Yang, Y. G., Lindahl, T., \& Barnes, D. E. (2007). Trex1 exonuclease degrades ssDNA to pre- 2598 vent chronic checkpoint activation and autoimmune disease. Cell 131(5), 873-886. 2599

Yoneyama, M., Kikuchi, M., Matsumoto, K., Imaizumi, T., Miyagishi, M., Taira, K., et al. 2600 (2005). Shared and unique functions of the DExD/H-box helicases RIG-I, MDA5, 2601 and LGP2 in antiviral innate immunity. J Immunol 175(5), 2851-2858. 2602

Yoo, J. S., Kato, H., \& Fujita, T. (2014). Sensing viral invasion by RIG-I like receptors. Curr 2603 Opin Microbiol 20, 131-138.

Zannella, V. E., Cojocari, D., Hilgendorf, S., Vellanki, R. N., Chung, S., Wouters, B. G., et al. 2605 (2011). AMPK regulates metabolism and survival in response to ionizing radiation. 2606 Radiother Oncol 99(3), 293-299.

Zarogoulidis, P., Lampaki, S., Yarmus, L., Kioumis, I., Pitsiou, G., Katsikogiannis, N., et al. 2608 (2014). Interleukin-7 and interleukin-15 for cancer. J Cancer 5(9), 765-773. 2609

Zhang, J. S., Nakatsugawa, S., Niwa, O., Ju, G. Z., \& Liu, S. Z. (1994). Ionizing radiation- 2610 induced IL-1 alpha, IL-6 and GM-CSF production by human lung cancer cells. Chin 2611 Med J (Engl) 107(9), 653-657. 2612

Zhang, X., Brann, T. W., Zhou, M., Yang, J., Oguariri, R. M., Lidie, K. B., et al. (2011). Cutting 2613 edge: Ku70 is a novel cytosolic DNA sensor that induces type III rather than type I IFN. 2614 J Immunol 186(8), 4541-4545. 2615

Zhang, Y., Zhang, Y., Gu, W., He, L., \& Sun, B. (2014). Th1/Th2 cell's function in immune 2616 system. Adv Exp Med Biol 841, 45-65.

Zheng, X., \& Bevilacqua, P. C. (2004). Activation of the protein kinase PKR by short double- 2618 stranded RNAs with single-stranded tails. RNA 10(12), 1934-1945.

Zhu, X., Wang, D., Zhang, H., Zhou, Y., Luo, R., Chen, H., et al. (2014). Molecular cloning and 2620 functional characterization of porcine DEAD (asp-glu-ala-asp) box polypeptide 412621 (DDX41). Dev Comp Immunol 47(2), 191-196.

Zingoni, A., Ardolino, M., Santoni, A., \& Cerboni, C. (2013). NKG2D and DNAM-1 activating 2623 receptors and their ligands in NK-T cell interactions: Role in the NK cell-mediated 2624

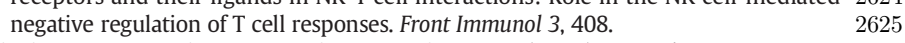

Zuliani, L., Graus, F., Giometto, B., Bien, C., \& Vincent, A. (2012). Central nervous system 2626 neuronal surface antibody associated syndromes: Review and guidelines for recogni- 2627 tion. J Neurol Neurosurg Psychiatry 83(6), 638-645. 